\title{
EXPERIENCES WITH RENAL HOMOTRANSPLANTATION IN THE HUMAN : REPORT OF NINE CASES ${ }^{1}$
}

\author{
By DAVID M. HUME, JOHN P. MERRILL, BENJAMIN F. MILLER, AND \\ GEORGE W. THORN

\begin{abstract}
(From the Departments of Surgery and Medicine, Harvard Medical School and the Peter
\end{abstract} \\ Bent Brigham Hospital, Boston, Mass.)
}

(Submitted for publication April 14. 1954; accepted September 8, 1954)

We report in this paper studies on nine patients in whom homologous kidney transplantation was performed. A preliminary report of some of these cases has already been made $(51,58)$.

All of the recipients were patients in the terminal stages of severe, advanced renal failure. The risks were fully discussed with the patients and their families, and the uncertain outcome made clear.

In several instances the function of the transplant was maintained for a surprisingly long period of time. All of the patients ultimately succumbed to their disease.

It was our aim in this investigation to study the subject of homotransplantation of the human kidney-not to offer a therapeutic procedure. We agree with Dempster (33) that "it is quite out of the question that kidneys should be homotransplanted in man just in case a permanent survival might be obtained." Nevertheless, we felt that this study should be undertaken for the following reasons :

1) It is important to know if the underlying chronic renal disease of the patient can produce changes which are able to influence-either adversely or favorably - the course of the homotransplant. It is difficult to simulate human renal disease accurately in the experimental animal.

2) It has been generally accepted that the higher an animal is in the phylogenetic scale, the more highly developed is its ability to form antibodies, and thus, presumably, to destroy homografted tissue. This thesis has recently been supported by Dempster (33). No conclusive study of the fate of human renal homotransplants was available, however. It seemed desirable to define the course of these transplants, and to see how

1 Aided by grants from the Bristol-Myers Pharmaceutical Company; The Lasdon Foundation; The National Institutes of Health; and Eli Lilly \& Company. the rejection of the transplanted kidney in man compared to that in lower animals.

3) It was felt that observations of the biologic response to kidney homotransplantation in man might yield information that could not be obtained by animal experimentation alone. Data might be acquired which would suggest new lines of approach to the homotransplant problem and these could then be further evaluated at the level of the laboratory animal.

Our results appear to indicate 1 ) that the disease of the patient can, under some circumstances, influence the course of the transplant, 2) that it is possible to perform renal homotransplants in the human that survive and function for far longer periods of time than those reported for any experimental animal, and 3) that the rejection of the human homotransplant is not always comparable to that seen in the dog.

The development of the artificial kidney (63), more than any other single thing, led to the undertaking of our study of human homotransplantation at this time. A modified Kolff kidney was constructed and put in operation at the Peter Bent Brigham Hospital in 1949 (99). By this means it became possible to prepare seriously ill uremic patients for surgery, and to maintain them in the post-operative period, so that it was feasible to perform transplantation in the terminal stages of chronic renal failure.

It would still not be tenable to attempt renal homografting in the human unless every effort were made to render the procedure as safe as possible, and to subtract nothing from whatever renal function remained to the patient. It was also imperative that the transplantation be performed in such a way that the function and course of the grafted kidney could be charted as accurately as possible.

We chose to transplant the kidneys into the 
thigh of the recipient for the following reasons: 1) It is preferable in a uremic patient to add a third kidney, rather than to remove one of the recipient's own kidneys and substitute a transplant; 2) It is less traumatic to place the kidney in the thigh than in the renal fossa; 3) A skin ureterostomy permits collection of urine directly from the transplant and facilitates comparison of its function with that of the other two kidneys; 4) The vascularity of the ureter is a good index to the circulation of the transplant, because the blood supply of the transplanted ureter comes entirely from the renal vessels; 5) If the ureter sloughs, no serious complication ensues, as it might in intra- or retro-peritoneal locations ; 6) If the transplanted kidney dies, or becomes seriously infected, the complication can be detected sooner than would be the case with a transplant in the renal fossa, and the kidney can be removed more readily ; 7) It is much easier to biopsy the kidney when it is placed in the thigh.

The location of the transplant in the thigh has the disadvantage that the circumference of the thigh has to be increased by skin grafting to receive the kidney without tension on the overlying tissues. This necessitates opening up planes of dissection which are often very vascular and which, in the uremic patient, sometimes continue to bleed despite strenuous measures to provide hemostasis.

\section{REVIEW OF THE LITERATURE}

There have been a great many papers written on the general problem of tissue homografting. Recent reviews and bibliographies are available which cover various aspects of the transplantation problem $(11,39,43,83,84$, $92,108,121,123,126,127,137)$. No attempt will be made here to do more than briefly summarize the more pertinent studies of renal homotransplantation. Reference will be made in the discussion to certain papers which deal with questions of immunity and transplant pathology, and that are considered relevant to the analysis of the cases reported in this communication.

\section{Renal homotransplantation in experimental animals}

It is difficult to evaluate much of the earlier work because details of urinary secretion and composition, experimental protocol, and studies of pathology are often wanting. The period of homograft survival is sometimes considered to be the time of stoppage of urinary secretion (accurate collections have seldom been achieved), and sometimes the death of the animal, if bilateral nephrectomy was carried out at, or subsequent to, the transplantation.

Ullmann, in 1902 (128) was the first to carry out renal auto-, homo-, and hetero-transplantation, using prosthetic tubes to make the anastomoses. He made transplants from one dog to another, and from a dog to a goat, placing the kidney in the neck. No details of urinary secretion were published.

Carrel, in 1902 (18) developed a new technique for vascular anastomosis, and performed several auto transplants to the neck, noting that they secreted clear urine. All transplants were ultimately destroyed by infection. Carrel and Guthrie in 1905 (19) compared the function of a renal homograft done three days before to the normal kidney. They found the rate of secretion to be greater than normal, but the excretion of metabolites to be less than normal. In 1906, the same authors developed the "patching method" for anastomosis of small vessels (20). They made brief mention of two transplants made in cats by this technique. In 1906 they also reported an experiment in which they had transplanted two kidneys from one dog to another by an "in mass" technique. The kidneys and surrounding tissues were removed en masse with segments of aorta and vena cava which were then anastomosed in continuity to the aorta and vena cava of the host (21). Both kidneys of the host were removed. The urine from the transplants was said to be within normal limits on the 8th day. The end result of this case, a 10-day survival, was published two years later (22).

In 1908, Carrel (22) reported the results of transplantation in mass of both kidneys (the host's kidneys being removed) to 14 cats. Five died in the immediate post-operative period. Seven of the remaining cats died within 14 days. $T_{w o}$ animals lived for 31 and 36 days, respectively. The first of these two animals was noted to have an enlargement of the transplants and marked albuminuria on the 18th day. At autopsy an acute interstitial nephritis with plasma cell infiltration was found, and was noted to be more marked in the cortex than in the medulla. In the second cat swelling of the transplant and albuminuria was noted on the 16th day. An exploratory laparotomy on the 18th day revealed the transplanted kidneys to be edematous and large. At autopsy on the 36th day a marked calcification of the aorta and other vessels was noted (23). The kidneys were said to have secreted urine up to the day of death.

Floresco in 1905 (46) performed renal homotransplants to the inguinal area, the neck, and the renal fossa in dogs. He concluded that the renal fossa was the most suitable location, the inguinal area the least. The average survival of the transplants was about 3 days.

Villard and Tavernier in 1910 (130) and Villard and Perrin in 1913 (131) homografted the kidney in nine instances. The longest time any of the transplants secreted urine was 8 days.

Avramovici in 1924 (4) reported doing renal heterotransplants from cat to dog en masse, taking out both 
the recipient's kidneys. Two of these cases were said to have survived 49 and 58 days, with normal renal secretion. At autopsy the transplanted kidneys were said to appear normal. No histological studies or urine analysєs were done. Homotransplantations, en masse, were done in 11 dogs, all recipients having bilateral nephrectomies. One dog was said to have lived 61 days, dying of bronchopneumonia. Another lived 73 days. No histological or urinary studies were reported. In six additional experiments, bilateral renal homografts were done in two stages. Three of these animals were said to have survived 33,44 , and 58 days. When transplanting only one kidney (leaving one of the host's kidneys in situ) survivals of 41,56 , and 60 days were obtained. The only mention made of microscopic studies was in the animal which survived 56 days. The transplanted kidney was said to show glomerular lesions, alterations of the tubular epithelium, and an inflammation-not too marked-of the interstitial tissue.

Avramovici also performed transplantations of kidneys which had been preserved in the cold for varying periods of time up to 30 hours. One transplant which had been thus preserved for 8 hours was then homotransplanted, one of the host's kidneys being removed. Fourteen days later the other kidney of the host was removed. The animal was said to have lived 36 days more.

Renal homotransplantaticns in experimental animals as successful as those reported by Avramovici have not been achieved by any other workers before or since. The absence of microscopic and urinary studies, added to the lack of confirmation by others, makes it difficult to attribute much importance to these findings.

Dederer, $1920(28,29)$, performed a homotransplant of a kidney from one puppy to another of the same litter, making the anastomosis in the neck and leaving both of the recipient's kidneys intact. The animal died of distemper on the 26th day. The only function test done was to inject PSP dye, which was said to have been excreted by the transplanted kidney, following injection, on the 26th day.

Williamson, 1923 (135) and 1926 (136), using dogs and goats, confirmed Carrel's findings that whereas autogenous kidney transplants would maintain the life of the animal for months after removal of the other kidney, homologous transplants functioned only for a period of days. The histologic picture said by him to follow homotransplantation in the dog was that of acute atypical glomerulonephritis with lymphocytic infiltration, followed by general acute nephritis and ascending infection. If the transplanted kidney was allowed to remain in place after anuria developed, there was a tendency for it to be replaced by fibrous tissue. He concluded that the failure of homologous kidney transplants seemed attributable to a biologic incompatibility between the donor and recipient. He felt that the agent causing this was blood-borne, attacking first the glomeruli, and then the tubules.

Ibuka, 1926 (61) reviewed the literature on renal homotransplantation up to that date. $\mathrm{He}$ did a series of autotransplants to the neck in dogs, to demonstrate that these were capable of functioning for months. He then did 14 homotransplants by the same technique. Two were technical failures, and 4 succumbed to immediate post-operative sequellae. The remaining 8 cases were carefully followed, and analyses were performed on the urine. The transplants secreted urine for from 1 to 5 days, averaging 3 days. They stopped secreting before infection set in, and in spite of having an adequate blood flow and maintaining a patent ureter. Microscopically they showed an acute nephritis with lymphocytic and plasma cell infiltration and tubular destruction. The glomeruli appeared fairly normal.

Holloway, 1926, (54) found that homotransplants remained viable only two to four days, the destructive process starting in 24 hours.

Wu and Mann, 1934, (139) made a microscopic study of the day to day progress of auto- and homo-transplants in the dog. The transplants functioned alike until 1) they were removed, 2) the animal died, 3) thrombosis of one or both vessels occurred, or 4) pyelonephritis supervened. Some transplants never functioned. This was not due to thrombosis. Microscopically, monocytic interstitial infiltration and tubular necrosis were observed. The glomeruli still looked quite normal.

Parkinson and Woodworth, 1947, (105) performed renal transplantations in goats, and refer to them as heterotransplants, on the basis that the goats used were of different types. The kidneys were placed in the neck. Anastomoses were made with vitallium tubes. Autografts always developed such good collateral supply that they continued to function even when the vessels thrombosed. Homografts had an active arterial supply and venous return at one week, but had become soft, nearly gelatinous, and poorly demarcated. They secreted urine for 10 days. At 14 days they were dissolved.

Oudot, 1948 (104) cooled the kidneys to 4 degrees C. for periods up to 8 days before transplanting them. Infarction of the kidneys occurred immediately after transplantation. Payr tubes of "superpolyamides" were used as prostheses. Non-cooled renal homografts with cutaneous ureterostomies stopped functioning in 10 days. This was felt to be on the basis of a suppurative necrosis due to ascending infection.

Lefebvre, 1949, (74) showed that a homograft can clear urea. He reports one dog which lived for 21 days after homotransplantation, with a normal blood urea nitrogen for the first 19 days. The transplants were made in the neck, with vitallium prostheses. He also studied the effect of perfusing the kidney and storing it at low temperatures before transplantation (75). The transplanted kidney was observed only for short periods of time. He found that kidneys stored up to 24 hours were capable of showing a return of function after transplantation, as measured by diuresis, chloride output, return of oxygen consumption, excretion of bilirubin and urochrome, and urea output. All of these indices, except chloride output, showed the function to be below that 
of a normal kidney. (Maximum urea concentration noted was five times that of blood).

Recently, Simonsen and his co-workers (119-121) and Dempster $(30-34)$ have studied renal homotransplantation in dogs. Their work will be considered in some detail later on in the paper.

To summarize, most investigators have found that renal homotransplants in the experimental animal function for from 1 to 18 days, with an average of about 4 days. They cease urine secretion at a time when blood flow through the renal vessels can still be demonstrated. Histologically, the kidney which has stopped secreting shows interstitial edema and round cell infiltration and tubular destruction. The glomeruli remain relatively normal.

\section{Renal homotransplantation in the human}

On occasion an attempt has been made to use a human kidney homograft as a temporary aid to tide the patient over an episode of acute anuria. Voronoy, 1936 (132) transplanted a kidney into the groin of a patient with bichloride of mercury poisoning, but the patient died in 48 hours and no conclusions can be drawn from this experiment. Details are lacking. Landsteiner and Hufnagel in 1945 (70) transplanted a kidney from a cadaver to the brachial artery and cephalic vein of a young woman in acute renal failure. The patient's own kidneys began to resume function a few hours after the transplantation, and the transplant was removed after 48 hours, without having secreted any significant amount of urine.

Lawler, West, McNulty, Clancy, and Murphy in 1950, (72) removed a kidney from a woman with polycystic kidney disease and anastomosed the kidney from a cadaver to the patient's renal artery and vein. The ureter was anastomosed to that of the recipient. These authors injected indigo carmine dye parenterally on the 52nd day, and stated that it was observed to emerge from both ureters, but in poorer concentration from the side of the transplanted kidney. No other kidney function tests were done. At the time of removal of the transplant, $91 / 2$ months after implantation, the kidney was found to be 4 by 3 by $2 \mathrm{~cm}$. in size, with absence of the ureteral and pelvic structures. It was not producing urine (73).

Servelle, Soulié, Rougeulle, Delahaye, and Touche $(115,116)$ reported one human homotransplant, and Dubost and his associates (35) reported two at a meeting of the Medical Society of Paris Hospitals in January, 1951. All transplants were made in the pelvis, and the vessels were anastomosed to the iliac vessels. The kidney transplanted by Servelle and his co-workers reached an output of $600 \mathrm{ml}$. by the 19th day, at which time the patient suddenly died. The two transplants reported by Dubost and his associates had been performed only 14 and 3 days before the meeting. The first kidney secreted a maximum of $230 \mathrm{ml}$. of urine in 24 hours, and the patient died on the 16th day (36). The second transplant secreted only a few milliliters.
Kuss, Tienturier, and Milliez are reported by Lawler, West, McNulty, Clancy, and Murphy (73) to have performed 16 homotransplants in the human, several of which have "functioned for several months," but in their publication (68) they describe only five, and in a personal communication to one of us (DMH) (69) Kuss reports having done only one more. Of the five published cases, one patient died on the operating table, and in one the graft was removed 48 hours after the transplantation. A third case developed necrosis of the ureter, and the transplant excreted small amounts of urine for only 18 days. The patient died on the 20th day. A fourth transplant developed necrosis of the ureter on the 20th day. The maximum output was $72 \mathrm{ml}$. in 24 hours, on the 10 th day. The kidney was still excreting a few drops of urine when it was removed after $3 \frac{1}{2}$ months. In the final subject the maximal 24-hour output was $45 \mathrm{ml}$. The ureter became necrotic on the 20th day, and the patient died on the 35th day. An extensive infarction of the kidney was found at necropsy. The sixth case was said to have shown no better function (69). In these cases the transplant was placed in the pelvis of the recipient, and an anastomosis was carried out between the hypogastric artery and the renal artery, and between the external iliac vein and the renal vein. The ureter was brought out to the skin.

Recently, Michon and his associates (101) have reported a case in which the transplant functioned well for 23 days. More will be said about this case later.

In general, renal homotransplantation in the human has not been any more successful than in experimental animals.

\section{METHODS}

In eight of the nine cases reported herein the homologous kidney was transplanted into a pocket created in the medial aspect of the upper thigh. In all eight cases anastomoses were carried out between the deep femoral artery and the renal artery, and between the renal vein and the femoral vein. In one instance an end-to-end anastomosis was made between the superficial femoral vein and the renal vein, and in one case a similar anastomosis was performed using the common femoral vein. In six cases an end-to-side anastomosis was made between the renal vein and the common femoral vein, and this was found to be the most satisfactory method. In all cases the deep femoral artery was isolated for a distance of 7 to $8 \mathrm{~cm}$., and all branches were ligated and divided. It was then ligated as far distally as possible, a bulldog clamp was placed on it proximally, just distal to the bifurcation of the common femoral, and it was divided just proximal to the tie. A site was selected along the isolated vessel which most closely conformed to the size of the renal artery, and it was again divided at this point, and end-to-end anastomosis with the renal artery was carried out. All anastomoses were done with 6-0 arterial silk, using continuous everting mattress sutures, and tying the suture to each of three or four interrupted stay sutures. The ureter was brought out 


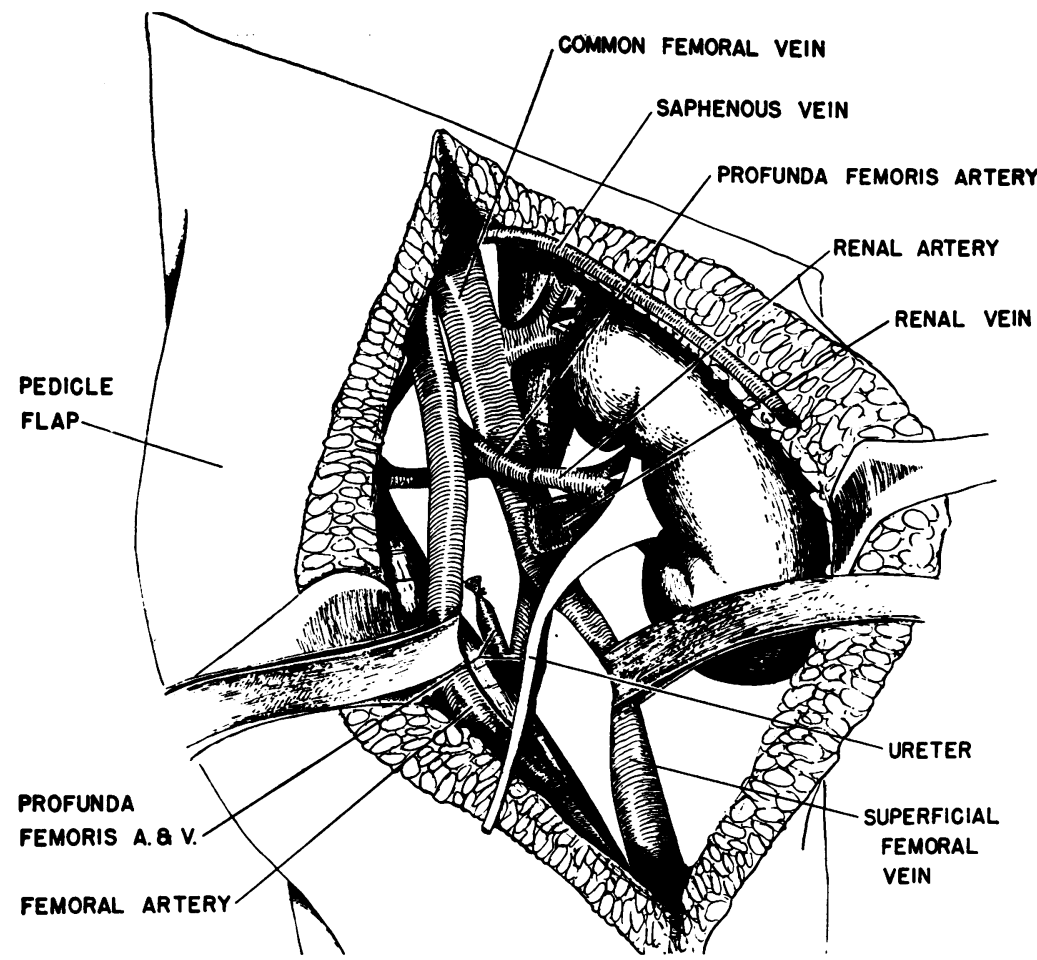

Fig. 1. The Method of Placing the Renal Transplant in the Right THIGH

The kidney is buried in a pocket created between the subcutaneous tissue and the muscles in the medial aspect of the thigh. The renal artery is anastomosed end-to-end to the profunda femoris artery, and the renal vein is anastomosed end-to-side into the common femoral vein. A double-ended pedicle flap is pulled over to help cover the kidney without tension on the skin. A split skin graft (not shown) is then applied over the lateral aspect of the thigh in the defect left by the moving over of the pedicle flap. The ureter will be brought out through a stab wound in the lower portion of the pedicle flap.

through a small incision in the skin. The relation of the vessels to the kidney is shown in Figure 1.

In the first two cases the kidney was placed in a space fashioned between the subcutaneous tissue and the fascia overlying the adductor muscles. This created a great deal of tension on the skin, and a slough of the skin developed. In five cases a double-ended pedicle of skin and subcutaneous tissue 30 by $15 \mathrm{~cm}$. in size was raised off the fascia laterally, swung over medially to create a covering for the kidney without tension on the skin. A split thickness graft taken from the other leg was then used to cover the defect left laterally over the fascia lata. This worked very satisfactorily. In one case pieces of the rectus femoris and sartorius muscle were removed and end-to-end anastomosis with the deep femoral artery and common femoral vein was carried out over polyethylene tubes which were temporarily tied in place to re-establish circulation as rapidly as possible. This technique of vascular suture has been described by Hufnagel (56). The kidney was then placed in the defect left by the removal of the muscles, and the skin was closed over it without tension. No skin flap was used. A great deal of tension developed by the 5 th day, however, because of hemorrhage from the cut muscles and edema of the leg, and the wound had to be reopened, and a relaxing incision made.

In eight cases heparin was used for varying lengths of time, and in six cases ACTH or cortisone or both were employed. Testosterone was given in every case. Various antibiotics were administered.

The donor kidneys were obtained from cadavers in six cases. ${ }^{2}$. Great care was taken not to injure the blood supply of the ureter. The kidneys were removed under strict aseptic conditions. In two cases the kidneys came from living donors and were essentially normal kidneys. These two cases were patients aged 2 and 33, the first with communicating hydrocephalus and the second with hydrocephalus caused by a block of the aque-

2 In three of these the kidney was removed by Dr. Frank Collins, in one by Dr. Phillip Walker, and in two by Dr. Robert Desautels. 


\begin{tabular}{|c|c|c|c|c|c|}
\hline & 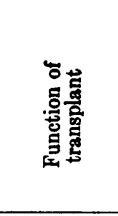 & 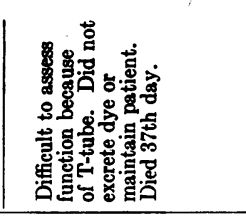 & 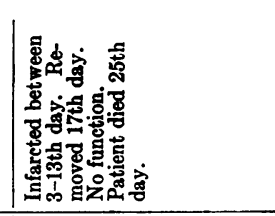 & 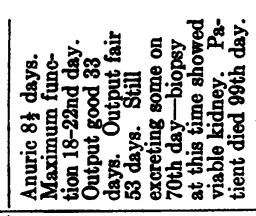 & 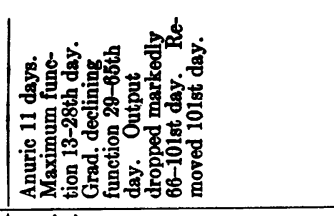 \\
\hline \multirow[t]{2}{*}{$\frac{1}{5}$} & $\begin{array}{l}. \\
\text { 量 } \\
\text { 旁 } \\
\text { 畐 } \\
\end{array}$ & 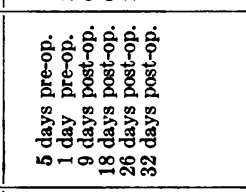 & 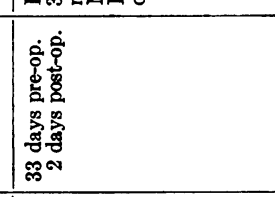 & 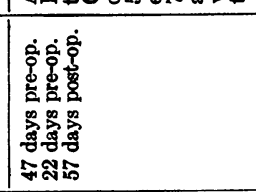 & 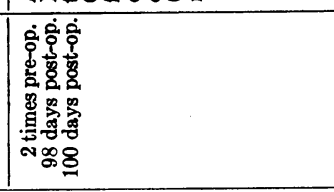 \\
\hline & 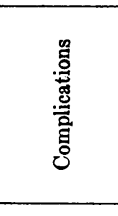 & 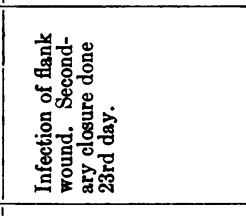 & 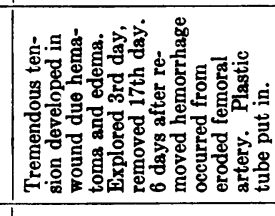 & 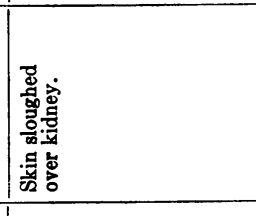 & 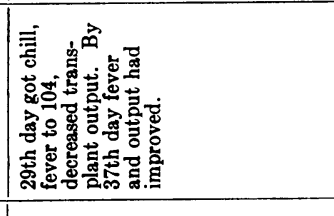 \\
\hline \multirow{8}{*}{ 高 } & $\begin{array}{l}\frac{8}{80} \\
\text { 高 } \\
\end{array}$ & 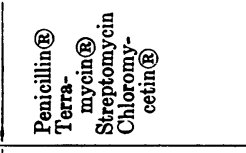 & 㣎 & 害 & 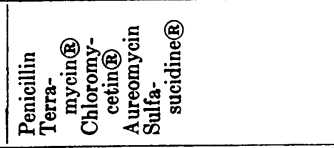 \\
\hline & 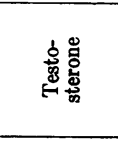 & 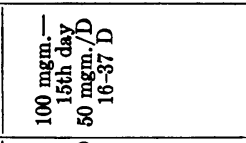 & 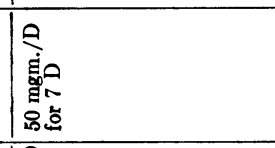 & 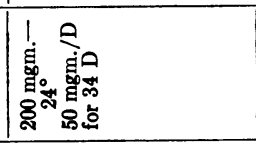 & 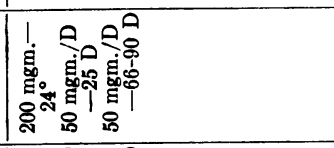 \\
\hline & $\begin{array}{l}\text { 喜 } \\
\text { 离 }\end{array}$ & 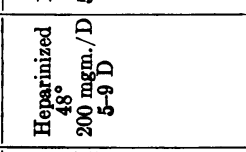 & $\mid$ & $\mid$ & 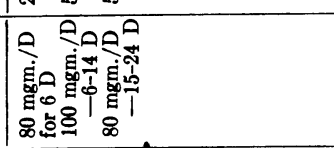 \\
\hline & 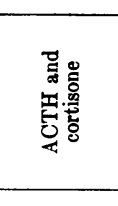 & 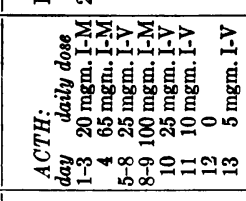 & 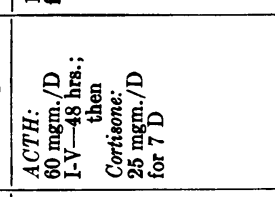 & 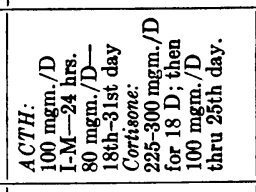 & 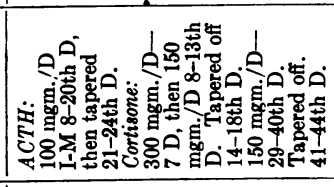 \\
\hline & 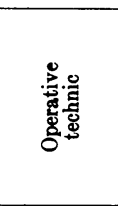 & 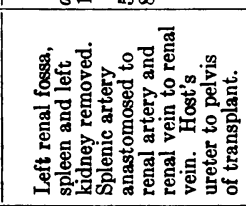 & 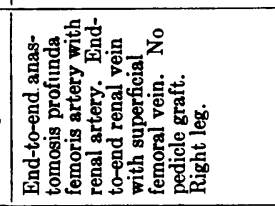 & 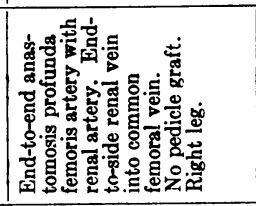 & 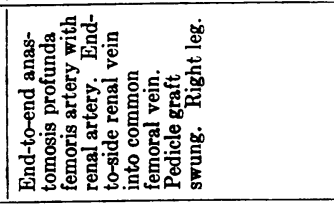 \\
\hline & 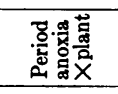 & 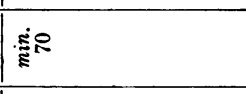 & 兽 & $\ddot{m}$ & \& \\
\hline & 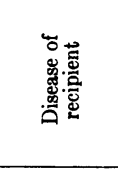 & 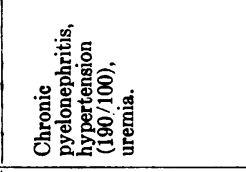 & 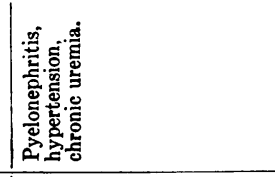 & 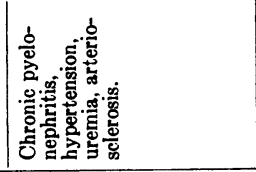 & 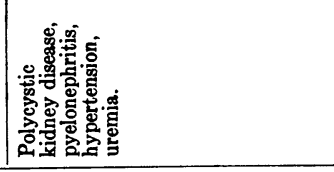 \\
\hline & 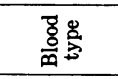 & \pm & $1 \pm$ & I血 & to \\
\hline \multirow{4}{*}{ 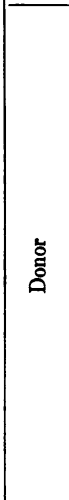 } & 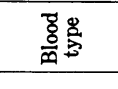 & \pm & $1+$ & I血 & $1+$ \\
\hline & 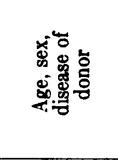 & 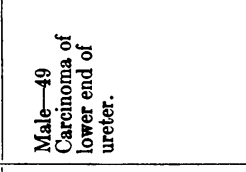 & 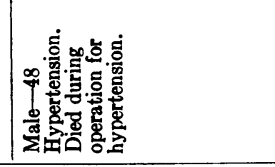 & 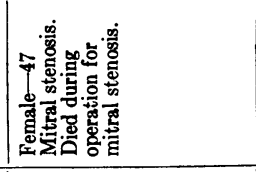 & 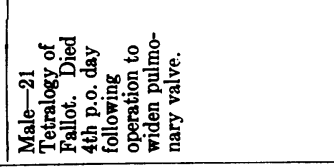 \\
\hline & 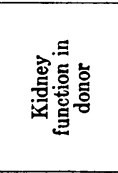 & 喜 & 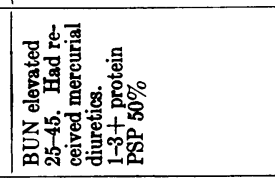 & 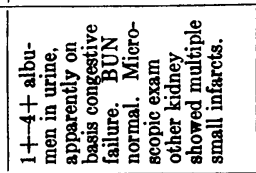 & 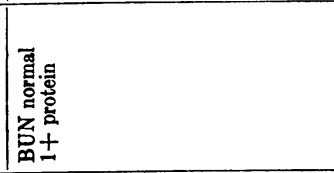 \\
\hline & 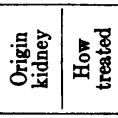 & 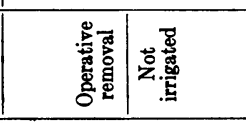 & 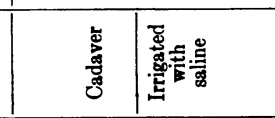 & 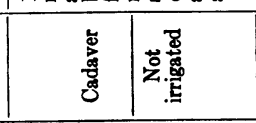 & 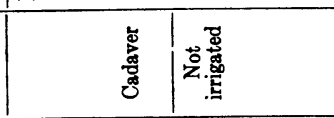 \\
\hline & 善 & 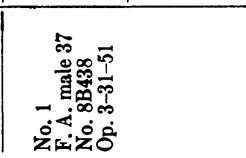 & 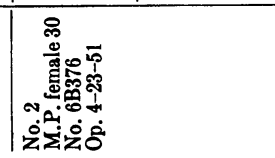 & 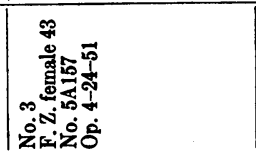 & 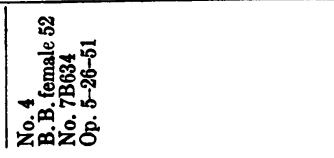 \\
\hline
\end{tabular}




\begin{tabular}{|c|c|c|c|c|c|c|}
\hline \multirow{3}{*}{ 蟚 } & 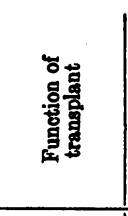 & 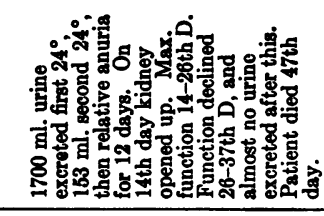 & 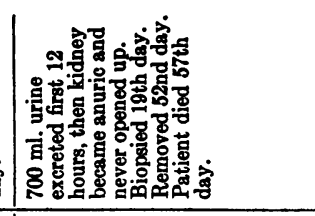 & 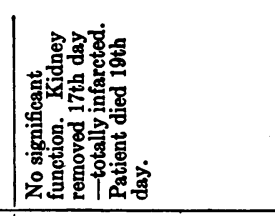 & 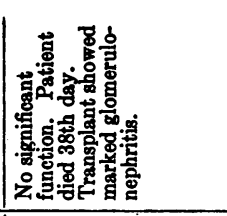 & 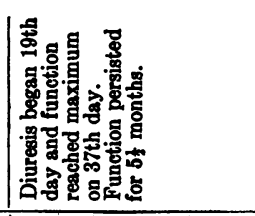 \\
\hline & 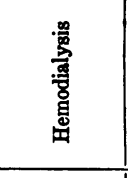 & $\frac{\mathrm{g}}{\mathrm{a}}$ & 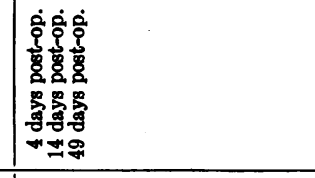 & 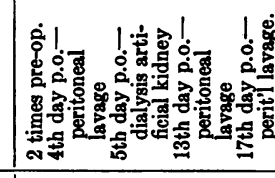 & 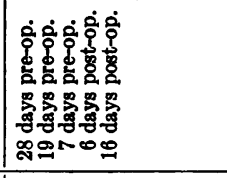 & 曽 \\
\hline & 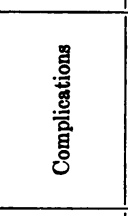 & 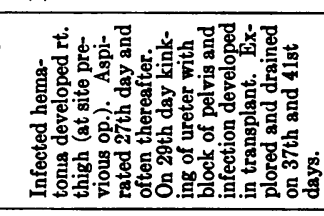 & 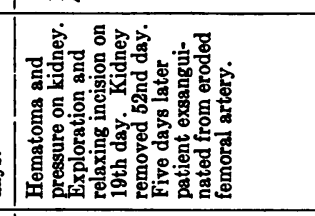 & 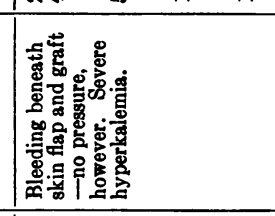 & 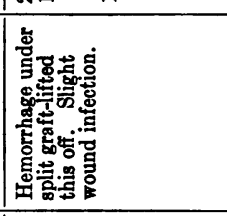 & 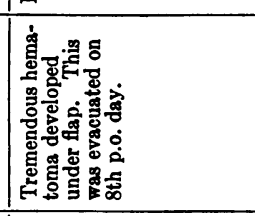 \\
\hline \multirow{8}{*}{ 言 } & 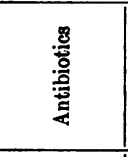 & 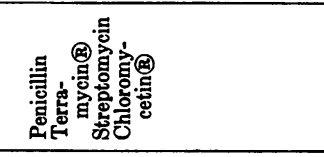 & 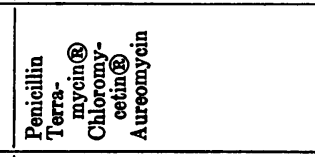 & 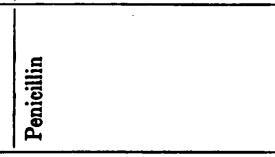 & 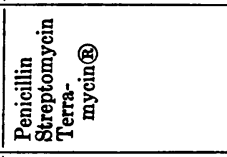 & 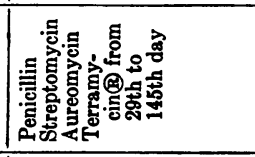 \\
\hline & 童害 & 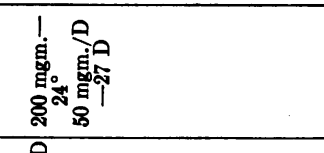 & 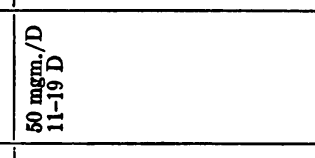 & 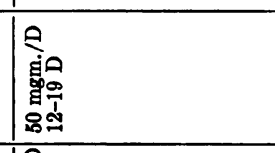 & 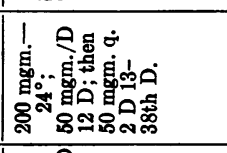 & 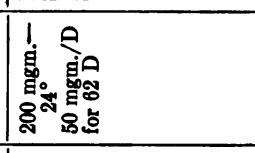 \\
\hline & 量 & 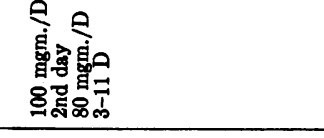 & 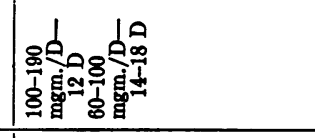 & 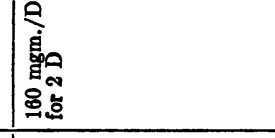 & 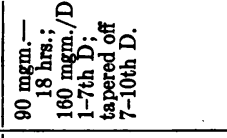 & 曽 \\
\hline & 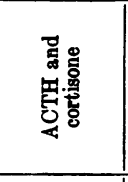 & 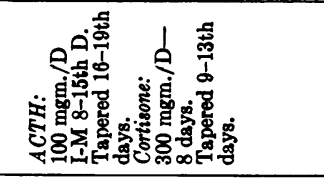 & 产 & 愛 & 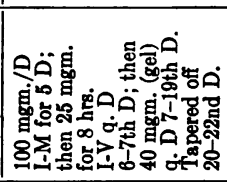 & 递 \\
\hline & 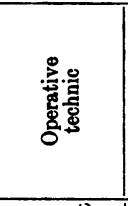 & 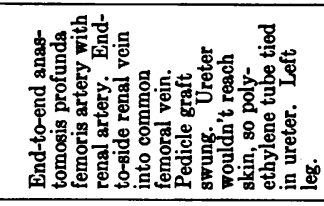 & 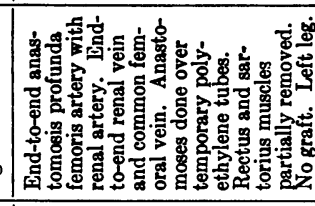 & 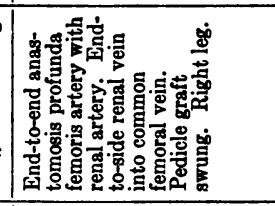 & 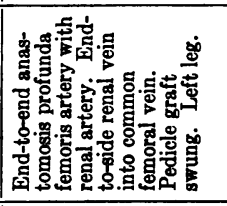 & 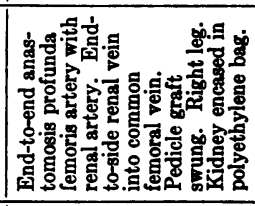 \\
\hline & 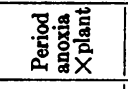 & $B$ & $=$ & 8 & $1 \%$ & $\Phi$ \\
\hline & 亳言 & 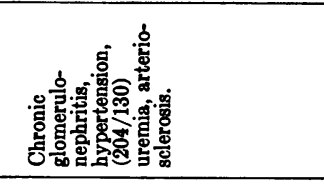 & 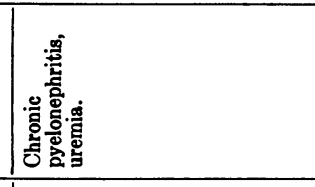 & 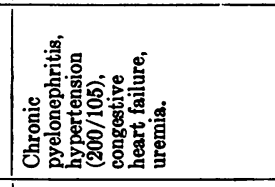 & 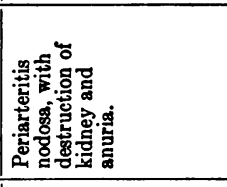 & 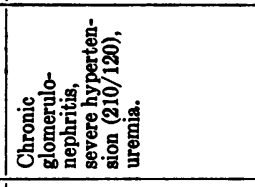 \\
\hline & 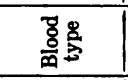 & $t$ & $1+$ & $1+$ & \pm & \pm \\
\hline \multirow{4}{*}{$\begin{array}{l}\text { 言 } \\
\end{array}$} & 酸亭 & + & $1+$ & 血 & $t$ & \pm \\
\hline & 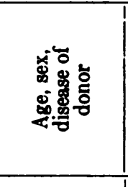 & 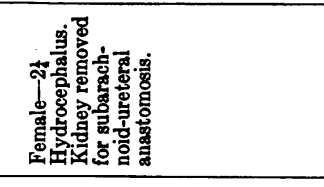 & 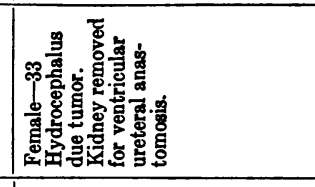 & 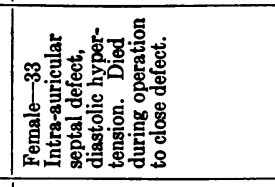 & 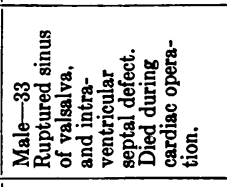 & 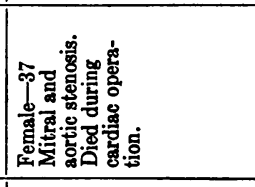 \\
\hline & 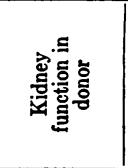 & $\frac{\bar{T}}{\frac{\mathrm{g}}{\mathrm{s}}}$ & 萦 & 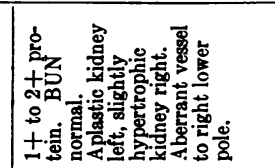 & 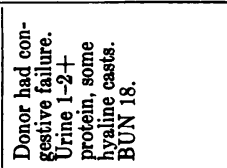 & 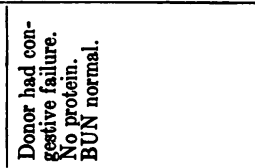 \\
\hline & 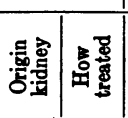 & 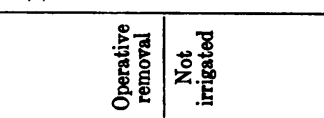 & 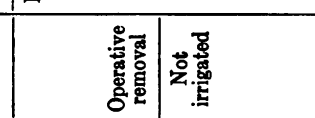 & 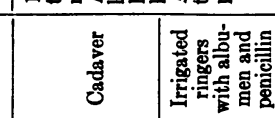 & 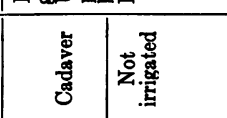 & 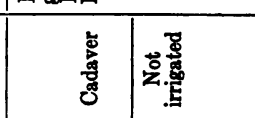 \\
\hline & : & 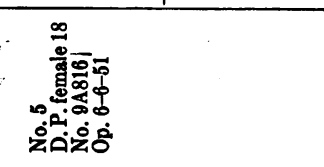 & 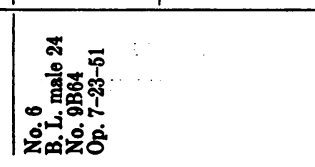 & 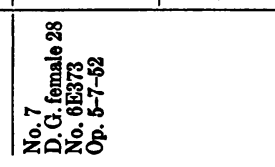 & 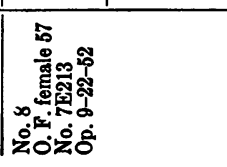 & 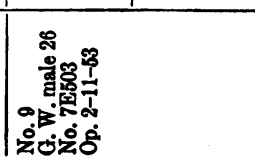 \\
\hline
\end{tabular}


duct by tumor. A communication was established via a polyethylene tube between the ureter and the subarachnoid space in one case, and between the ureter and ventricle in the other, to relieve the increased intracranial pressure. This operation, which was developed and performed by Dr. Donald Matson (89), necessitates the removal of one kidney.

The recipients were all patients in irreversible terminal uremia on the basis of chronic pyelonephritis in five cases, chronic glcmerulonephritis in two cases, polycystic kidney disease in one case, and periarteritis nodosa in one case. The transplanted kidneys came from donors of the same blood type as the recipients in seven cases, and different blood types in two cases.

When hemodialysis was necessary it was carried out with a modification of the Kolff artificial kidney (99).

One patient (F. A.), a 37-year-old man with chronic pyelonephritis and severe uremia, was referrcd to the Peter Bent Brigham Hospital where he was twice dialyzed on the artificial kidney during a 14-day hospitalization. $\mathrm{He}$ was then transferred to an outside hospital where a donor kidney was available. A transplant was performed by Dr. James V. Scola. ${ }^{3}$ The left kidney and spleen of the recipient were removed and anastomoses were made end-to-end between the splenic artery and the renal artery, and between the two renal veins. The pelvis of the transplant was anastomosed to the ureter of the recipient, and a $\mathrm{T}$-tube was brought out from the ureter through a stab wound. The patient was readmitted to the Peter Bent Brigham Hospital on the 3rd day, and was followed by us until his death on the 37 th day.

Sodium and potassium were determined with the Beckman flame photometer; inulin by the method of Schreiner (111) ; para-amino-hippurate by the method of Finkelstein. Aliminosa, and Smith (44); urea by the method of Archibald (2): chloride by the method of Schales and Schales (109), and Asper, Schales and Schales (3); urine creatinine by the method of Bonsnes and Taussky (14) ; phosphorus by the method of Fiske and Subbarow (45); ammonia by the method of Folin and Bell (47) : carbon dioxide by the method of Van Slyke and Neill (129); and urinary protein by the method of Chinard (27). Urinary sediment was evaluated by the semiquantitative method of Addis (1).

\section{RESULTS}

A summary of the results in the cases reported here is shown in Table I. A detailed report of the cases follows in their chronological order.

Case I-F. A., male, age 37, No. $8 B 438$

Diagnosis: Chronic pyelonephritis, hypertension, uremia. The patient was referred to the Peter Bent Brigham Hospital from the Springfield Hospital, Springfield, Massachusetts, on 3-20-51 by Dr. L. H. Doolittle. A diagnosis of acute nephritis had been made at the Spring-

\footnotetext{
3 Springfield Hospital, Springfield, Massachusetts.
}

field Hospital 18 years previously. In 1950 he was again admitted there and studies were made which led to a diagnosis of chronic pyelonephritis. He had known hypertension for two years. For three months before admission, he had complained of nausea, vomiting, drowsiness, and increasing weakness.

Physical examination showed a chronically ill, semicomatose man complaining bitterly of hack pain. Optic fundi showed narrowing of the arterioles with an occasional fresh punctate hemorrhage. Lungs were clear. The heart was slightly enlarged to percussion, and there was an apical presystolic gallop. Blood pressure was 170/90. There was bilateral costo-vertebral tenderness.

Laboratory data: The urine specific gravity was 1010 with $4+$ proteinuria, 5-10 red cells, and a few white blood cells in the unspun sediment. The hematocrit was 24 , white blood count 6,900, blood urea nitrogen 296 mgm. per cent, carbon dioxide combining power $10 \mathrm{mM}$. per L., serum sodium $132 \mathrm{mEq}$. per L., serum potassium $5.2 \mathrm{mEq}$. per L. Urine culture grew enterococci and E. coli. A chest film showed the heart to be at the upper limits of normal, the contours suggesting left ventricular hypertrophy. The vascular markings were increased.

In spite of 5 days of conservative therapy, there was no improvement in the clinical status. On the 6th hospital day, dialysis with the artificial kidney was performed with good chemical result but little clinical change. The patient was again dialyzed on the 10th hospital day, and following this procedure, there was definite marked clinical improvement.

On 3-30-51, the day of the last dialysis, the patient was transferred to the Springfield Hospital. The following day a renal homograft was performed by Dr. James V. Scola. The donor was a patient with carcinoma of the lower end of the ureter whose kidney was removed by Dr. L. H. Doolittle at the same time that exposure was being obtained in the recipient. Both patients were blood type $\mathrm{A}, \mathrm{Rh}+$. A left nephrectomy and splenectomy were performed, and the splenic artery was anastomosed to the renal artery of the homograft, and the renal vein to renal vein. The recipient's ureter was anastomosed to the pelvis of the transplant, and a $\mathrm{T}$-tube was placed in the ureter and brought to the outside. The period of ischemia of the transplanted kidney was 70 minutes. The patient tolerated the procedure well, and on the 4th day he was readmitted to the Peter Bent Brigham Hospital. Following operation, the urine volume had decreased, although the clinical condition on readmission was generally better than prior to operation. The patient received seven blood transfusions on the operative day.

Physical examination on the second admission was much as before, with the exception that breath sounds were absent and tactile fremitus reduced over the left lower lung field. A marked pericardial friction rub was present. The abdomen was now distended and tympanitic, although peristalsis was present. The hematocrit was 32 , white blood count 22,400 , blood urea nitrogen $101 \mathrm{mgm}$. per cent, serum carbon dioxide combining 


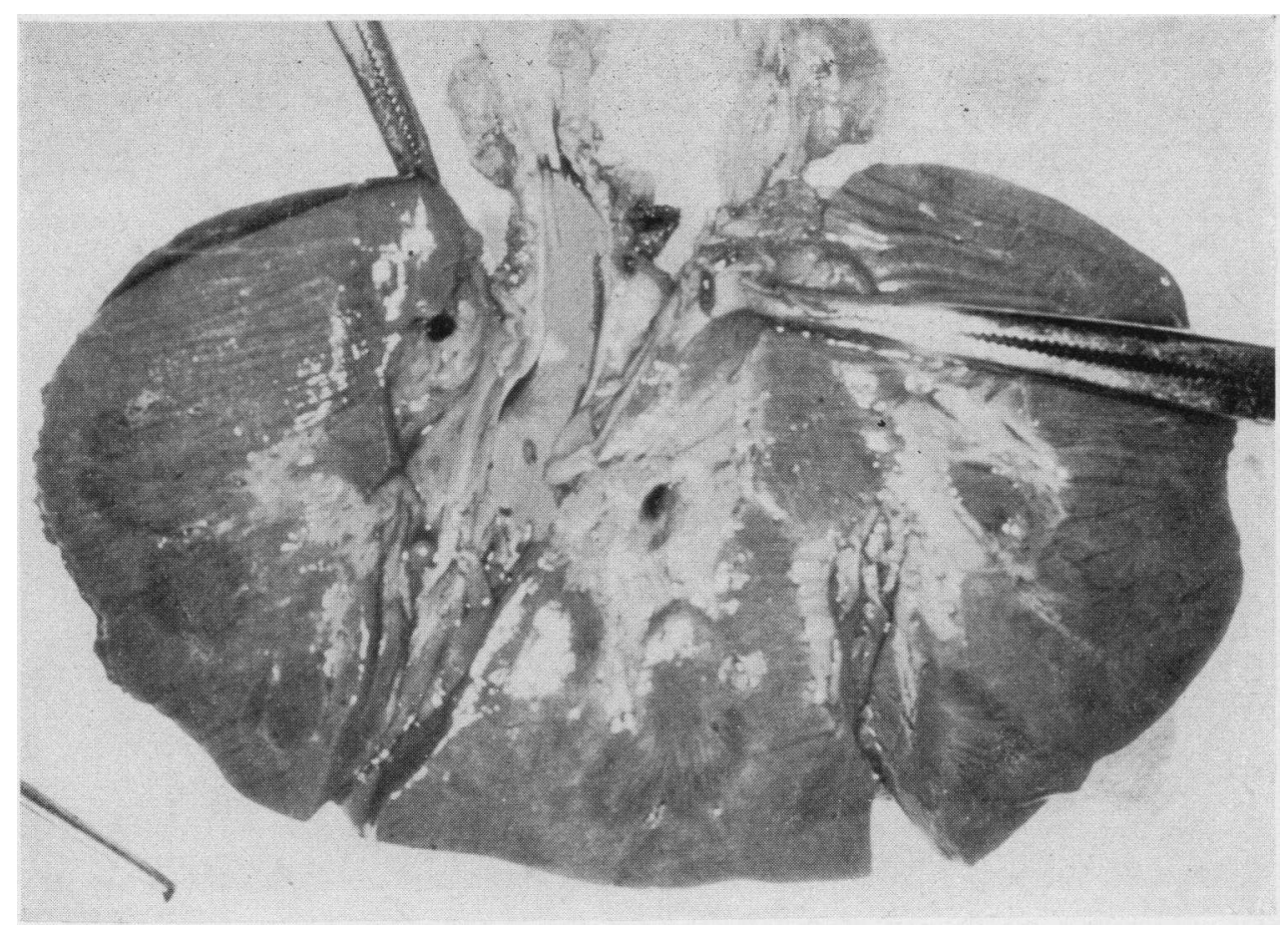

Fig. 2. F. A., Case No. 1-The Appearance of the Cut Surface of the Renal HOMOGRAFT

Grossly, the transplant appears normal, except for a slight mottling. Both anastomoses are patent.

power $15 \mathrm{mM}$. per L., sodium $140 \mathrm{mEq}$. per L., potassium $6.9 \mathrm{mEq}$. per L. X-ray of the chest showed a small area of consolidation at the left base, and the sputum cultured Pseudomonas aeruginosa which was almost completely resistant to all antibiotics.

$\mathrm{He}$ was heparinized for the first 2 days following operation, and subsequently received $200 \mathrm{mgm}$. of heparin a day from the 5 th to the 9 th day. He was given $20 \mathrm{mgm}$. per day of ACTH intramuscularly (I-M) 4 for 3 days. On the 4th day he received $65 \mathrm{mgm}$. I-M, and from the 5 th through the 11 th day he received $25 \mathrm{mgm}$. per day intravenously $(\mathrm{I}-\mathrm{V})^{4}$ or $100 \mathrm{mgm}$. I-M. It was tapered off from the 11th to 13th day. No cortisone was given. He received $100 \mathrm{mgm}$. of testosterone propionate on the 15 th day, and $50 \mathrm{mgm}$. per day thereafter from the 16th through the 37 th day.

On the 9th day, because of deterioration in the clinical condition, hemodialysis was performed with good clinical response. The abdominal distention, however, continued to be a major problem. Hemodialysis was performed again on the 18th, the 26th, and the 32nd days with deterioration of the clinical state between each procedure. The urine output varied between 300 and 100 $\mathrm{ml}$., of which varying amounts came from the ureteral T-tube of the homograft. It was difficult to evaluate what percentage of the $\mathrm{T}$-tube drainage was reflux from

${ }^{4}$ Hereafter I-M will be used as an abbreviation for intramuscularly, and $\mathrm{I}-\mathrm{V}$ for intravenously. the bladder urine. Indigo carmine was injected once and PSP twice, but neither of these dyes appeared in bladder or $\mathrm{T}$-tube urine.

On the 15th hospital day, a friction rub appeared in the right axilla. On the 23rd day, because of separation and infection of the abdominal wound, a debridement and secondary closure were carried out. On the 27 th day a retrograde injection of contrast media into the T-tube catheter showed what appeared to be a small drainage cavity resulting in some break in the continuity of the suture line near the renal pelvis of the homograft. On the 34th day a left thoracentesis yielded $620 \mathrm{ml}$. of apple-jelly colored fluid. The patient now appeared brighter. On the 37th day he complained of chest pain, and shortly after an intercostal block for this pain, the patient gasped suddenly and expired.

Post-mortem examination showed chronic pyelonephritis of the right kidney, perinephric abscess about the left homograft, empyema of the right pleural cavity, left pulmonary atelectasis, and left ventricular hypertrophy. Gross examination of the homograft showed it to be slightly enlarged and somewhat mottled. Except, however, for the perinephric abscess, the gross appearance was not markedly abnormal (see Figure 2). Microscopic examination showed a dense avascular connective tissue sheath surrounding the capsule of the transplanted kidney. This reaction appeared to be mostly extra-capsular (see Figure 3). The glomeruli appeared 


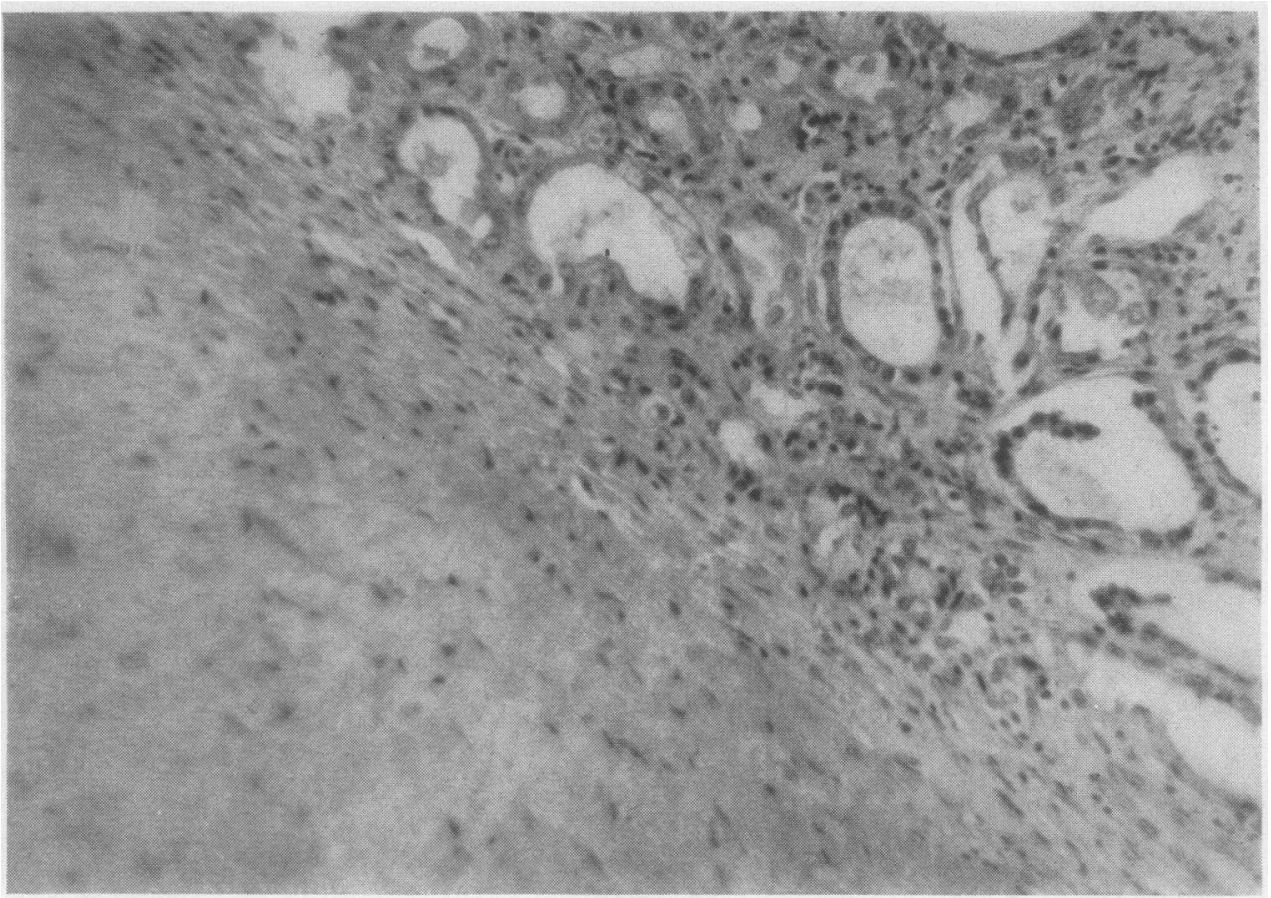

Fig. 3. F. A., Case No. 1-A Dense, Avascular Connective Tissue Capsule Surrounds the Transplanted Kidney ( H \& E $\times 250$ )

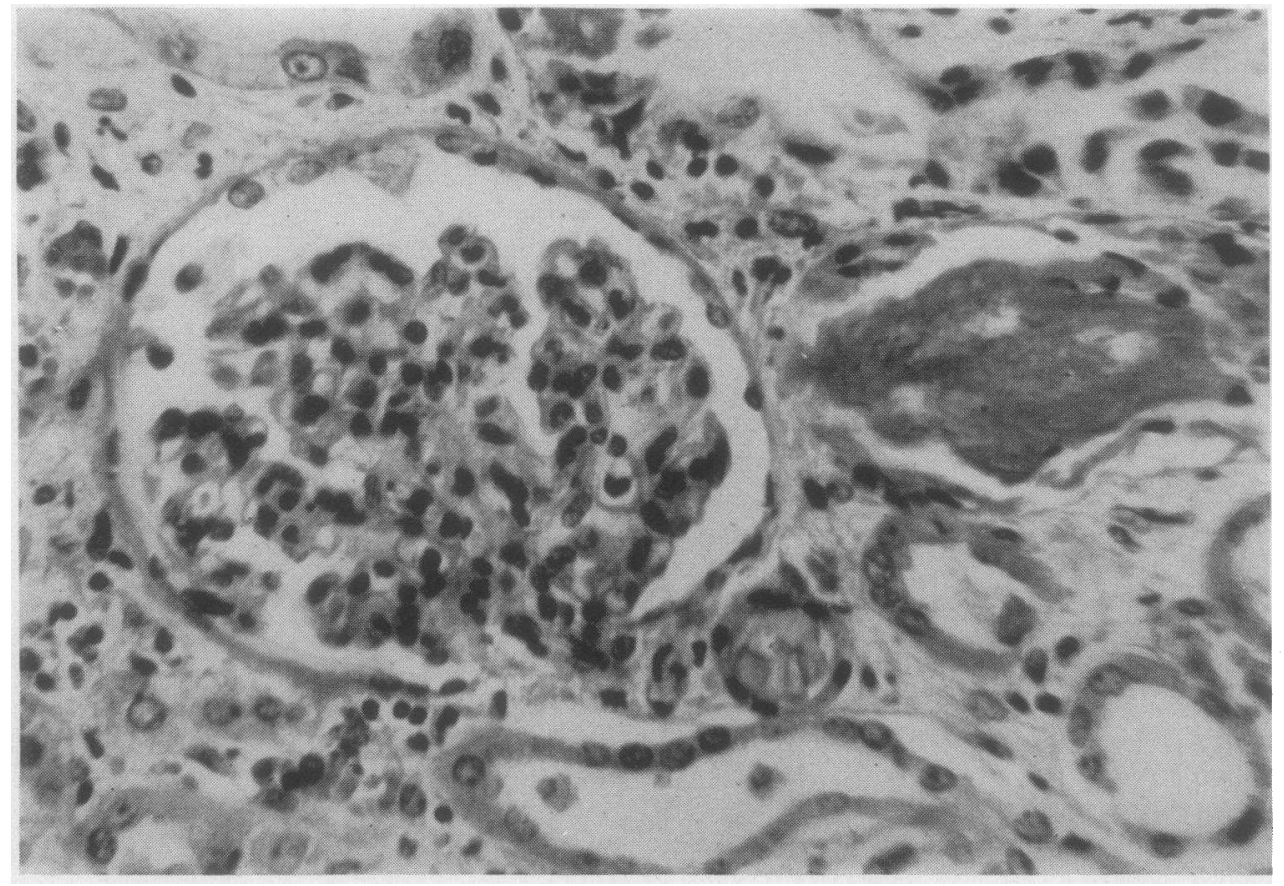

Fig. 4. F. A., Case No. 1-A Glomerulus is Relatively Bloodless, But Shows no Appreciable Inflammation or Proliferation-There is Degeneration of the Epithelium of Adjacent Tubules, and Basophilic Casts are Present ( $\mathrm{H} \& \mathrm{E} \times 500$ ) 


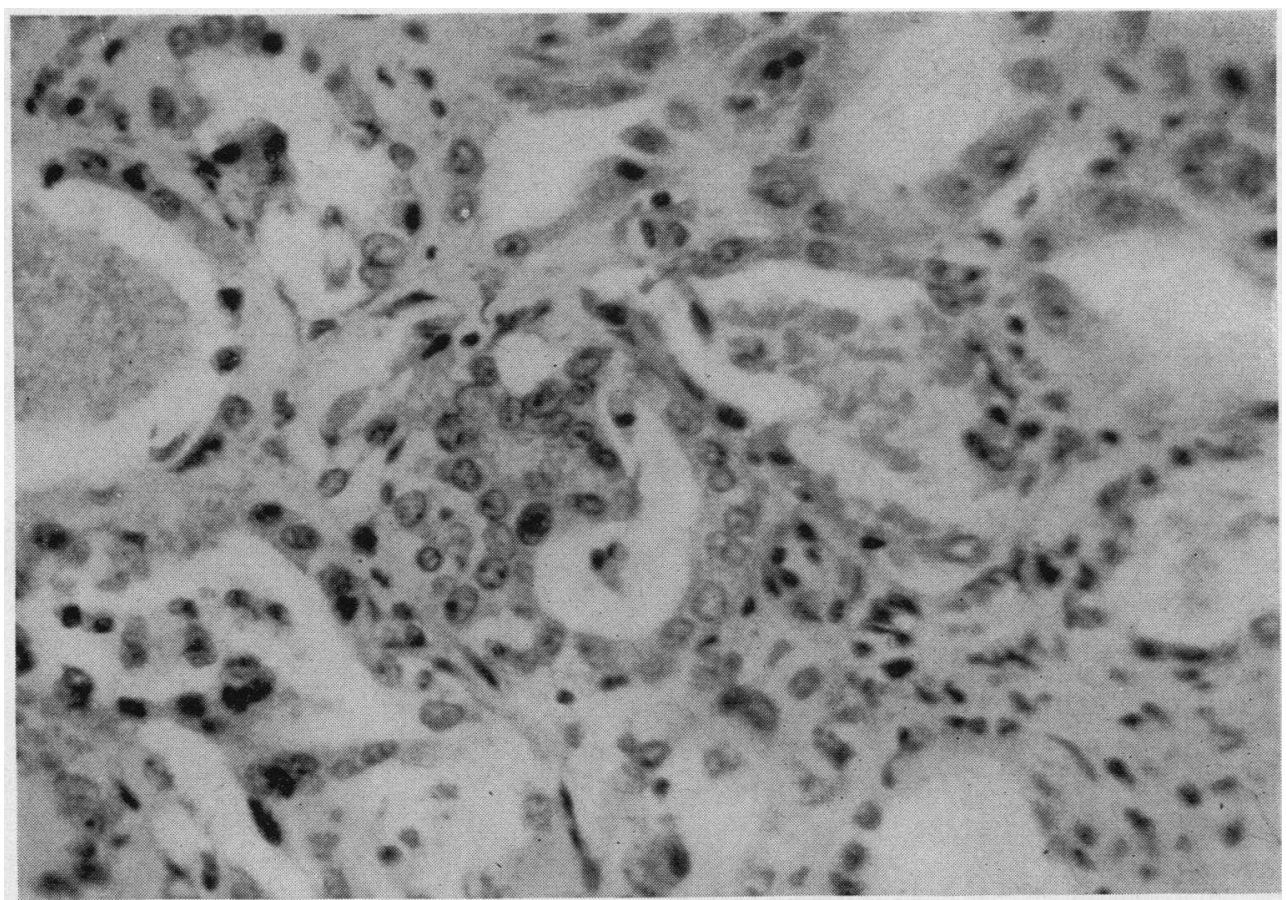

Fig. 5. F. A., Case No. 1-The Epithelium of the Convoluted Tubule in the Center of the Illustration is Heaped up and Nuclei Are Closely Approximated, Suggesting Focal Regenerative Proliferation-In Nearby Tubules, Degenerative Changes Persist $(\mathrm{H} \& \mathrm{E} \times 500)$

relatively bloodless, but there was no appreciable inflammation or increased cellularity (see Figure 4 ). The tubules showed a moderate amount of degeneration, which was most prominent in the proximal tubules and in the loops of Henle. Calcium oxalate crystals were present in the lumen of the tubules. There was also some regeneration of tubular epithelium which was most noticeable in the distal tubules (see Figure 5). The histologic picture was not unlike that of a severe acute ischemic nephrosis ("lower nephron nephrosis") in a repairing state. There was very little interstitial infiltration. ${ }^{5}$

\section{Case II-M. P., fernale, age 30, No. 6 B376}

Diagnosis: Chronic pyelorephritis, hypertension, uremia.

This 30-year-old white female was admitted to the Peter Bent Brigham Hospital for the second time on 3-14-51. On a previous admission, 13 months before, the diagnosis of hypertensive vascular disease, pyelonephritis, and uremia had been made. The hospital stay

${ }^{5}$ For the description of the pathology of the homotransplants in Cases 1 through 8 we are indebted to Dr. Clinton Van Zandt Hawn, formerly Pathologist-in-Chief of the Peter Bent Brigham Hospital, and at present Pathologist-in-Chief of the Mary Imogene Bassett Hospital, Cooperstown, N. Y. For the description in Case No. 9 we are indebted to Dr. Gustave Dammin, Pathologist-in-Chief of the Peter Bent Brigham Hospital. revealed positive cultures from each ureter, proteinuria, hypertension without cardia enlargement, and a blood urea nitrogen of $40 \mathrm{mgm}$. per cent. The present admission was occasioned by severe nausea and vomiting following an upper respiratory infection. In an outside hospital, in spite of therapy, this had progressed to semi-coma accompanied by twitching and convulsions.

Physical examination: On admission the patient was a critically ill, dehydrated, semi-comatose young woman. Blood pressure was $158 / 100$. The optic fundi were unremarkable except for moderate arterio-venous nicking. The heart was now enlarged by $x$-ray, and there was a presystolic gallop with a grade II apical systolic murmur. There was no venous distension, and no peripheral edema. A few dry rales were heard at the left base. The reflexes were markedly hypoactive.

Laboratory data: The blood urea nitrogen was 113 mgm. per cent, carbon dioxide combining power 14.1 mM. per L., serum chloride $86 \mathrm{mEq}$. per L., sodium 133 mEq. per L., potassium $4.3 \mathrm{mEq}$. per L., and phosphate $4.3 \mathrm{mEq}$. per $\mathrm{L}$. The hematocrit was 19, and the white blood count was 5,300 with a normal differential.

Hospital course: The patient showed very little improvement after 8 days of conservative therapy, and on 3-22-51 hemodialysis with the artificial kidney was performed. There was a temporary improvement following this. However, on 4-14-51 the patient again had a generalized convulsion, following which she was maintained on Dilantin ${ }^{\circledR}$ without further convulsive episodes. By 
4-20-51 the blood urea nitrogen had risen to $210 \mathrm{mgm}$. per cent with a serum potassium of $7.9 \mathrm{mEq}$. per L. On 4-23-51 a renal homograft was transplanted into the right thigh, employing a kidney from a patient who had died during a surgical procedure for hypertensive vascular disease. The donor's blood type was $\mathrm{O}, \mathrm{Rh}+$, while that of the recipient was $\mathrm{A}, \mathrm{Rh}+$, thus presenting compatibility in the major grouping but not in the minor. The period of time which elapsed between the death of the donor and the re-establishment of blood flow through the transplant in the host was 150 minutes. (In subsequent cases this interval will be spoken of as the period of ischemia of the kidney. In cases in which the donor was living, the beginning of the interval will be reckoned from the time when the renal vessels were clamped.)

The kidney was perfused with normal saline solution as soon as it was removed from the cadaver, because of the blood group incompatibility. Fnd-to-end anastomoses were made between the profunda femoris artery and the renal artery, and between the superficial femoral vein and renal vein. The bulldog clamp was removed from the femoral vein and heparin was inserted through a No. 26 needle into the renal artery. The arterial clamp was now removed, and with the re-establishment of the circulation, the kidney became pink. There are two details worth noting at this point: 1) By mistake 125 mgm. of heparin, instead of $25 \mathrm{mgm}$., was injected into the renal artery, and thus into the general circulationthis was followed shortly by oozing from the wound edges; and 2) this kidney and the kidney in Case No. 6 were not quite as vigorously or quickly distended with blood when the clamps were removed as the other transplants were. Both these kidneys, unlike the others, came from hypertensive donors, whose blood types were different from that of the recipient, and both kidneys were perfused before being anastomosed. One or all of these three factors may have had some bearing on the apparently initially somewhat diminished blood flow of these kidneys compared to the other grafts.

A pocket was fashioned between the fascia of the adductor muscles and the subcutaneous tissue, and the subcutaneous tissue and skin were closed over the kidney. The ureter was brought out through a stah wound.

For 48 hours the patient was given heparin, $40 \mathrm{mgm}$. every 6 hours I-M, and ACTH, $20 \mathrm{mgm}$. every 8 hours $\mathrm{I}-\mathrm{V}$. She was then given $225 \mathrm{mgm}$. of cortisone and $50 \mathrm{mgm}$. of testosterone daily for 7 days. Hemodialysis was again performed on the 2 nd day because of her poor clinical condition, and she improved markedly following this. A large hematoma developed beneath the skin flaps, and by the 3rd day the skin overlying the transplant had become shiny and tense, and the ureter was necrotic. It was decided to re-explore the transplant. There was a large hematoma around the kidney. The kidney was a normal pink color, and there was a good blood flow through it. The capsule bled freely, and it was therefore replaced and a relaxing incision was made in the skin laterally.
Sepsis developed in the wound. A biopsy of the kidney on the 13th day showed infarction of the kidney, and it was removed 4 days later. The renal vessels were thrombosed and massive infarction of the kidney had occurred. Six days later the infection in the wound eroded through the superficial femoral artery, and a severe hemorrhage occurred. The patient was reoperated and it was found that an eroded area in the artery $2 \mathrm{~cm}$. long and $0.5 \mathrm{~cm}$. wide had given way. It was impossible to suture the vessel because the wall was necrotic. A lucite tube was placed in the vessel, therefore, and tied in with nylon rings after the method described by Hufnagel and Gillespie (57). A skin graft was laid over the blood vessel. During the next 2 days the sensation, movement, and temperature of the leg were normal. Good pulses could be felt in the foot. At this time the patient had an episode of pulmonary and cerebral edema and died suddenly. At post-mortem the lucite tube was patent, and the femoral artery appeared viable on either side of the nylon rings which held the tube in place.

Gross and microscopic examination of the homograft in this case revealed total infarction of the tissues, the renal structure being so distorted that no other changes were discernible.

\section{Case III-F. Z., female, age 43, No. 5 A157}

Diagnosis: Chronic pyelonephritis, hypertension, arteriosclerosis, uremia.

This was the sixth admission of this patient with chronic progressive uremia who had been treated on two previous occasions by the artificial kidney with satisfactory results. Her blood urea nitrogen prior to dialysis had been as high as $188 \mathrm{mgm}$. per cent. She was admitted to the hospital on this occasion specifically for a renal homograft, having been discharged one week previously, following dialysis.

Physical examination: The patient was a well developed woman with dry scaling skin and generalized pallor. The blood pressure was $165 / 90$. There was slight sclerosis of the retinal vessels. The lung fields were clear, and the heart was enlarged to percussion with a protodiastolic gallop and a course systolic bruit at the fourth interspace. Chest $\mathrm{x}$-ray showed hilar congestion and marked cardiac enlargement. The liver was enlarged three finger breadths below the right costal margin and was slightly tender. There was minimal presacral and pretibial edema.

Laboratory data: The urine showed $2+$ proteinuria, and 10-20 white cells with rare granular casts in the spun sediment. The blood urea nitrogen was $96 \mathrm{mgm}$. per cent, serum carbon dioxide combining power $11.6 \mathrm{mM}$. per L., sodium $130 \mathrm{mEq}$. per L., and potassium $6.8 \mathrm{mEq}$. per L.

On 4-24-51, the day of admission, a renal homograft was done. The donor was a patient with severe mitral stenosis who died during a valvuloplasty. Her urine contained from $1+$ to $4+$ albumen on many occasions, but her blood urea nitrogen was within the normal range. 
TABLE II

Case No. 3-A comparison between the sodium, potassium, creatinine, and urea nitrogen content of the bladder urine and the transplant urine. The collection of urine from the transplanted kidney was not complete

F. Z. -5-13-51-19th day. BUN: 148

\begin{tabular}{lccccccc}
\hline & 24-hr. Vol. & $\begin{array}{c}\mathrm{Na} \\
m E q . / L .\end{array}$ & $\begin{array}{c}\mathrm{K} \\
m E q . / L .\end{array}$ & $\begin{array}{c}\text { Creatinine } \\
m g m . \%\end{array}$ & $\begin{array}{c}\text { Creatinine } \\
m g m . / 24^{\circ}\end{array}$ & $\begin{array}{c}\text { Urea } \mathrm{N} \\
m g m . \%\end{array}$ & $\begin{array}{c}\text { Urea } \mathrm{N} \\
\text { gram } / 24^{\circ}\end{array}$ \\
\hline Bladder urine & 580 & 16.2 & 35 & 44 & 225 & 832 & 4.8 \\
Transplant urine & $600^{*}$ & 3.5 & 47 & 52 & $312+$ & 1,023 & $6.1+$ \\
\hline
\end{tabular}

* Not complete.

Examination of her other kidney showed multiple small infarcts-apparently caused by emboli. Both donor and recipient were blood group $\mathrm{B}, \mathrm{Rh}+$, and their bloods were cross-matched and found to be compatible. The period of ischemia was 135 minutes. The kidney was transplanted into the right thigh by means of an end-toend anastomosis of the profunda femoris artery with the renal artery, and an end-to-side anastomosis of the renal vein into the common femoral vein. The kidney was not perfused. There was marked sclerosis of the recipient's vessels, and some sutures were taken through arterio-sclerotic plaques. Nonetheless the kidney became distended with blood as soon as the clamps were removed, and was a normal pink color. The kidney was placed in a pocket created between the fascia overlying the adductor muscles and the subcutaneous fat. The subcutaneous tissue and skin were closed over the kidney, and there was a moderate amount of tension on the skin. The patient received $25 \mathrm{mgm}$. of ACTH every 6 hours for 24 hours, and was then given 225 to $300 \mathrm{mgm}$. of cortisone daily for 18 days, at which time it was reduced to $100 \mathrm{mgm}$. daily and ACTH, $80 \mathrm{mgm}$. a day, was begun again. The cortisone was stopped after 25 days, and the ACTH was gradually tapered off after 31 days. She was given $40 \mathrm{mgm}$. of heparin every 6 hours for 14 days, and $50 \mathrm{mgm}$. of testosterone daily for 29 days, at which time it was tapered off and stopped on the 34th day. Penicillin and Purodigin ${ }^{\circledR}$ were also given.

During the first week after the transplantation, necrosis of the skin overlying the kidney began to develop because of edema in the wound and tension on the skin flaps. The ureter was not yet involved in this process, but it was edematous and it ultimately became markedly swollen and pale. After $8 \frac{1}{2}$ days of anuria the trans-

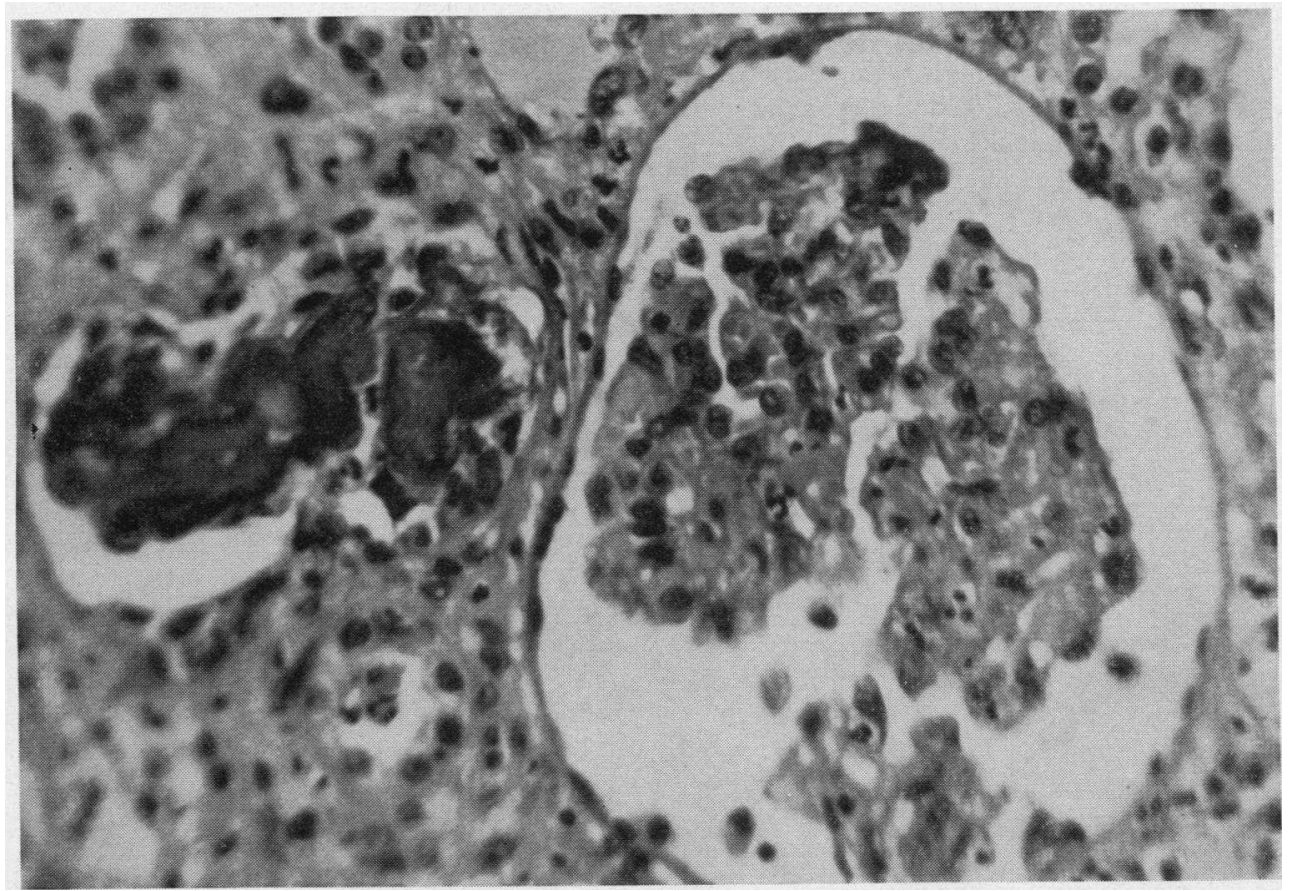

Fig. 6. F. Z., Case No. 3-Biopsy of the Homograft Taken on the 70th Day

The glomerular tuft is relatively bloodless, but shows no appreciable exudative or proliferative response. An adjacent tubule is denuded of epithelium and contains an irregularly laminated calcific mass. (H\& E $\times 500)$ 


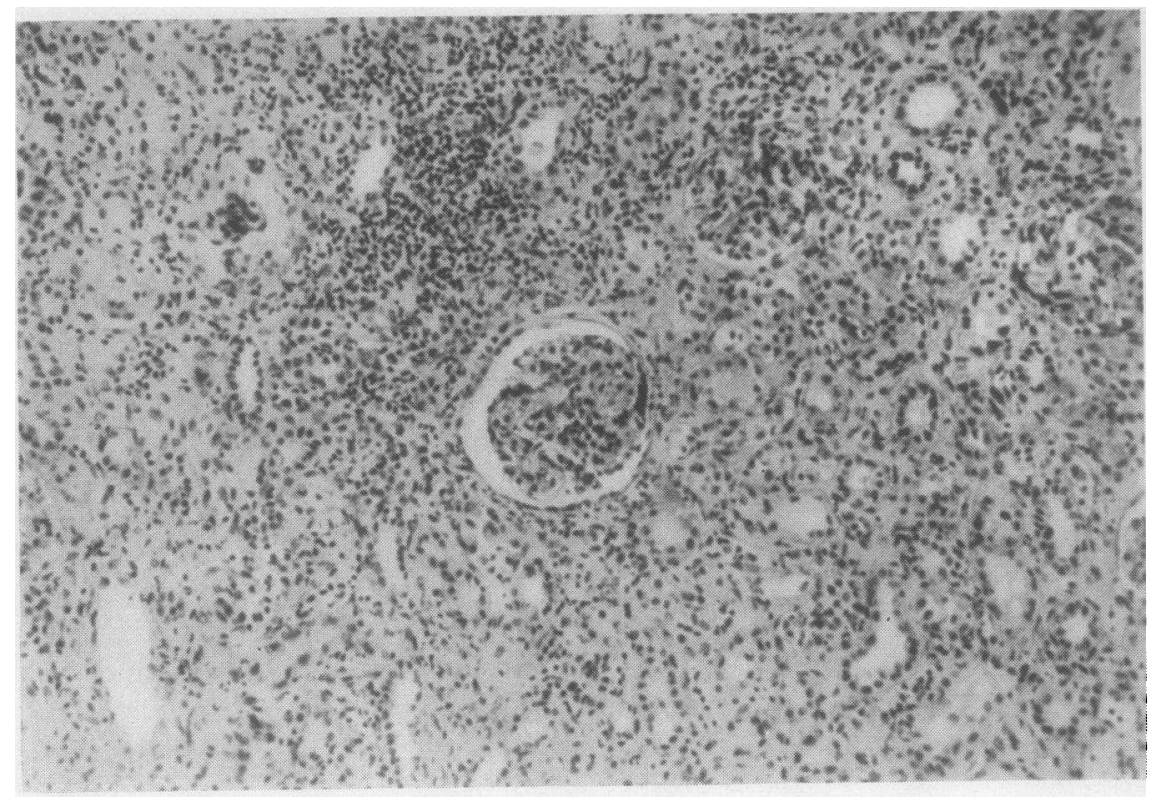

Fig. 7. F. Z., Case No. 3-Biopsy of the Homograft Taken on the 70th Day

There is marked infection, with round cell and polymorphonuclear leucocytic infiltration of the interstitial spaces. There is no evidence of acute or chronic glomerulonephritis. The glomerulus in the center of the picture is somewhat ischemic, but otherwise appears surprisingly normal. ( $\mathrm{H} \& \mathrm{E} \times 150)$

planted kidney began to excrete urine. The urine was collected by letting the tip of the ureter hang down into a polyethylene sac which led through tubing to a bottle. These collections were somewhat inaccurate, at first because the ureter would sometimes pull out of the sac when the patient turned in bed, and later because as progressive slough of the ureter occurred, there was leakage from the wound. On the 14th day, $6 \mathrm{ml}$. of indigo carmine was injected intravenously. Small quantities of dye were noted to appear in the urine from the transplanted kidney, but none was seen in the bladder urine. By the 18th day the transplant had reached an output of more than $600 \mathrm{ml}$. per day. A phenolsulfonphthalein excretion (PSP) test was performed on this day and showed an output of 10 per cent of the dye in 2 hours in the urine from the transplanted kidney and less than 5 per cent in the bladder urine. An injection of aminophyllin intravenously produced a marked transient increase in urinary output from the transplanted kidney. A comparison between the bladder and transplant urine is shown in Table II.

The slough of skin over the kidney continued to increase in size, and after the 22 nd day it was no longer possible to obtain accurate urine collections.

On the 24th day the patient was re-operated and a polyethylene tube was placed in the wound and led to a gravity drain bottle, and wound suction was started over the dressings in an attempt to get more complete collections and keep the patient's leg drier. About 500 $\mathrm{ml}$. per day was collected by these routes. After 6 days the slough had spread so much the tube had to be removed.

PSP tests were repeated on the 22nd and 31st days, and dye was seen to appear within 10 minutes each time. No quantitative tests were possible. Urinary output began to diminish from the 33rd day on, although by the 53rd day the kidney was still excreting an estimated 200 to $300 \mathrm{ml}$. per day. On the 57 th day the patient was dialyzed because of deterioration of her clinical state.

As the slough spread, the kidney finally became almost completely exposed. The wound was debrided and granulation tissue grew over the transplant. The cortex still bled vigorously when cut. On the 70th day a biopsy of the kidney was performed. The kidney parenchyma bled freely during the biopsy. Microscopically the biopsy showed the glomeruli to be relatively bloodless, but without any specific exudative or proliferative response (see Figure 6). There was edema and polymorphonuclear and round cell infiltration of the interstitial spaces (see Figure 7). The predominate picture was that of infection-pyelonephritis and interstitial nephritis-associated with a conspicuous calcific degeneration of the tubular epithelium. There were pigment casts and calcific masses in the tubular lumina (see Figure 8). Thrombosis of some of the smaller vessels could be seen, associated with focal infarcts.

On the 73rd day a retrograde pyelogram was done on the homograft. The renal pelvis and calyces appeared fairly normal. The urinary output fell off almost to nothing. The entire transplant became necrotic and 


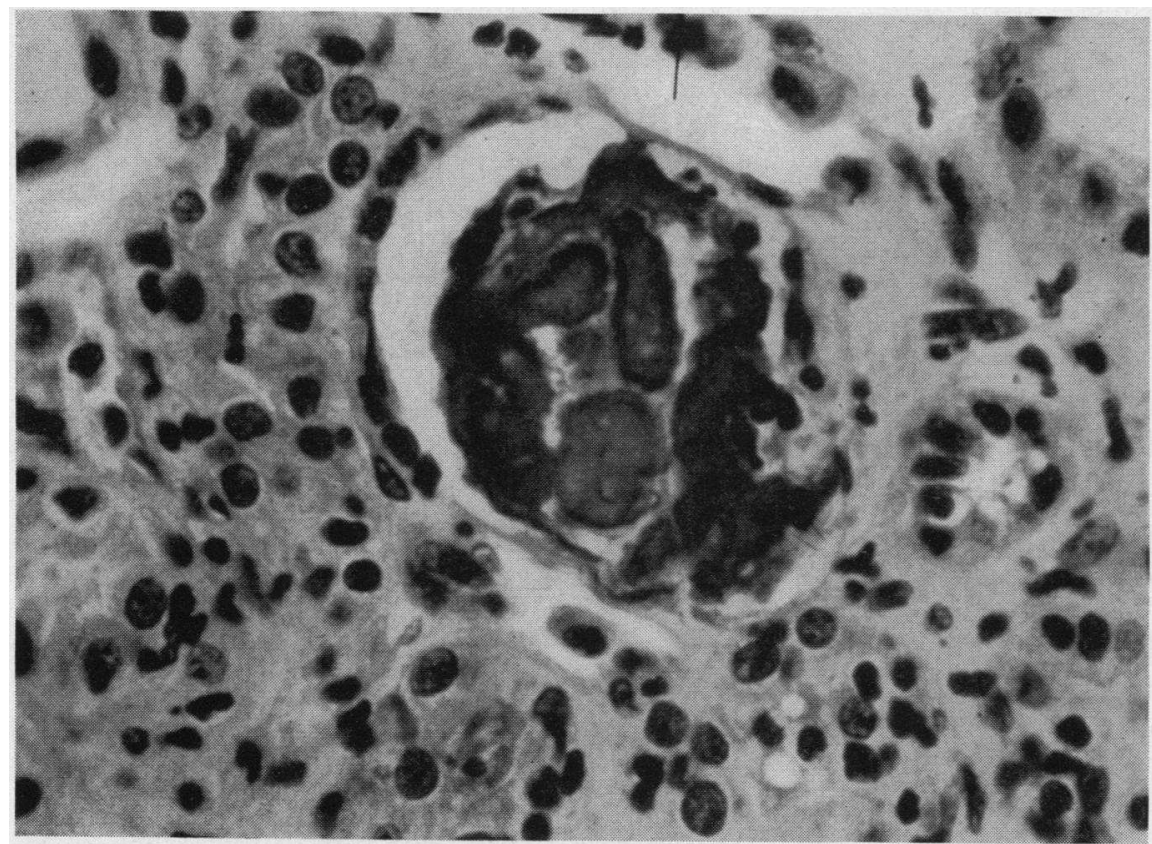

Fig. 8. F. Z., Case No. 3-Biopsy of the Homograft Taken on the 70th Day There are laminated basophilic casts in the tubular lumen. (H \& E $\times 400)$

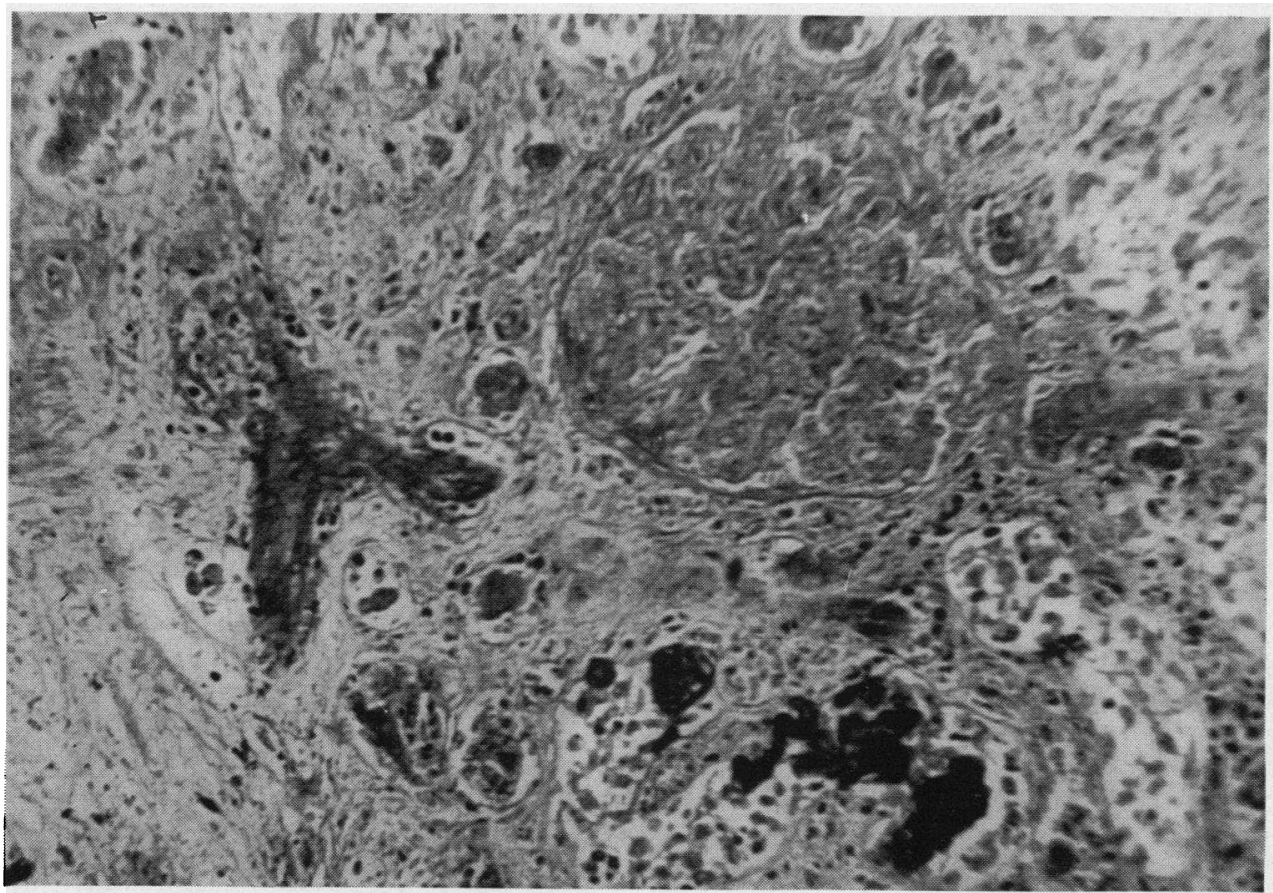

Fig. 9. F. Z., Case No. 3-The Microscopic Appearance of the Transplant at POST-MORTEM

Infarction and necrosis of the kidney occurred. The glomerular infarction is not associated with appreciable evidence of pre-existing inflammatory or proliferative changes. Nearby blood vessels are thrombosed. Many tubules contain densely basophilic masses. (H \& E $\times 250)$ 


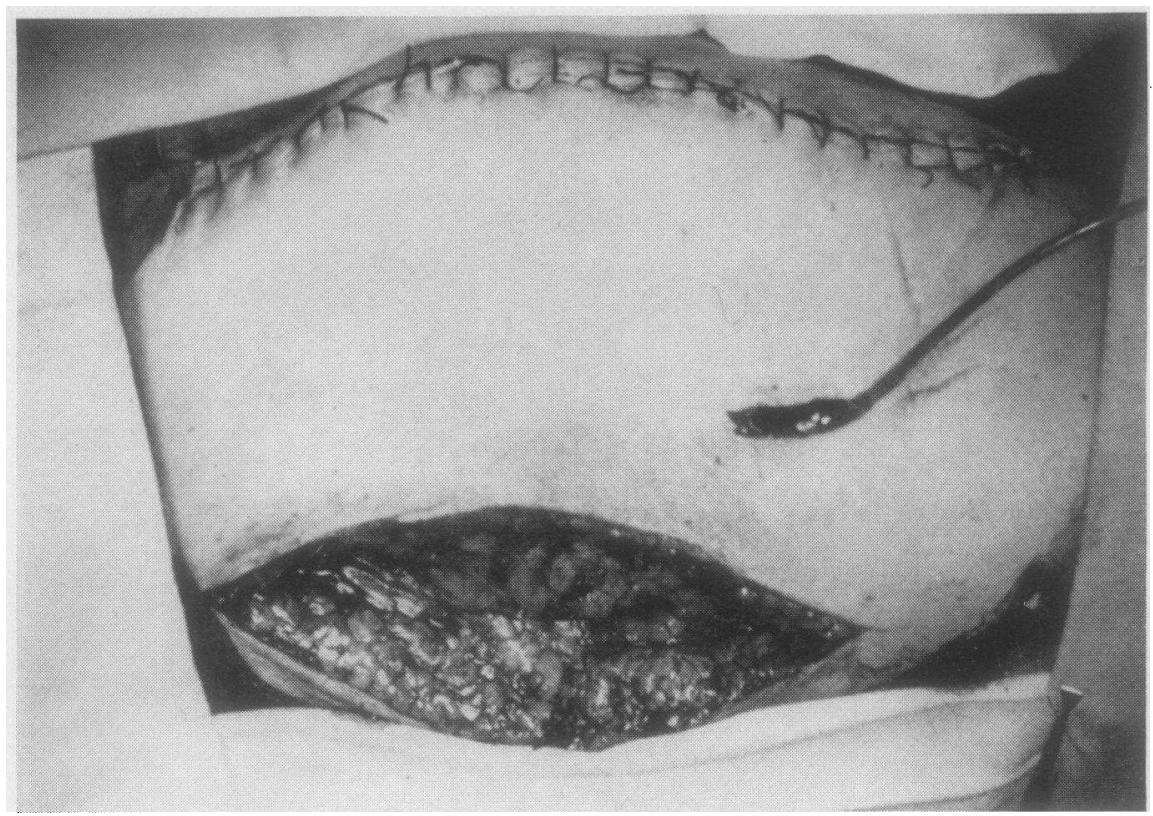

Fig. 10. B. B., Case No. 4-View of the Right Thigh on the Day of Operation, Showing Method of Sliding Double-Ended Flap of Skin and Subcutaneous Tissue over the Kidney to Eliminate Tension on the Skin Suture LINE

The ureter can be seen projecting through a stab wound. A catheter in the ureter leads to a drainage bottle. A denuded area is left over the fascia lata laterally.

thrombosed, and the patient went steadily downhill and died on the 99th day.

Post-mortem examination was limited to the homograft, and showed extensive autolysis and vascular thrombosis (see Figure 9). Marked evidence of infection, with colonies of bacteria, and extensive infarction, were seen. Again the dominant inflammatory cell was the polymorphonuclear leucocyte, and there was no evidence of acute arteritis.

Case IV-B. B., femalc, age 52, No. 7 B634

Diagnosis: Polycystic kidney disease, pyelonephritis, hypertension, uremia.

This was the third admission of a 52-year-old housewife with known polycystic kidney disease. She had been admitted to this hospital for the first time 7 months before the present admission for drowsiness, vomiting, and oliguria. Good symptomatic improvement was obtained by dialysis with the artificial kidney on two occasions. She was again admitted 7 weeks before the present admission, being discharged 4 weeks later. Her present admission on 5-24-51 was in preparation for a renal homotransplant.

Physical examination: On this occasion, examination revealed a well developed white female in no apparent distress. The skin was dry and rough with spotty café-au-lait pigmentation. Blood pressure was 170/100. The arterioles of the fundi showed some irregularity and slight A-V nicking. The heart was enlarged to per- cussion with a grade I apical systolic murmur, and normal sinus rhythm. The lungs were clear. The kidnєys were enlarged and easily palpable. There was no peripheral edema.

Laboratory data: The urine was clear, with a specific gravity of 1.009 , and $2+$ proteinuria. The sediment showed no red blood cells or casts, but 3 to 4 white blood cells per high power field. Hematocrit was 33, white blood count 6,900 , blood urea nitrogen $78 \mathrm{mgm}$. per cent, serum total protein $6.3 \mathrm{gm}$. per cent, carbon dioxide combining power $18 \mathrm{mM}$. per L., chloride 103 mEq. per L.

On 5-26-51 a kidney was transplanted into the right thigh. The donor was a patient with tetralogy of Fallot who died 4 days after an operation to widen the pulmonary valve. Both donor and recipient were blood type $\mathrm{B}, \mathrm{Rh}+$, and their bloods were cross-matched and found to be compatible. An end-to-end anastomosis was again made between the profunda femoris artery and the renal artery, and an end-to-side anastomosis was performed between the renal vein and the common femoral vein. The kidney was not perfused. The period of ischemia was 200 minutes. $^{6}$ An injection of $25 \mathrm{mgm}$. of heparin was made into the renal artery with a No. 26 needle. Circulation through the kidney appeared excellent, and the ureter, which was left about 5 inches long,

6 This long period of ischemia was occasioned by a delay in obtaining the donor kidney. 


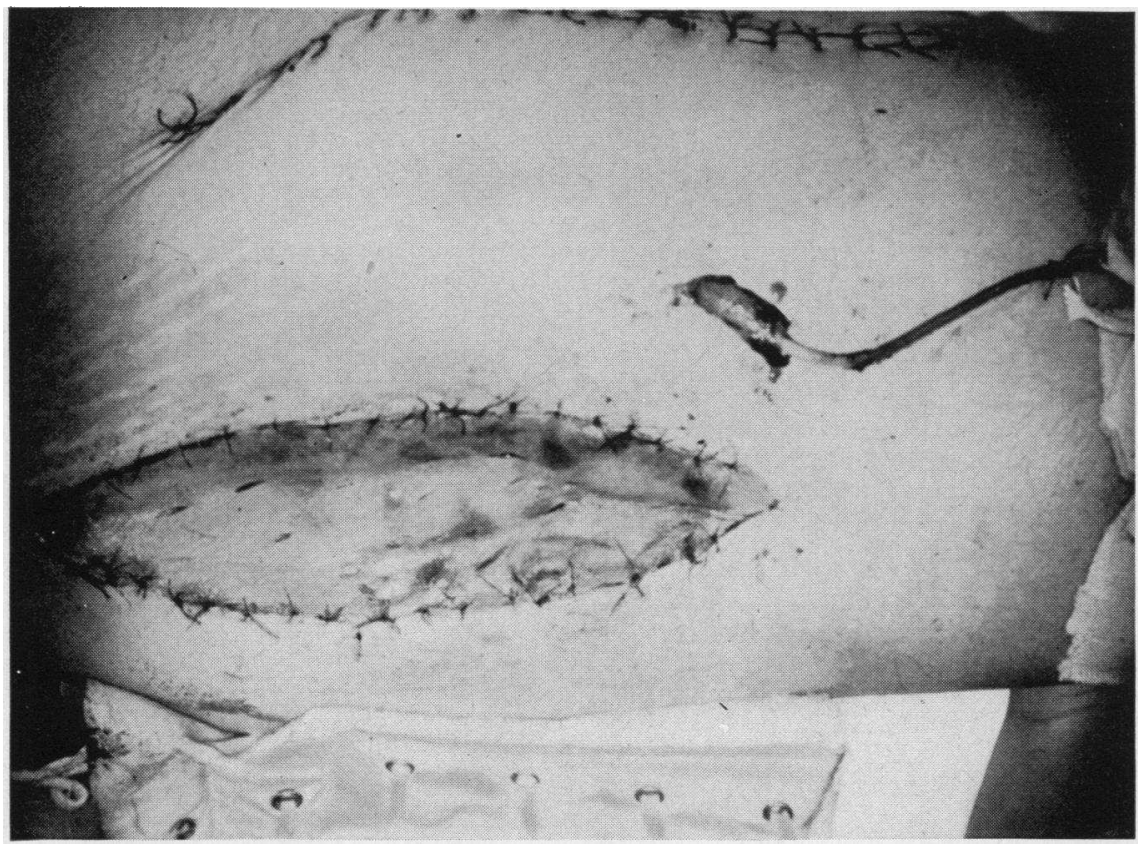

Fig. 11. B. B., Case No. 4-View of the Right Thigh on the Day of Operation, Showing How a Skin Graft Was Placed to Cover the Defect in Lateral Portion OF The Thigh

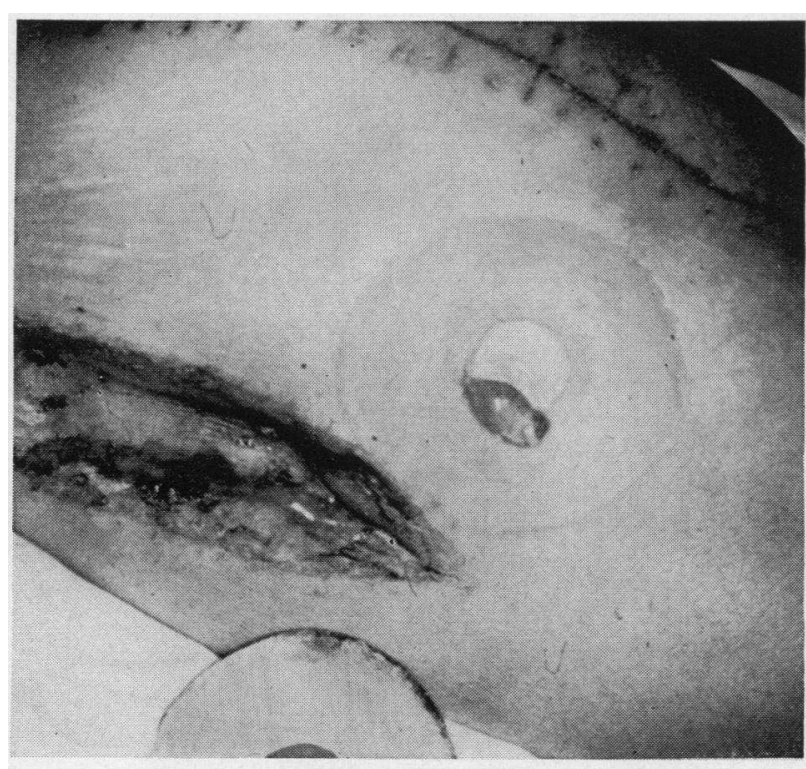

A

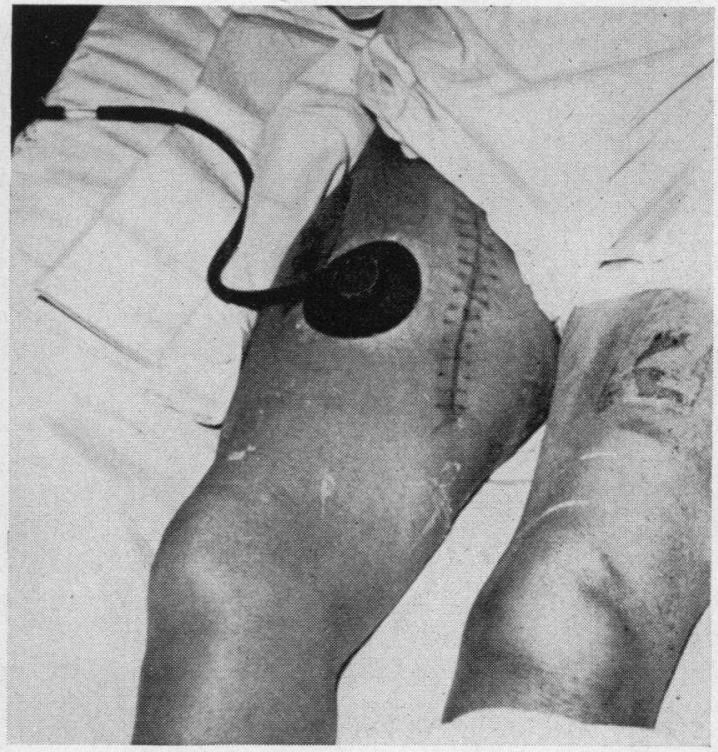

B

Fig. 12. B. B., Case No. 4-View of the Right Thigh on the 18th Day, Showing the Method of Collecting THE URINE

At the left the ureter may be seen protruding above the skin (A). On the right, the ureterostomy cup has been glued in place (B). 
TABLE III

B. B. Case No. 4-A comparison between transplant and bladder urine at representative periods throughout the patient's course

\begin{tabular}{|c|c|c|c|c|c|c|c|c|c|c|c|c|c|c|c|c|c|c|c|}
\hline & \multirow[b]{2}{*}{ Day } & \multicolumn{2}{|c|}{$\begin{array}{l}\text { 24-hr. } \\
\text { Volume }\end{array}$} & \multicolumn{2}{|c|}{$\begin{array}{l}\text { Specific } \\
\text { gravity }\end{array}$} & \multicolumn{2}{|c|}{$\begin{array}{c}\text { Creatinine } \\
m g m . \%\end{array}$} & \multicolumn{2}{|c|}{$\begin{array}{c}\text { Creatinine } \\
m g m . / 24 h r .\end{array}$} & \multicolumn{2}{|c|}{$\begin{array}{c}\text { Urea } \\
\text { nitrogen } \\
m g m . \%\end{array}$} & \multicolumn{2}{|c|}{$\begin{array}{c}\text { Urea } \\
\text { nitrogen } \\
\mathrm{gm} . / 24 \mathrm{hr} .\end{array}$} & \multicolumn{2}{|c|}{$\begin{array}{l}\text { Sodium } \\
m E q . / L .\end{array}$} & \multicolumn{2}{|c|}{$\begin{array}{l}\text { Potassium } \\
m E q . / L .\end{array}$} & \multicolumn{2}{|c|}{$\begin{array}{l}\text { Chloride } \\
m E q . / L \text {. }\end{array}$} \\
\hline & & B* & $\mathrm{T}^{*}$ & B & $\mathrm{T}$ & B & $\mathrm{T}$ & B & $\mathrm{T}$ & B & $\mathrm{T}$ & B & $\mathrm{T}$ & B & $\mathrm{T}$ & B & $T$ & $B$ & $T$ \\
\hline $\begin{array}{l}\text { Period of } \\
\text { maximal } \\
\text { function }\end{array}$ & $\left\{\begin{array}{l}14 \\
16 \\
17 \\
18 \dagger\end{array}\right.$ & $\begin{array}{r}1,600 \\
1,575 \\
875\end{array}$ & $\begin{array}{r}1,100 \\
1,560 \\
900 \\
2,826\end{array}$ & $\begin{array}{l}1.010 \\
1.011 \\
1.007\end{array}$ & $\begin{array}{l}1.011 \\
1.020 \\
1.010\end{array}$ & $\begin{array}{l}23 \\
17\end{array}$ & $\begin{array}{l}34 \\
35\end{array}$ & $\begin{array}{l}360 \\
148\end{array}$ & $\begin{array}{l}534 \\
314\end{array}$ & 293 & 390 & $\begin{array}{l}4.7 \\
2.0\end{array}$ & $\begin{array}{r}4.3 \\
4.1\end{array}$ & & & & & 40 & 43 \\
\hline $\begin{array}{l}\text { Period of } \\
\text { declining } \\
\text { function }\end{array}$ & $\left\{\begin{array}{l}33 \\
37 \\
40 \\
44 \\
47 \\
54 \\
58\end{array}\right.$ & $\begin{array}{l}2,500 \\
2,900 \\
2,100 \\
1,860 \\
1,800 \\
1,500 \\
1,400\end{array}$ & $\begin{array}{l}400 \\
565 \\
775 \\
745 \\
450 \\
700 \\
350\end{array}$ & $\begin{array}{l}1.004 \\
1.002 \\
1.010 \\
1.003 \\
1.003\end{array}$ & $\begin{array}{l}1.006 \\
1.006 \\
1.005 \\
1.004 \\
1.005\end{array}$ & $\begin{array}{l}12 \\
17 \\
18 \\
\\
18 \\
18 \\
20\end{array}$ & $\begin{array}{l}56 \\
48 \\
45\end{array}$ & $\begin{array}{l}298 \\
479 \\
378 \\
\\
326 \\
270 \\
280\end{array}$ & $\begin{array}{l}223 \\
273 \\
349 \\
\\
221 \\
329 \\
224\end{array}$ & $\begin{array}{l}132 \\
198 \\
300 \\
309 \\
290 \\
330 \\
381\end{array}$ & $\begin{array}{l}280 \\
417 \\
571 \\
352 \\
550 \\
487 \\
552\end{array}$ & $\begin{array}{l}3.3 \\
5.8 \\
6.3 \\
5.8 \\
5.2 \\
5.0 \\
5.3\end{array}$ & $\begin{array}{l}1.1 \\
2.4 \\
4.4 \\
2.6 \\
2.5 \\
3.4 \\
1.9\end{array}$ & $\begin{array}{l}53 \\
51 \\
54 \\
55\end{array}$ & $\begin{array}{r}15 \\
9 \\
12 \\
17\end{array}$ & $\begin{array}{l}21 \\
23 \\
17 \\
18\end{array}$ & $\begin{array}{l}52 \\
48 \\
42 \\
42\end{array}$ & $\begin{array}{l}59 \\
64 \\
53 \\
43 \\
53 \\
45 \\
49\end{array}$ & $\begin{array}{l}17 \\
22 \\
17 \\
21 \\
29 \\
37 \\
42\end{array}$ \\
\hline
\end{tabular}

* B: Bladder urine.

T: Transplant urine.

$\dagger$ No creatinine or urea nitrogen determinations were done on the days when the transplant function was probably at its peak (days 18 through 26 ).

was well vascularized, and active peristaltic waves passed along it.

A pocket was again created between the adductor fascia and the subcutaneous fat, but this time a large 15 by 30 $\mathrm{cm}$. double-ended pedicle flap of skin and subcutaneous fat was raised laterally off the anterior and lateral deep fascia. This pedicle was used to cover the kidney. The fascia lata, which was left bare by moving this flap over, was covered with a split thickness skin graft taken from the other leg. The ureter was brought out through a small incision in the pedicle, and allowed to project about 1 inch past the skin margin. A catheter was left in the ureter for 2 weeks. These relationships are shown in Figures 10 and 11 . The skin was closed without tension.

The patient was treated with heparin, $20 \mathrm{mgm}$. I-M every 6 hours for 24 days. Cortisone $100 \mathrm{mgm}$. I-M every 8 hours was given for 1 week, then $50 \mathrm{mgm}$. every 8 hours for 1 week. It was then gradually tapered off over the next 4 days, being stopped on the 18th day. $\mathrm{ACTH}, 100 \mathrm{mgm}$. per day, was given from the 8 th to 21 st day, and it was then tapered off over the next 3 days. On the 29th day cortisone, $150 \mathrm{mgm}$. a day, was again resumed and continued until the 45th day. Testosterone propionate, $50 \mathrm{mgm}$. a day, was given from the 1 st to the 25th day, and from the 66th to the 90th day. Penicillin was given for the first 30 days, following which various antibiotics were administered, including Chloromycetin $\AA$, Aureomycin $®$, and Terramycin $®$.

Following the operation, the tip of the ureter protruding through the skin ureterostomy appeared pink and healthy. It was necessary on the 3rd day to ligate a small bleeding artery on the tip of the ureter.

The wounds healed well. For the first 11 days after the operation the transplant was essentially anuric, secreting only a few $\mathrm{ml}$. of clear urine. On the 12th day, however, urine began to flow in gradually increasing amounts reaching a maximum 24-hour output of 2826 $\mathrm{ml}$. on the 18th day. The urine was collected by fastening a regular ureterostomy cup over the ureter with skin glue, and leading the outflow to a bottle beside the patient's bed, or to a bag strapped to her leg when she was up (see Figure 12).

The specific gravity of the urine from the transplant varied between 1.008 and 1.020. The sediment contained 2 to 3 white blood cells and 3 to 4 red blood cells per high power field, as contrasted with 25 to 30 white blood cells and 0 to 1 red blood cells per high power field for the bladder urine. The protein varied from $1+$ to $2+$, while the bladder urine ran $1+$ to $3+$. Urine sugar was negative. Both bladder and transplant urine contained many bacteria, and cultures showed various coliform organisms which were resistant to all antibiotics. A comparison between the transplant urine and bladder urine at various times in the post-operative period is shown in Table III. It may be seen from this chart that during

TABLE IV

B. B. Case No. 4-Kidney function studies done simultaneously on the transplanted kidney and the recipient's own kidneys

\begin{tabular}{|c|c|c|c|}
\hline \multicolumn{4}{|c|}{ The 18th day } \\
\hline & $\begin{array}{l}\text { Urea } \\
\text { clearance } \\
m l . / m i n .\end{array}$ & $\begin{array}{l}\text { Creatinine } \\
\text { clearance } \\
m l . / m i n .\end{array}$ & $\begin{array}{c}\text { PSP } \\
\% / 2 h r s\end{array}$ \\
\hline $\begin{array}{l}\text { Both host kidneys } \\
\text { Transplant } \\
\text { Transplant } \times 2 \\
\text { Normal }\end{array}$ & $\begin{array}{r}2.5 \\
6.4 \\
12.8 \\
71.0\end{array}$ & $\begin{array}{r}5.8 \\
18.5 \\
37.0 \\
148.0\end{array}$ & $\begin{array}{r}0 \\
22 \\
44 \\
75\end{array}$ \\
\hline \multicolumn{4}{|c|}{ The 21st day } \\
\hline & \multicolumn{2}{|c|}{$\begin{array}{l}\text { Inulin } \\
\text { clearance } \\
\text { ml. } / \text { min. }\end{array}$} & $\begin{array}{c}\text { Plasma } \\
\text { flow } \\
\mathrm{ml} . / \mathrm{min} .\end{array}$ \\
\hline $\begin{array}{l}\text { Both host kidneys } \\
\text { Transplant } \\
\text { Transplant } \times 2 \\
\text { Normal }\end{array}$ & \multicolumn{2}{|c|}{$\begin{array}{r}2.1 \\
14.4 \\
28.8 \\
126.0\end{array}$} & $\begin{array}{r}11 \\
112 \\
224 \\
620\end{array}$ \\
\hline
\end{tabular}


TABLE $V$

A comparison of the urinary output of the transplanted kidney with the blood urea nitrogen and serum potassium concentrations of the recipient

\begin{tabular}{|c|c|c|c|c|}
\hline & $\begin{array}{l}\text { Post- } \\
\text { op. } \\
\text { day }\end{array}$ & $\begin{array}{l}\text { 24-Hour } \\
\text { urine } \\
\text { volume } \\
\text { from the } \\
\text { transplant }\end{array}$ & BUN & $\underset{\mathbf{K}}{\text { Serum }}$ \\
\hline $\begin{array}{l}\text { Period of } \\
\text { maximal } \\
\text { function }\end{array}$ & $\begin{array}{l}13 \\
14 \\
15 \\
16 \\
17 \\
18 \\
19 \\
20 \\
21 \\
22 \\
23 \\
24 \\
25 \\
26\end{array}$ & $\begin{array}{c}400+ \\
1,100 \\
1,125 \\
1,560 \\
900 \\
2,826 \\
1,500+ \\
\text { lost } \\
1,350 \\
1,660 \\
\text { lost } \\
1,100 \\
1,050 \\
950\end{array}$ & 140 & 4.3 \\
\hline $\begin{array}{l}\text { Period of } \\
\text { declining } \\
\text { function }\end{array}$ & $\begin{array}{l}34 \\
41 \\
47 \\
51 \\
65 \\
66\end{array}$ & $\begin{array}{c}435 \\
780 \\
450+ \\
650 \\
225\end{array}$ & $\begin{array}{r}65 \\
130 \\
136 \\
122 \\
154 \\
\text { ed }\end{array}$ & $\begin{array}{l}4.3 \\
6.8 \\
5.8 \\
5.6\end{array}$ \\
\hline
\end{tabular}

the period of maximal function the transplant urine continued to show greater concentrations of urine urea nitrogen, creatinine, and potassium, and lower concentrations of sodium and chloride than the bladder urine.

Renal function studies were carried out simultaneously on the homograft and the patient's own kidneys. The results of one of these studies are shown in Table IV. During the period of maximal function of the transplant, between the 14th to 28th day, the patient's blood urea nitrogen and potassium steadily dropped, and the patient became symptom-free for the first time in two years. As the function of the transplant dropped off again, the blood urea nitrogen and potassium rose, and it was necessary to dialyze the patient on the 66th day (see Table V). It was of interest that the volume of the bladder urine decreased as the transplant diuresed, and increased again as the volume of the transplant fell off.

The patient became febrile on the 25th day, and on the 29th day she had a chill with a temperature to $104^{\circ}$. This was accompanied by tenderness and heat over the transplanted kidney, and some pain in the leg. It appeared that the patient had developed a pyelitis of this

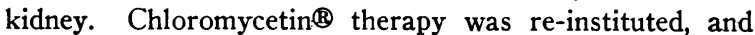
cortisone was given, as well, because of the feeling that the "immune response" might be playing some part in this reaction. There was a gradual fall in temperature over the next 5 days, accompanied, however, by a decrease in the output of the homotransplant. It is interesting that after this acute episode had subsided somewhat the transplant was again able to increase its urinary volume and urea nitrogen output temporarily.

The temperature again rose to $103^{\circ}$ on the 41 st day, and thereafter, in spite of antibiotic therapy, the daily

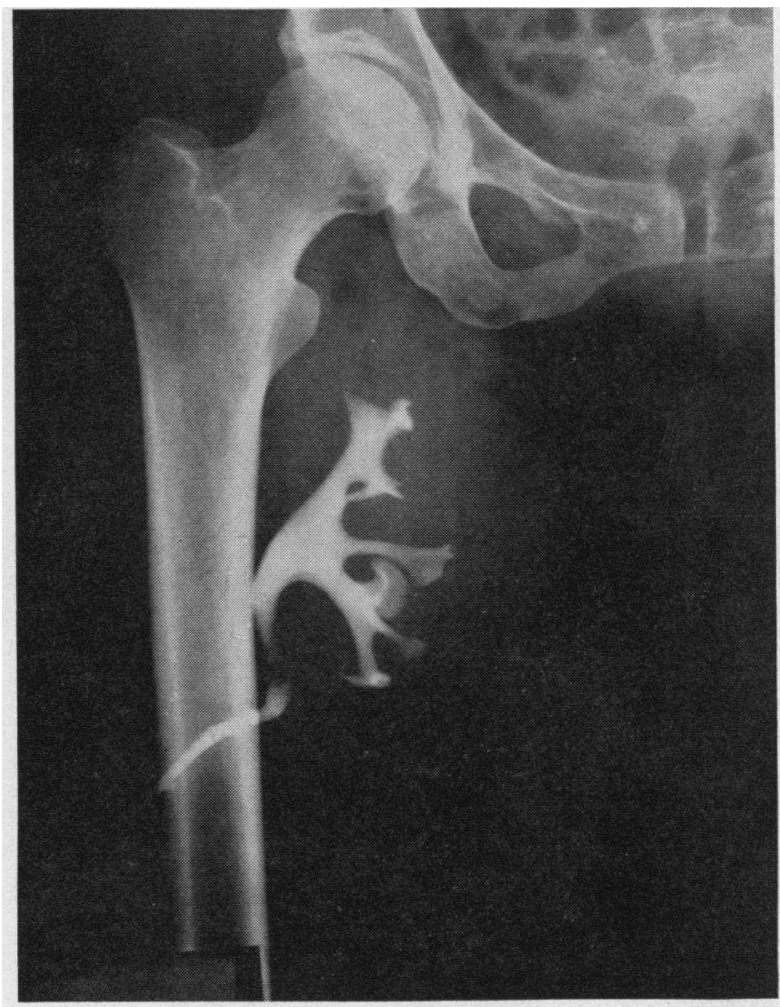

Fig. 13. B. B., CASE No. 4-The 83Rd Day

A retrograde pyelogram of the transplanted kidney shows no evidence of obstruction or distortion of the calyces, pelvis, or ureter.

rises were accompanied by a deterioration in the clinical condition. The spiking fever persisted until the 84th hospital day, at which time there was an 8-day period when the patient was afebrile. Output from the homograft had diminished at this time to 50 to $75 \mathrm{ml}$. a day. On the 92nd day she again developed a swinging, septic type of fever, and the clinical condition again deteriorated. Hemodialysis was carried out on the 98th day and again on the 100th day in order to prepare her for exploration of the homograft site. The urine from the transplant now was scanty with a greenish sediment. Retrograde pyelograms of the homograft made on the 48th and 83rd days demonstrated no evidence of obstruction or deformity. The pyelogram obtained on the $83 \mathrm{rd}$ day is shown in Figure 13.

The ureter continued to remain well vascularized. The mucosa grew out of the end of the ureter and down the outside, until it ultimately reached the skin. As the kidney became more involved with infection the ureter became somewhat paler than it had been, but even on the 101 st day it was obviously viable (see Figure 14).

On the 101st day the homograft site was explored. There was a well developed membrane about $3 \mathrm{~mm}$. thick surrounding the kidney. Although it was loosely adherent to the kidney capsule, it could be stripped off the capsule with no great difficulty. The kidney was moderately en- 


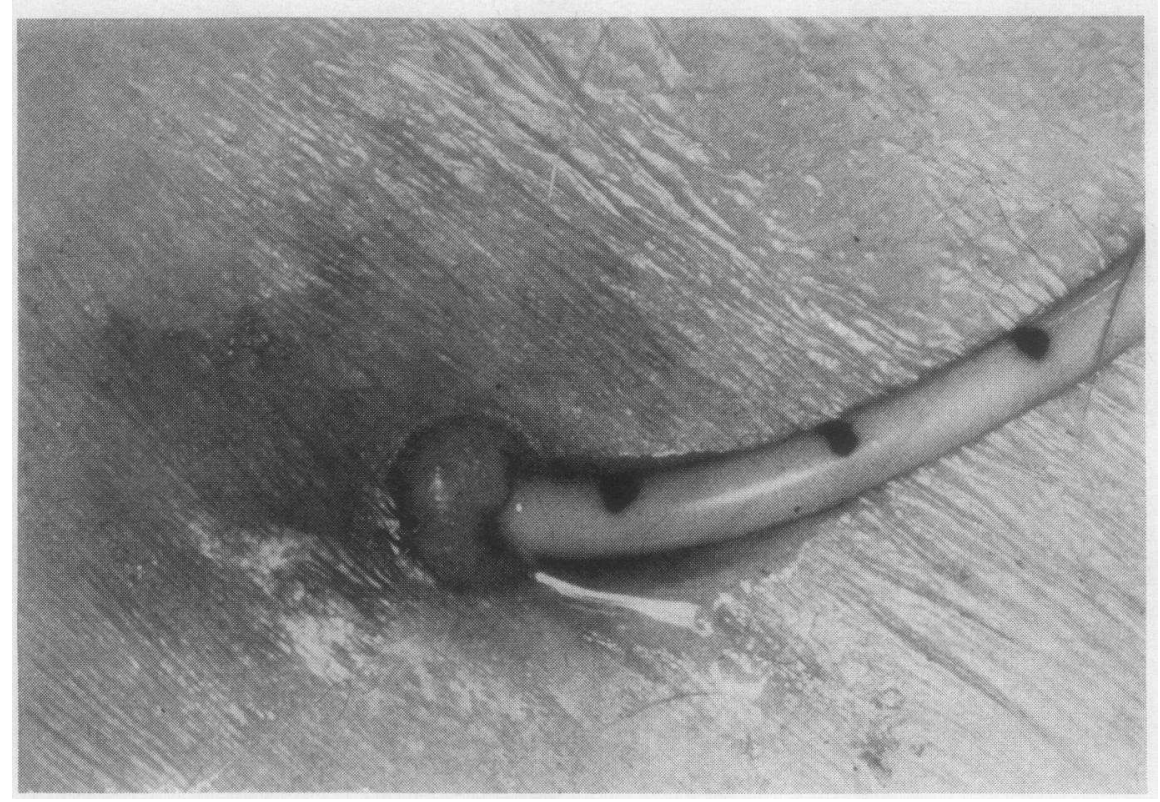

Fig. 14. B. B., Case No. 4-A Close-Up View of the Homograft Lreter on the 101st Day

The ureter is still viable, but appears paler than it did. Note that the mucosa has reached the skin.

larged, soft, and dark brown in color. It was obviously severely infected. The renal artery and vein and both anastomoses were still patent, and the capsule of the kidney bled when cut. The pedicle was clamped and the kidney was removed.

Grossly, the kidney showed multiple cortical ab-

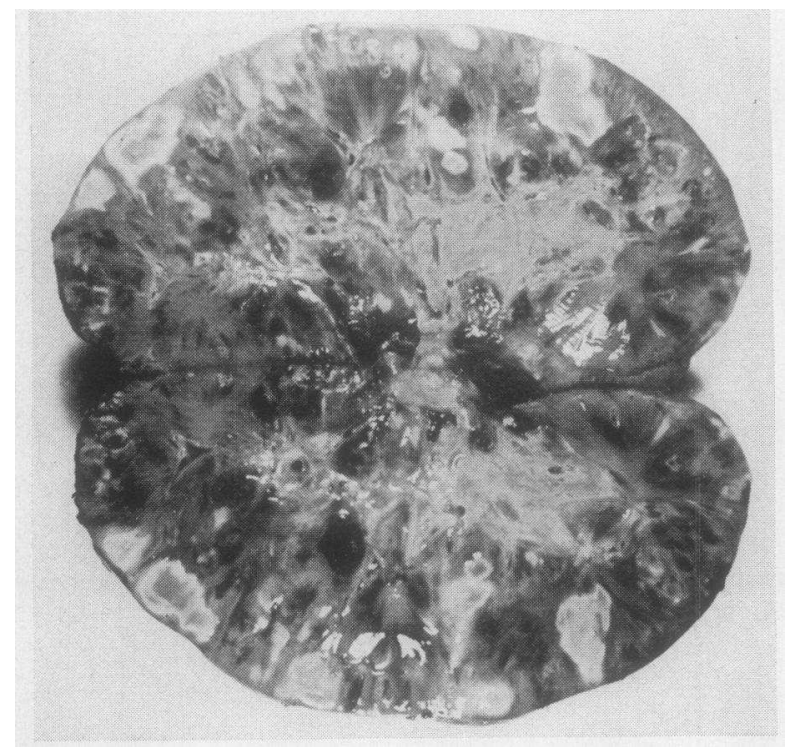

Fig. 15. B. B., Case No. 4-The Cut Surface of the Homograft, Showing Areas of Infarction and Cortical Abscesses scesses and areas of infarction, with thromboses of some of the intrinsic vessels (see Figure 15). Microscopically, the pseudo-capsule surrounding the kidney was composed of a thick layer of dense fibrous connective tissue. The inner layer of this capsule, which lay against the renal transplant, was composed of a loose vascular stroma which resembled granulation tissue. There was extensive focal infarction of the kidney. In some areas thrombosis at the level of the arcuate or interlobular arteries, with subsequent infarction, had led to the formation of abscesses. In these areas the polymorphonuclear leukocyte was the predominant inflammatory cell. In other areas there was a prominent interstitial round cell infiltration. A few glomeruli showed changes resembling subacute glomerulonephritis, but this was not a striking lesion. The principle feature was that of focal infarction (see Figure 16).

The patient was discharged home on the 107th hospital day. There was some drainage from her leg wound for a month thereafter. She lived for 7 months, during which time a hemodialysis was performed on one occasion.

Case V-D. P., female, age 18, No. 9 A816

Diagnosis: Chronic glomerulonephritis, hypertension.

The patient was an 18-year-old single girl whose fifth admission was necessitated by blurring of vision. A diagnosis of glomerulonephritis had been made 5 years ago. In spite of treatment, her symptoms had progressed.

Physical examination: On this admission the patient appeared pale and chronically ill. Blood pressure was $210 / 120$. There were scattered ecchymoses over both 


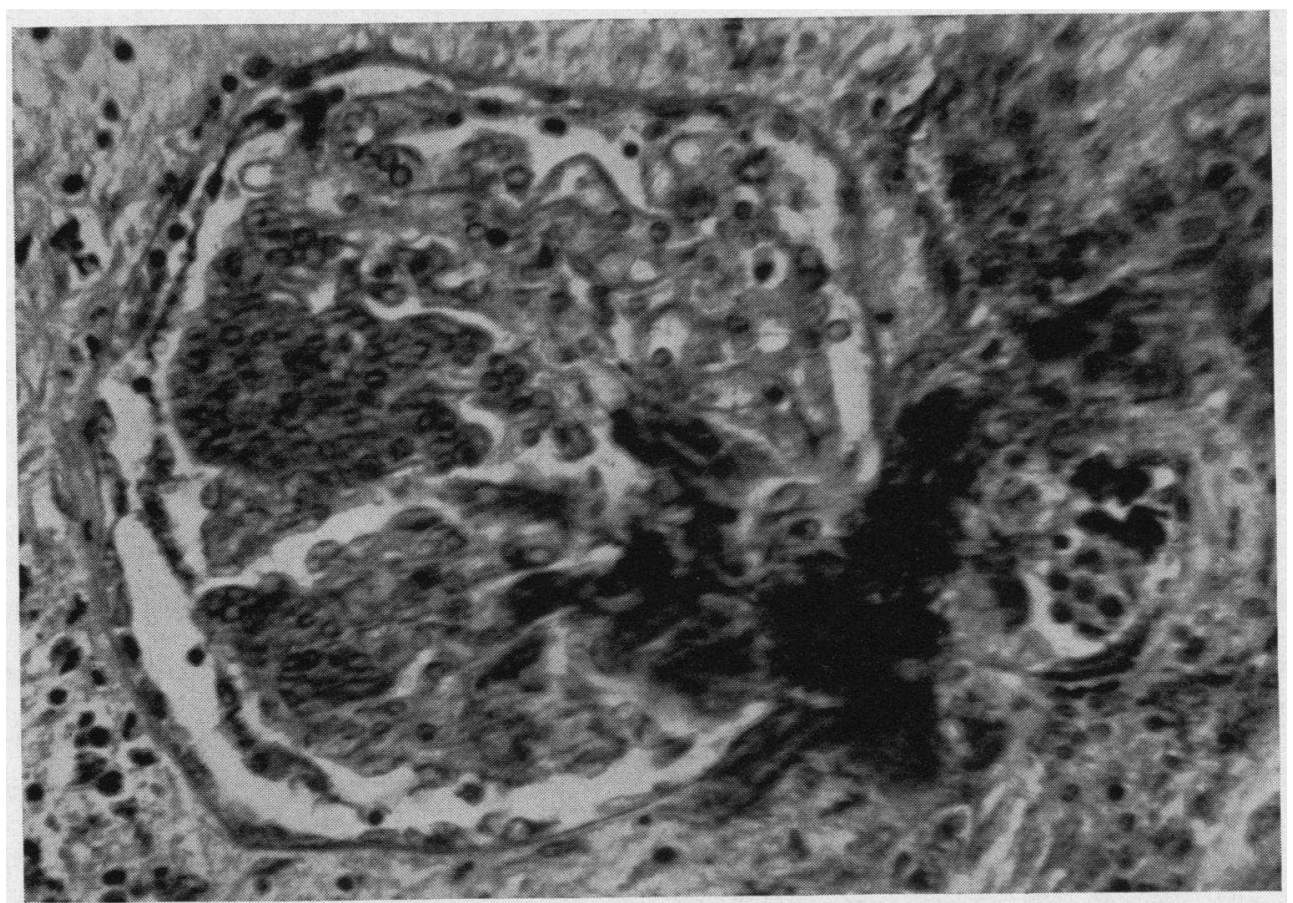

Fig. 16. B. B., Case No. 4-Microscopic Appearance of the Transplant at 101 Days, Following its Removal

This glomerulus is partially infarcted as the result of recent thrombosis of the afferent arteriole. The fibrin thrombus is densely basophilic and extends into capillaries at the hilum of the glomerular tuft. (Giemsa $\times 500)$

lower extremities. The optic fundi showed fresh flameshaped retinal hemorrhages, with old scars and exudate. The heart was enlarged to the anterior axillary line. There was a presystolic gallop rhythm. The lungs were clear. The liver edge was two finger-breadths below the costal margin. There was no ankle or sacral edema.

Laboratory data: Urine showed a 4 proteinuria. The spun sediment was loaded with red blood cells, and occasional white blood cells. Hematocrit was 21, blood urea nitrogen $97 \mathrm{mgm}$. per cent, total protein $4.9 \mathrm{gm}$. per cent, serum carbon dioxide combining power $17 \mathrm{mM}$. per L., chloride $112 \mathrm{mEq}$. per L., sodium $142 \mathrm{mEq}$. per L., potassium $6.5 \mathrm{mEq}$. per L.

Hospital course: Patient was placed on a rice diet and improved subjectively, although serum sodium values decreased to $126 \mathrm{mEq}$. per L. On 5-26-51 a skin flap was raised from the right thigh as a preparation for renal homotransplantation. An infection developed under this flap, however, and it could not be used.

On 6-6-51, a normal kidney was removed from a 2year-old child during the course of an elective operation for relief of hydrocephalus. ${ }^{7}$ The donor and recipient were of the same blood group $(\mathrm{O}, \mathrm{Rh}+)$, and their bloods were compatible. The kidney was transplanted into the patient's left thigh, after a period of ischemia of 65 minutes. The arteries were anastomosed end-to-end,

\footnotetext{
7 Performed by Dr. Donald Matson.
}

and the veins end-to-side. A double-ended pedicle flap was brought over from the lateral side of the leg, as in the previous case, and the defect was grafted with a split thickness graft from the other leg. The ureter was only $3 \mathrm{~cm}$. long, and would not reach the skin, so a polyethylene tube was put in the ureter and brought out through a stab wound in the pedicle.

The transplant began to secrete urine at once, and during the first 24 hours following operation it secreted a total of $1,700 \mathrm{ml}$. of urine. The second 24 hours following operation only $153 \mathrm{ml}$. were elaborated. The urine was blood tinged. The urine urea nitrogen concentration was $177 \mathrm{mgm}$. per cent. Blood urea nitrogen at that time was $92 \mathrm{mgm}$. per cent. The patient tolerated the procedure well. Following this, there was only' a small amount of bloody drainage from the homograft for a period of 12 days, during which time clots could be aspirated from the renal pelvis. The patient was given $200 \mathrm{mgm}$. testosterone propionate the first 24 hours, and was then maintained on $50 \mathrm{mgm}$. per day for 27 days.

Cortisone, $300 \mathrm{mgm}$. per day, was given for 8 days, and then gradually tapered off over the next 5 days. ACTH, $100 \mathrm{mgm}$. a day, was given from the 8 th to 15 th day and gradually tapered off over the next 4 days. Heparin was begun on the 2nd day with a dose of 100 $\mathrm{mgm}$. and then continued until the 11th day at a level of $80 \mathrm{mgm}$. a day. Penicillin was given for the entire post-operative course at various dosage levels, and other 
TABLE VI

Case $V-A$ comparison between the transplant and bladder urine on the 20th day*

\begin{tabular}{|c|c|c|c|c|c|c|c|}
\hline & $\begin{array}{c}\text { 24-hr. } \\
\text { Vol. }\end{array}$ & $\mathrm{Cl}$ & $\begin{array}{c}\mathrm{Cl} \\
24 \mathrm{hr} .\end{array}$ & Creatinine & $\begin{array}{c}\text { Creatinine } \\
24 \mathrm{hr} .\end{array}$ & UUN & $\begin{array}{l}\text { UUN } \\
24 \mathrm{hr} .\end{array}$ \\
\hline & & $m E q . / L$ & $m E q . / L$ & mgm. \% & $m g m$. & $m g m . \%$ & grams \\
\hline Bladder & 180 & 13 & 2.3 & 67 & 120 & 519 & 0.93 \\
\hline Transplant $\dagger$ & $780+$ & 33 & $25.8+$ & 45 & $351+$ & 615 & $4.8+$ \\
\hline
\end{tabular}

* BUN-128.

$\mathrm{Cl}-105$.

† Urinary collections were incomplete due to leakage.

antibiotics were added from time to time, including Chloromycetin ${ }^{\circledR}$, streptomycin, and Terramycin ${ }^{\circledR}$.

After 12 days of almost complete anuria which followed the short-lived diureses, the kidney began to excrete urine again on the 14 th day. The volume increased until $1400 \mathrm{ml}$. was obtained on the 23rd day. Maximum function occurred between the 14th and the 26th day. Thereafter the volume decreased until almost none was obtained on the 37 th day. It was difficult to obtain accurate collections because of leakage around the catheter. Analysis of the urine from the transplant and that of the bladder urine on the 20th day is shown in Table VI. On that day the intravenous injection of $2 \mathrm{ml}$. of PSP resulted in prompt excretion of this dye from the homograft, but because of the difficulty in collection, this could not be quantitated.

Infection developed in a hematoma beneath the right leg flap. Cultures of paracolon bacterium aerogenes were obtained from this source, and from the bladder urine, transplant urine, and blood stream. The patient's general condition deteriorated rapidly from the 41st day on. She became comatose, developed EKG changes of hyperkalemia, and her blood urea nitrogen rose to 261 mgm. per cent. She died on the 49th day after transplantation.

Examination of the homograft at autopsy showed marked hemorrhage, infarction, and infection. There was frank abscess formation, and the inflammatory response was primarily that of polymorphonuclear leukocytosis. The pre-existing architecture of the kidney was almost entirely destroyed by these processes, but no evidence of glomerulonephritis could be found in the surviving glomeruli.

Case VI-B. L., male, age 26, No. 9B64

Diagnosis: Chronic pyelonephritis.

The patient was first admitted on 7-20-51 with a 7-year history of proteinuria. One year before admission a diagnosis of uremia with bilaterally contracted kidneys had been made. The blood NPN varied from $150 \mathrm{mgm}$. per cent to $230 \mathrm{mgm}$. per cent with a persistent anemia. He had several convulsions which had been controlled with Dilantin ${ }^{\circledR}$ before admission. Because of progressive uremia and intractable kidney disease, he was transferred from the West Roxbury Veterans Hospital to the Peter Bent Brigham Hospital for a renal homograft.

Physical examination revealed a small, pale, mentally dull young man in no distress. The optic fundi showed no changes. The lung fields were clear. The heart was not enlarged; there was a grade II basal systolic murmur. Blood pressure was $105 / 65$. There were many spontaneous twitching movements of the extremities.

Laboratory data: Urine showed a $1+$ protein. There were occasional red cells, white cells, and rare hyaline casts in the spun sediment. The hematocrit was 26 . The white blood count was 3,350 with a normal differential. The blood urea nitrogen was $83 \mathrm{mgm}$. per cent, serum carbon dioxide combining power $11.3 \mathrm{mM}$. per L., chloride $106 \mathrm{mEq}$. per L., sodium $140 \mathrm{mEq}$. per $\mathrm{L}$. and potassium $5 \mathrm{mEq}$. per $\mathrm{L}$.

On 7-23-51 a previously normal functioning kidney removed from a 33-year-old woman at an elective operation for hydrocephalus ${ }^{8}$ was transplanted into the patient's left thigh. ${ }^{9}$ Donor and recipient blood types were both $\mathrm{O}, \mathrm{Rh}+$, and their blood was cross-matched and found compatible. The period of ischemia in this case was shortened to 14 minutes by performing the anastomoses over polyethylene tubes which were temporarily tied in place, after the technique of Hufnagel (56). Portions of the rectus femoris and sartorius muscles were removed to make room for the kidney, and no skin flap was used. The patient tolerated the procedure well, and $700 \mathrm{ml}$. of urine was elaborated from the homograft in the first 12 hours. This showed a urine urea nitrogen content of $800 \mathrm{mgm}$. per cent. Thereafter, however, no urine was produced by the kidney. The portion of the ureter projecting beyond the skin appeared necrotic within 24 hours. For 5 days there was no appreciable tension on the skin suture line, but after this time edema and tension became progressive.

Following the operation there was a marked rise in the blood urea nitrogen. The patient became confused and began to vomit. On the 3rd day, dialysis with the artificial kidney was accomplished with marked clinical and chemical improvement. The patient was treated with heparin 100 to $190 \mathrm{mgm}$. per day for 12 days, and 60 to $100 \mathrm{mgm}$. per day from the 14th day through the 18 th day. No ACTH or cortisone were given. No testosterone was given until the 11 th day at which time 50 mgm. per day was started and continued for 8 days. His course following operations was a septic one, with

8 Performed by Dr. Donald Matson and Dr. Hathorne Brown.

9 The transplantation was performed by Dr. Charles A. Macgregor. 
a swinging fever rising as high as $103^{\circ}$, for a period of 51 days following operation. This febrile course was refractory to therapy with penicillin, Aureomycin ${ }^{\circledR}$, Terramycin ${ }^{\circledR}$ and Chloromycetin $\$$.

By the 14th day, the left leg had become tremendously swollen and tense. On that day, the patient had a generalized tonic, clonic convulsion similar to those prior to admission. Dilantin $\AA^{\circledR}$ therapy was again begun. There were no further convulsions, but the patient continued to vomit and remain drowsy. On the 14th day hemodialysis was again performed with good chemical and clinical results. The patient continued to run a septic fever. On the 18 th day a retrograde injection of dye into the ureter of the homograft showed no definite calcyceal pattern and suggested "marked infection and necrosis." Blood culture on the 18th day was positive for enterococci and proteus vulgaris. On the 19th day, the homograft site was explored. The kidney itself appeared viable although it was surrounded by blood clots. Because of extreme edema of the skin and tension on the kidney an incision of the skin was made laterally and a flap of skin and subcutaneous tissue was swung medially to cover the transplant. The defect left by raising the skin flap was grafted by skin taken from the other thigh.

A biopsy of the kidney taken at operation showed marked ischemia, but no evidence of infarction or thrombosis. There was a marked interstitial round cell infiltration which was more prominent in this case than any of the others. The tubular changes again suggested those of an acute ischemic nephrosis ("lower nephron nephrosis"), with focal tubular degeneration and some regeneration. There were pigment casts present in several of the tubular lumena. The glomerular tufts showed no striking abnormalities. In some areas there was an accumulation of inflammatory cells around Bowman's capsule (see Figure 17). The kidney appeared viable.

Within a short period of time following operation, however, the wounds became foul and necrotic. Wound cultures grew enterococci and B subtilis, which were resistant to all but prohibitively large doses of the common antibiotics. Proteus vulgaris, staph. aureous, and pseudomonas aerogenosa were also grown from the wound. The swinging temperature continued. On the 49th day hemodialysis was again performed because of the deteriorating clinical condition, and on the 52nd day, since the homograft had produced no urine and appeared to be the obvious site for this infection, it was removed at operation. The homograft itself was covered with a thick, fibrinopurulent exudate, and there was complete distortion of the architecture with necrosis of the cortex and most of the medulla and pyramids. Thrombosis and infection were seen throughout the parenchyma.

Following the removal of the homograft there was a dramatic improvement in the signs of sepsis, and 5 days later the patient was transferred to the West Roxbury Veterans Hospital for further chronic care. Four hours after transfer, however, the patient suddenly exsangui-

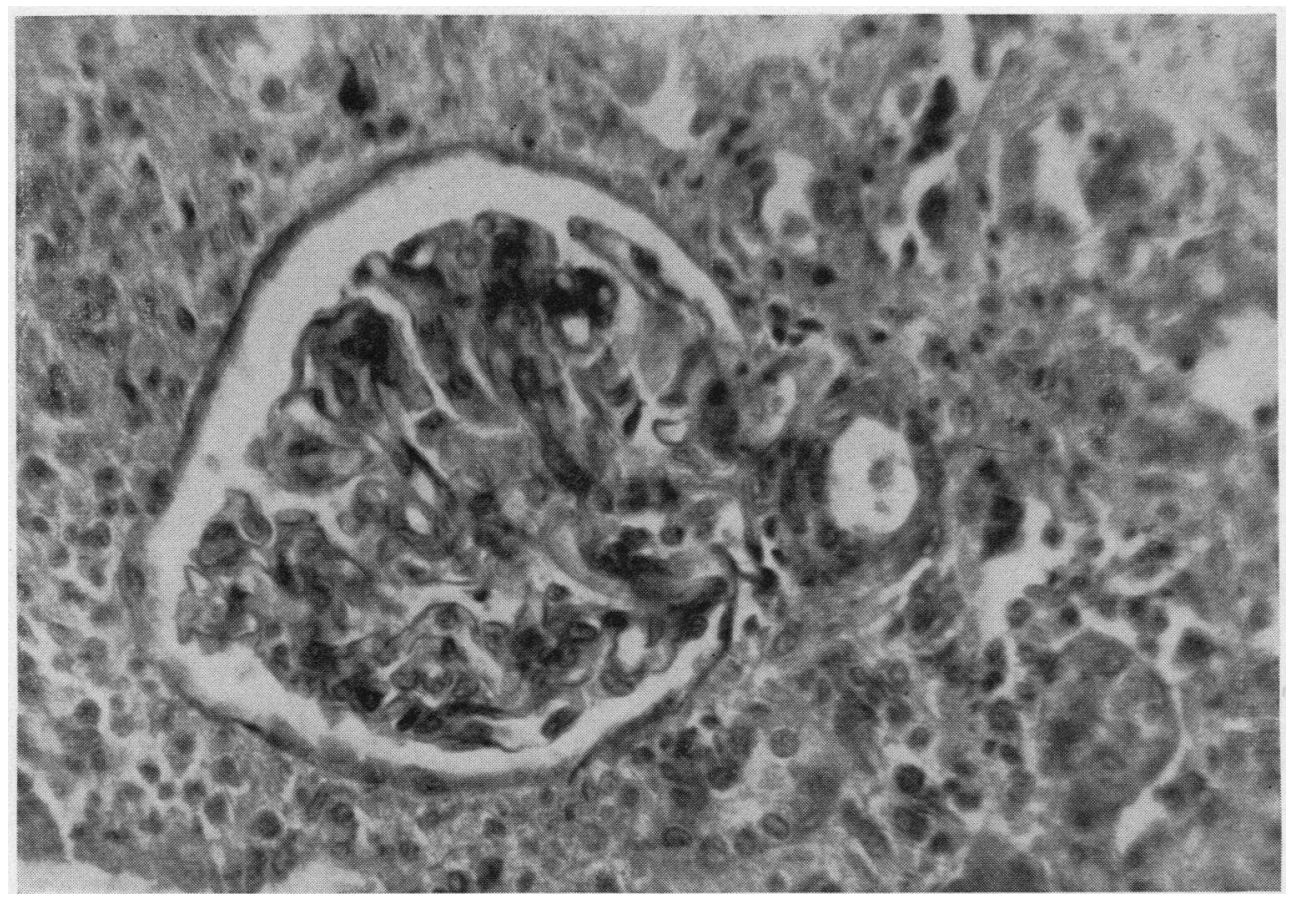

Fig. 17. B. L., Case No. 6-Biopsy of the Homograft on the 19th Day

The glomerular tuft shows no striking abnormalities. There is a conspicuous accumulation of inflammatory cells around Bowman's capsule. Tubules show focal degenerative changes. $(\mathrm{H} \& \mathrm{E} \times 500)$ 
nated from an eroded, infected portion of the common femoral artery just proximal to the bifurcation. Postmortem examination 10 showed marked chronic pyelonephritis of the patient's own kidneys, and a rupture of the common femoral artery where the wall had been weakened by infection.

Case VII-D. G. femalc, age 28, No. 6E373

Diagnosis: Chronic pyelonephritis, hypertension.

The patient was first admitted on March 8, 1952. Two years before admission she noted the onset of decreased appetite and fatigue and had frequent upper respiratory infections. A year before admission she noted the onset of pallor, and six months before she had an acute episode of back pain. Two weeks before admission she was admitted to an outside hospital where a diagnosis of hypertension and kidney disease was made. Her treatment at this hospital included three transfusions of packed red cells. In spite of treatment, she began to vomit and had several convulsions. Because her condition continued to deteriorate, she was transferred to the Peter Bent Brigham Hospital for further treatment.

Physical examination at this time showed a thin, pale, weak woman who responded to commands, but was disoriented as to time and place. The skin was dry and yellow. There were several ecchymoses. There was a grade II precordial systolic murmur. Blood pressure was 190/70. The rhythm was regular. The abdomen was slightly distended but there was no peripheral edema. A chest film showed the heart to be of normal size.

Laboratory data: Urine showed $1+$ protein and many white cells. Specific gravity 1.012. Culture of the urine showed four different coliform organisms. Urine urea nitrogen averaged $244 \mathrm{mgm}$. per cent. The 24 -hour urine volume averaged $856 \mathrm{ml}$. The hematocrit on admission was 30 and the blood urea nitrogen, $284 \mathrm{mgm}$. per cent. The serum carbon dioxide combining power was 11.6 mM. per L., chloride $77 \mathrm{mEq}$. per L., sodium $124 \mathrm{mEq}$. per L., potassium $6.0 \mathrm{mEq}$. per L.

Dialysis on the artificial kidney was performed on two occasions with marked chemical and clinical improvement. She was discharged on the 21st hospital day. She was re-admitted on 4-16-52 to await kidney homotransplantation.

On May 7, 1952 kidney homotransplantation was carried out to the right thigh. The recipient was blood type $\mathrm{O}, \mathrm{Rh}+$. The donor was a 33-year-old woman with an intra-articular septal defect and hypertension who died during a cardiac operation. The donor's blood type was $\mathrm{B}, \mathrm{Rh}+$. Because of the incompatibility of the blood types, the kidney was perfused with $500 \mathrm{ml}$. of Ringer's solution to which 25 grams of albumin and 200,000 units of penicillin had been added.

There was an accessory artery leading to the lower pole of the donor kidney, and this had to be tied off. The left kidney of the donor was hypoplastic, and the

${ }^{10} \mathrm{We}$ are indebted to the Pathology Department of the West Roxbury Veterans Hospital for the results of this examination. right kidney, which was used for the transplantation, was slightly hypertrophied.

The arteries were anastomosed end-to-end, and the veins end-to-side. A double-ended pedicle flap was brought over as previously described, and the defect was split-grafted. When the clamps were taken off the blood vessels, the kidney became pink more slowly than the previous transplants, with the exception of the second one. This had also been performed with a kidney from a hypertensive donor of incompatible blood type.

After about a minute, it did become pink, though not quite as intensely pink as the previous ones. The area of the kidney supplied by the accessory artery remained dark blue. The blood supply of the ureter appeared adequate. It was brought out through a stab wound in the flap. A soft rubber catheter was placed in the ureter and led out to a bottle.

Post-operatively the patient was placed on heparin. $160 \mathrm{mgm}$. a day, for 48 hours. Penicillin was administered. No ACTH or cortisone was given. The patient received testosterone from the 12th to the 19th day. By the end of the first 48 hours a large hematoma had developed beneath the split-thickness skin graft. Attempts to evacuate the clot were only partially successful. Heparin was discontinued. There was no tension on the wound, because the wound had decompressed itself under the skin graft.

By evening of the 3rd day the patient had developed severe potassium intoxication. This was treated by peritoneal lavage because of fear of increasing hemorrhage and potassium absorption if heparinization and hemodialysis were used (76). The patient made a good temporary response to this, but by the fifth day she again showed severe hyperkalemia. A dialysis on the artificial kidney was performed at this time. Later this same day the patient was taken to the operating room and, under a small amount of nitrous oxide, the hematoma under the graft was evacuated and the wound packed.

Peritoneal lavage was necessary again on the 13th day, for hyperkalemia.

The homograft excreted a few $\mathrm{ml}$. of blood-tinged urine at first, but by the end of the first 24 hours the urine was clear. By the end of the 3rd day a total of $100 \mathrm{ml}$. had been collected. The ureter appeared viable at this time. On the 4th day an infarct of the ureter had apparently developed and the urine was again slightly blood tinged. On the 5 th and 6 th days the urine became more bloody, and by the 7 th day urine output had ceased. At no time was the 24-hour volume more than 50 to $60 \mathrm{ml}$, , but the course of this transplant differed from that of the "anuric" phase of compatible blood type grafts in that the urine became bloody again after it once cleared, and then ceased flowing entirely, instead of gradually increasing in amount and staying clear.

On the 17th day the homograft was removed. Both vessels were occluded by thrombus with infarction of the kidney. There was no infection, and no appreciable blood clot around the kidney. The host's vessels were patent right up to the anastomoses. Histologically there 
were changes in the walls of the large blood vessels of the transplant, and generalized infarction of the kidney with extersive calcification. There was no evidence of intrinsic inflammatory or proliferative change (see Figure 18).

Despite peritoneal dialysis on the day of operation, the patient died 2 days later. At post-mortem examination severe pyelonephritis with almost total destruction of the patient's kidneys was found.

\section{Case VIII-O. F., female, age 57, No. 7E213}

Diagnosis: Periarteritis nodosa with complete anuria. This 57-year-old woman was admitted to the Peter Bent Brigham Hospital for the first time on 8-22-52 with a chief complaint of anuria of 13 days' duration. She was well until four years before when she first noted onset of asthma, which increased in severity so that two years before she had to be hospitalized for oxygen therapy. In November, 1950 she received 4 days of ACTH therapy with excellent results. In November, 1951, 9 months prior to admission, she received a 2-weeks' course of "Pyromine." Following the last injection of this substance she noted the rapid onset of pain, weakness, numbness, coldness of the extremities, and periorbital edema, associated with a temperature of 101 . She was admitted to an outside hospital where a consultant felt that asymmetrical peripheral neuropathy suggested the diagnosis of periarteritis nodosa. A biopsy of the right gastrocnemius muscle confirmed this impression. A blood urea nitrogen at this time was $6 \mathrm{mgm}$. per cent. She was given ACTH 30 to $90 \mathrm{mgm}$. a day from December, 1951 to July, 1952, with relief of her peripheral neuritis and asthma.

Three weeks prior to entry, following excessive exposure to the sun, the patient developed a temperature of 100.8 and became fatigued and nauseated. Her urinary output gradually diminished until she became essentially anuric 13 days prior to entry. Ten days prior to entry she was admitted to an outside hospital. Retrograde pyelograms were negative. Her total urinary output for 10 days was $20 \mathrm{ml}$. Her blood urea nitrogen rose from 126 to 175 , and she was transferred to the Peter Bent Brigham Hospital for dialysis.

Physical examination: On admission the patient was a pale, middle-aged woman lying quietly in bed without complaint. Blood pressure was $155 / 75$. The optic fundi were unremarkable. The heart and lungs were normal. The abdomen was moderately distended, and fluid wave was present. The liver was felt to be somewhat enlarged. There was $2+$ pitting edema of the extremities and sacrum. The deep tendon reflexes were hyperactive. There was a positive Babinski on the left. Vibration sense was diminished over the left lower leg, and there was hyperalgesia of the left foot.

Laboratory data: Blood urea nitrogen $264 \mathrm{mgm}$. per cent, carbon dioxide combining power $14.6 \mathrm{mM}$. per L., chloride $99 \mathrm{mEq}$. per L., sodium $136 \mathrm{mEq}$. per L., potas-

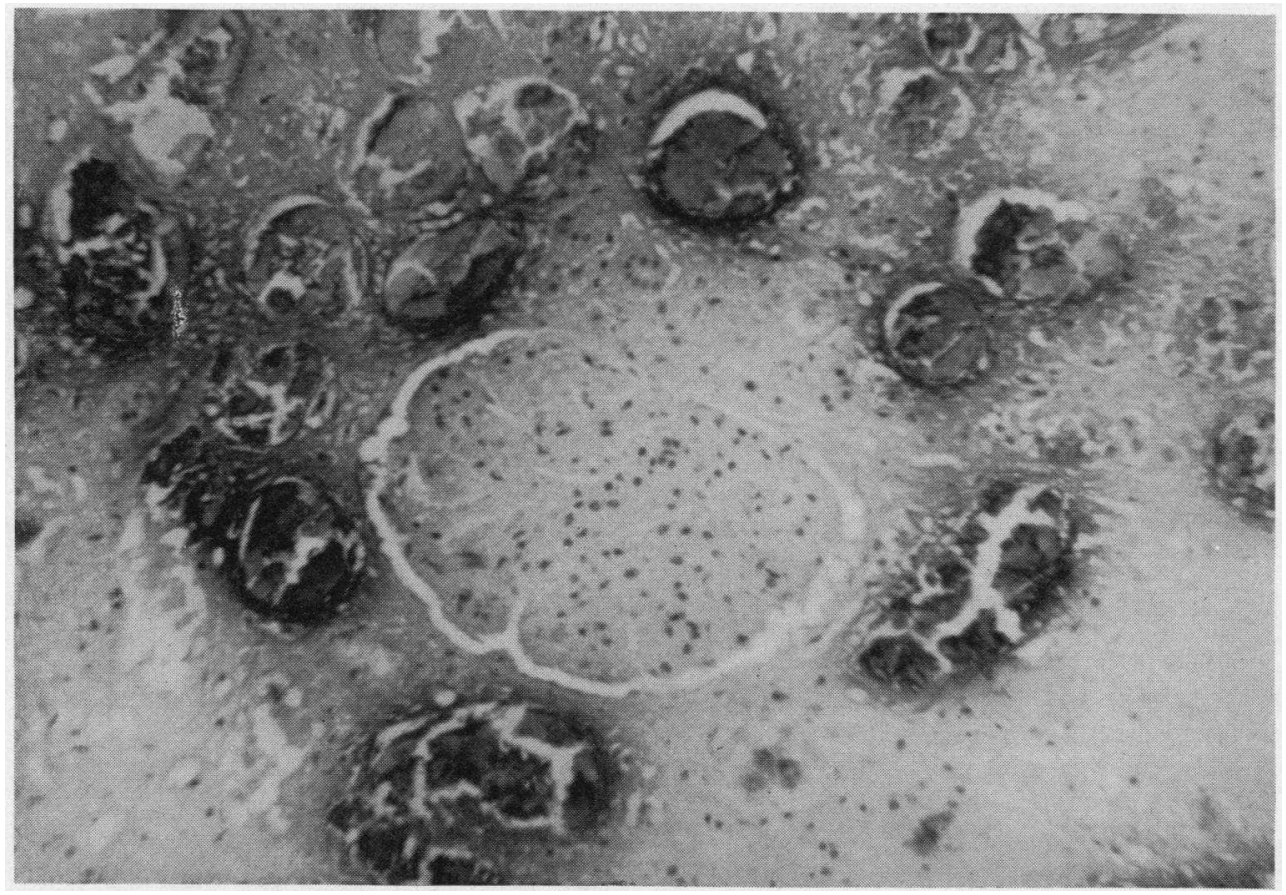

Fig. 18. D. G., Case No. 7-Microscopic Appearance of the Transplant at Post-Mortem

The outlines of an infarcted glomerulus can be identified. There is no evidence of intrinsic inflammatory or proliferative change. Adjacent tubules show striking degeneration and calcification of epithelium. (H \& $\mathrm{E} \times 250)$ 


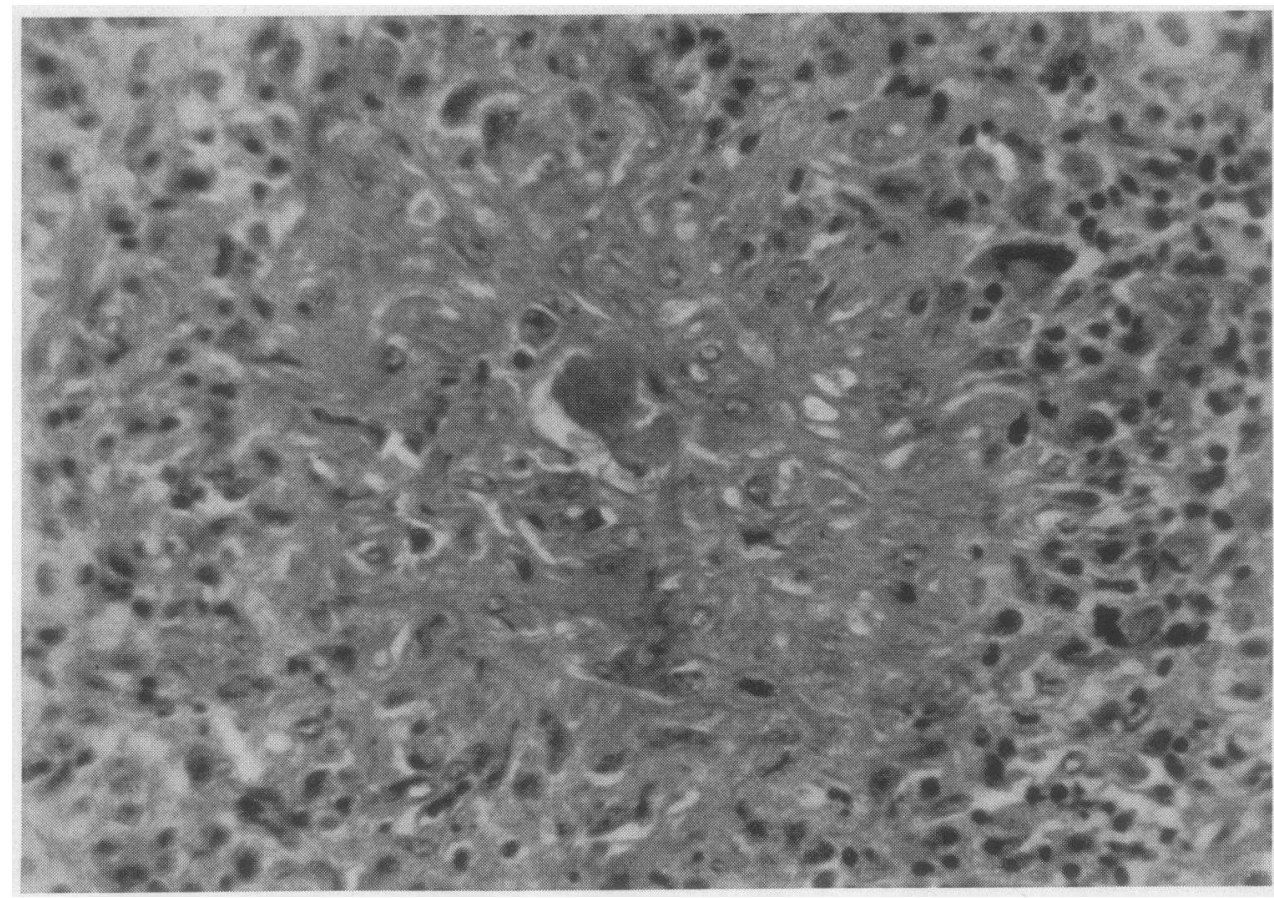

Fig. 19. O. F., Case No. 8-A Biopsy of the Left Kidney of the Patient Taken on the 41st Day of Anuria, 4 Days Before Renal. Homotransplantation Was Done

The glomerular architecture is virtually obliterated by the proliferative and inflammatory changes. At the periphery inflammatory cells are present in moderate numbers. ( $\mathrm{H} \& \mathrm{E} \times$ 500)

sium $6.1 \mathrm{mEq}$. per L., hematocrit 19, white blood count 8,600 with 89 per cent polymorphonuclear leukocytes.

Hospital course: A catheter was inserted in the femoral vein and the patient was begun on 50 per cent glucose 400 to $700 \mathrm{ml}$. a day. On the $3 \mathrm{rd}$ day she had a convulsion, and on the following day hemodialysis was carried out with good clinical improvement. She continued to be anuric, and she was again dialyzed because of progressive signs of uremia on 9-4-52 and on 9-16-52, each time with good response. On 9-18-52 a biopsy of the left kidney was carried out. ${ }^{11}$ This showed severe renal damage. The proliferative and inflammatory changes were so pronounced in some areas as virtually to eliminate the glomerular architecture (see Figure 19). A moderate number of inflammatory cells were present around the glomeruli. The picture was felt to be consistent with marked periarteritis of the kidney. On 9-22, the 45th day of anuria, a kidney homotransplant to the left thigh was performed. The donor was a patient with ruptured sinus of Valsalva who died during a cardiac operation. The blood types of the donor and recipient were both $\mathrm{O}, \mathrm{Rh}+$, and their bloods were compatible. The left kidney of the donor was used, and an end-to-end anastomosis was made between the profunda femoris artery and the renal artery, and an end-to-side anastomosis

11 This operation was performed by Dr. J. Hartwell Harrison. was made between the renal vein and the common femoral vein. The kidney was not perfused. The period of ischemia was 275 minutes. ${ }^{12}$ No heparin was injected. Circulation through the kidney appeared excellent, and the color of the transplant became normal as quickly as any we have done. Peristaltic waves were seen in the ureter, and the blood supply to the tip of the ureter appeared normal.

A pocket was created medially in the usual fashion, and a double-ended pedicle flap was used to cover the kidney. The fascia lata was covered with a split thickness graft taken from the abdomen. The ureter was brought out through a stab wound in the flap, and a soft rubber catheter was inserted in it.

Post-operatively the patient was treated with heparin $90 \mathrm{mgm}$. in the first 18 hours, then $160 \mathrm{mgm}$. per day for 7 days, gradually tapering it off from the 7 th to the 10th day. She was placed on ACTH $100 \mathrm{mgm}$. a day I-M for 5 days, then $25 \mathrm{mgm}$. I-V over an 8-hour period for 2 days, and then $20 \mathrm{mgm}$. ACTH gel twice a day through the 19th day. It was gradually tapered off from the 19 th to the 22 nd day. The first 24 hours she was given $200 \mathrm{mgm}$. testosterone, and thereafter she received 50 mgm. a day for 12 days, and $50 \mathrm{mgm}$. every other day

12 This long period of ischemia was occasioned by a delay in obtaining the donor kidney. 


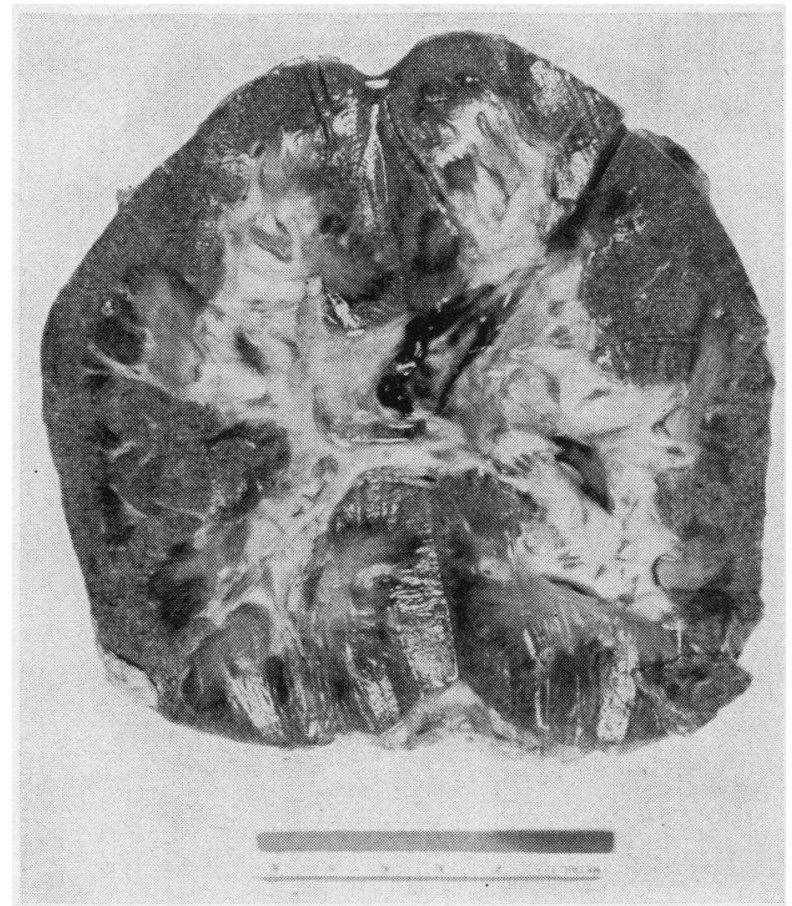

Fig. 20. O. F., Case No. 8-Appearance of the Cut Surface of the Renal Transplant at Post-Mortem

Note the stippled appearance of the cortex. from the 13th to the 38th day. Penicillin, streptomycin, and Terramycin were given at various times.

The patient's only food, except for an occasional cup of tea, was 200 to $700 \mathrm{ml}$. (usually 400 to $500 \mathrm{ml}$.) per day of 50 per cent glucose given I-V via the femoral catheter over the course of 24 hours. She received one transfusion of washed red blood cells on the 10th day. For 83 days she had essentially no protein or fat intake. Daily electrocardiograms were taken, and these plus the patient's clinical status were used to determine when hemodialysis was to be done.

There was no edema of the leg in which the kidney was implanted, although a hematoma formed under the split-thickness skin graft. The wound through which her own kidney had been biopsied never entirely healed, nor did the skin graft donor site or the skin graft heal. The wound in the thigh only partially healed, there being some necrosis of the upper aspect. A small collection of pus was aspirated through a needle from the lower end of the leg wound, but there was surprisingly little infection present.

By the 3rd post-operative day the end of the ureter had become black and dry. Only a few milliliters of bloody fluid came through the catheter, and no function of the transplant developed.

The patient ran a sub-normal temperature $\left(95.2^{\circ}\right.$ to $97.2^{\circ}$ ) from the time of the operation until the 6 th postoperative day, when she was dialyzed. Her temperature rose to $98.6^{\circ}$ following the dialysis, and persisted at a

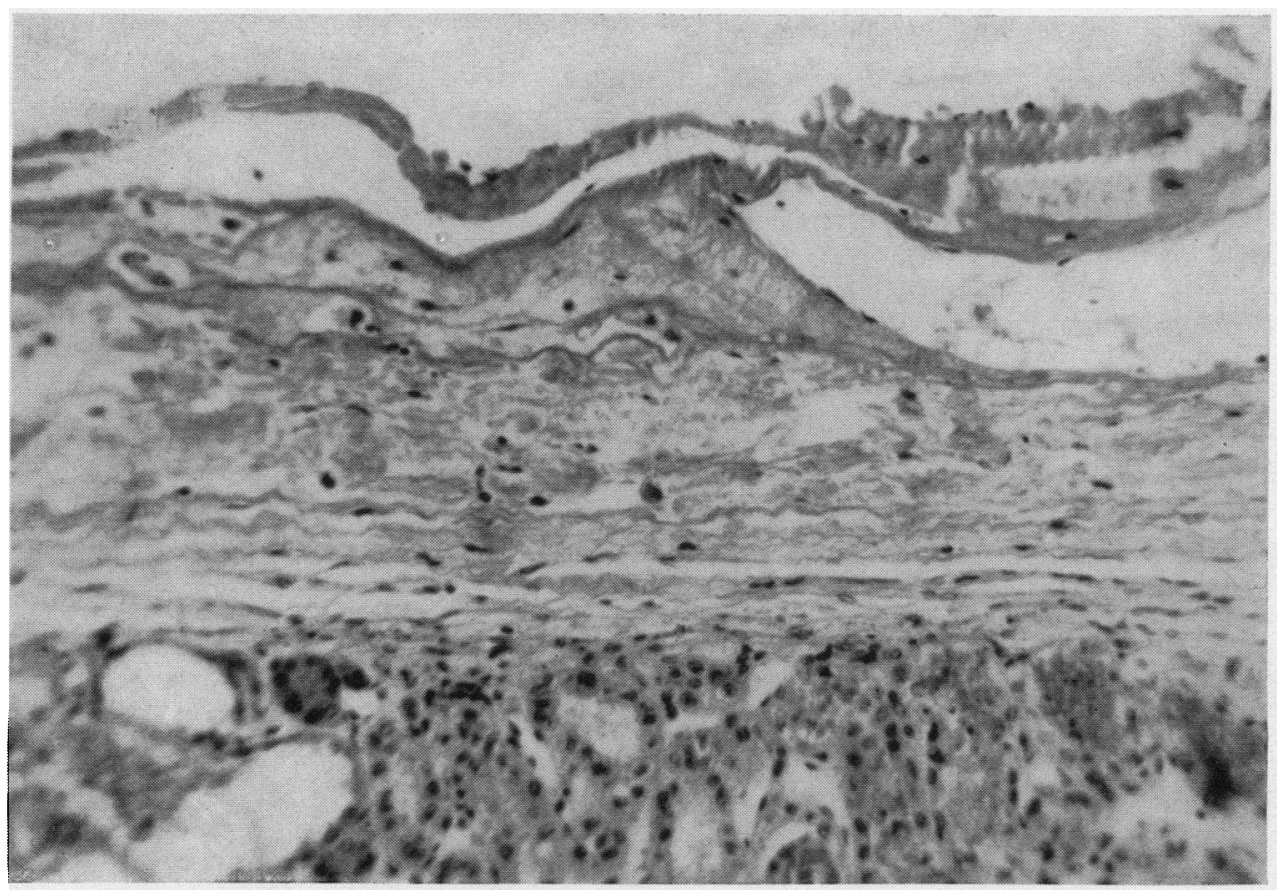

Fig. 21 O. F., Case No. 8-Microscopic Appearance of the Capsule of the Transplanted Kidney at Post-Mortem

Around the capsule there is a thin layer of fibrin, with only occasional inflammatory cells, and no proliferating fibroblasts. 


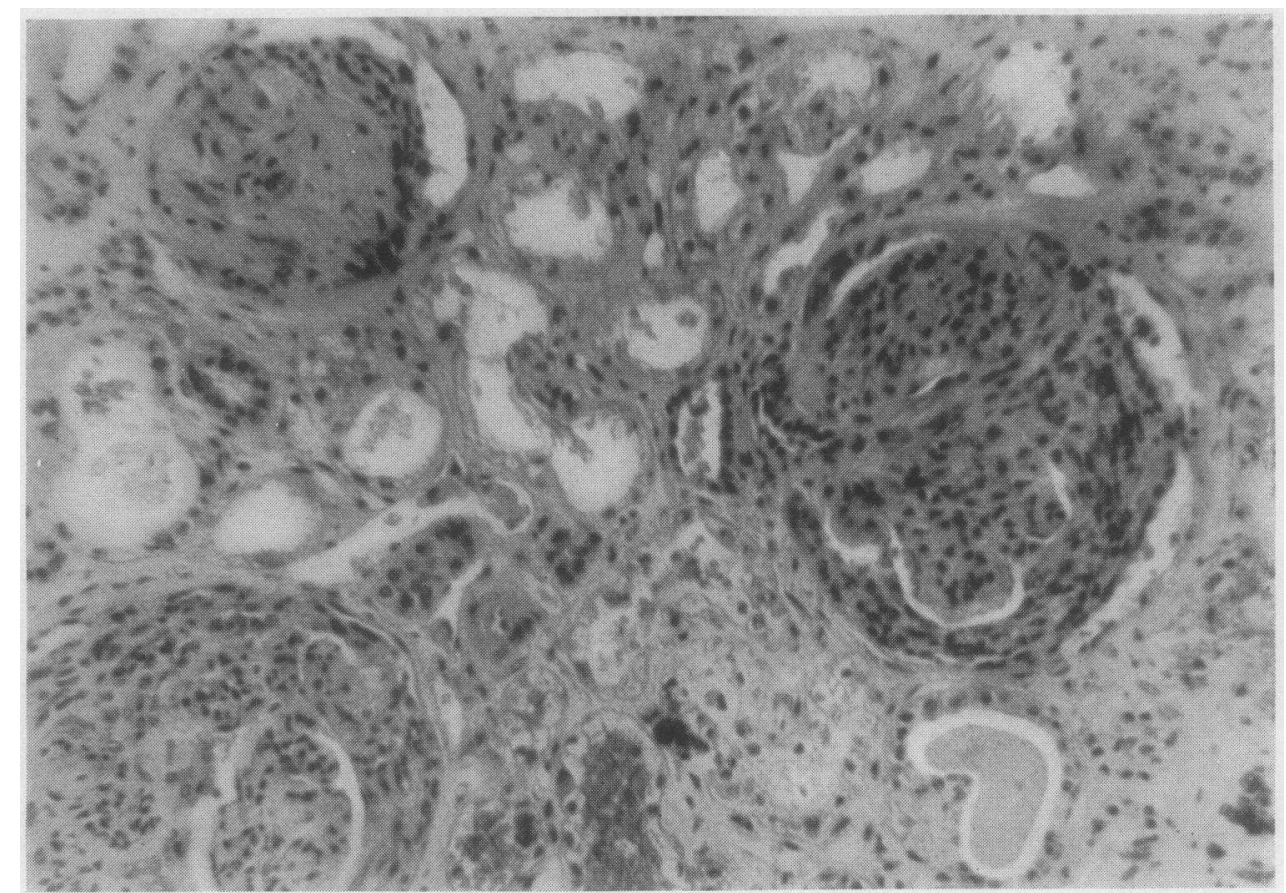

Fig. 22. O. F., Case No. 8-Microscopic Appearance of the Transplant at Post-Mortem

The glomeruli show striking proliferative changes with resulting "crescent" formation, and obliteration of capillaries. Adjacent tubules exhibit vacuolated epithelium, and some contain recently extravasated blood. $(\mathrm{H} \& \mathrm{E} \times 250)$

low normal range $\left(96.6^{\circ}\right.$ to $\left.98.6^{\circ}\right)$ until the 2 nd postoperative dialysis on the 15 th day, at which time it rose to $99.8^{\circ}$. It then remained within normal range until the 32nd day, at which time it again became sub-normal. It gradually went down, until during the last 24 hours it was too low to record on standard clinical thermometers. The patient died quietly on the 38 th post-operative day, the 83rd day of complete anuria, the 23rd day since the last dialysis. Prior to the 22nd post-operative day the patient was communicative and pleasant, reading during the day, and having no complaints. On the 22nd day she began having seizures, followed by semi-coma. The blood urea nitrogen at that time was 119 , serum potassium 5.1, hematocrit 19. From this time until the time of death the patient was semi-comatose. A blood urea nitrogen on the 32nd day was 204 , and a white blood count and hematocrit on this day were 3,850 and 15 , respectively. An electrocardiogram on the 33rd day showed no evidence of hyperkalemia, but one taken on the 38th day shortly before death showed definite changes of hyperkalemia.

At post-mortem examination there were several very remarkable findings. The kidney biopsy site and the skin graft donor site on the abdomen were very poorly healed. The skin graft over the lateral aspect of the leg had completely sloughed away. The medial leg wound had only weakly healed, and there was some necrosis at the upper end.

When the wound was opened it was very easy to strip the subcutaneous tissues away from the kidney, there being very little reaction between host and the graft. The blood vessels were easily identified, and there was very little reaction around them. There was a small, completely organized, non-occluding clot in the common femoral vein just below the inguinal ligament where a bulldog clamp had been applied during the operation. The transplant appeared normal in size, and there was no significant infection around it.

The cut surface of the kidney appeared normal, except that there were multiple pin-point, brownish-red spots scattered throughout the cortex (see Figure 20). The patient's own kidneys showed almost no recognizable normal architecture on cut section.

The microscopic findings were as follows:

A. The transplanted kidney: Unlike Cases No. 1 and No. 2, there was no pseudocapsule present (see Figure 21). There were no thromboses or infarcts present. There was a striking proliferation of the parietal epithelial layer of Bowman's capsule and of the epithelium of adjacent capillary loops, leading to marked "crescent" formation. The rest of the tuft was contracted and relatively bloodless (see Figures 22 and 23). These findings 
were compatible with a severe acute glomerulonephritis. The tubules showed vacuolation of the epithelium, and in some instances there was recently extravasated blood in the lumen. There were areas of tubular degeneration with calcification and also of tubular repair. There was very little round cell infiltration.

$B$. The contralateral donor kidncy: At the time of transplantation both of the donor's kidneys appeared similar, and grossly normal. The kidney which was not used for transplantation was examined microscopically. It appeared normal, and there was no evidence of glomerular disease.

C. The patient's ow'n kidneys: Proliferative and inflammatory changes had almost completely destroyed the glomeruli. The tubules were atrophic. Periglomerular inflammatory cells were less conspicuous than in the biopsy specimen (see Figure 24).

Comment: The transplanted kidney had developed, in 38 days, glomerular changes of such magnitude that it was never able to elaborate urine. Presumably these glomerular changes began during the anuric phase following transplantation, and were well enough developed at the end of this time to prevent recovery of function. No changes diagnostic of periarteritis were seen in the transplant, but the large doses of ACTH post-operatively may have been enough to arrest these, as it apparently had elsewhere in the patient. It failed to halt the glomerular damage, however, just as it had failed in the case of the patient's own kidneys.

The failure of this recipient to react violently locally to the transplant is in marked contrast to Case No. 4. This may have been due to the protracted anuria and lack of adequate caloric and protein intake, and it correlates well with the failure of the wounds to heal, and the lack of clotting in the blood vessels. On the other hand, the severe glomerular changes are in marked contrast to the other cases reported here, where tubular destruction, thromboses of small blood vessels within the kidney substance, and infection were the predominant changes. Since this patient had a severe, generalized, allergic disease, it is tempting to postulate that these glomerular changes were the consequence of this disease.

Case IX-G. W., male, age 26, No. $7 E 503$

Diagnosis: Chronic glomerulonephritis and hypertension.

This 26-year-old male physician first entered the Peter Bent Brigham Hospital on October 17, 1952 with the complaint of chronic glomerulonephritis. His illness began at the age of 12 with an upper respiratory infection, which was followed in a few days by microscopic hematuria and albuminuria. One and one-half years prior to

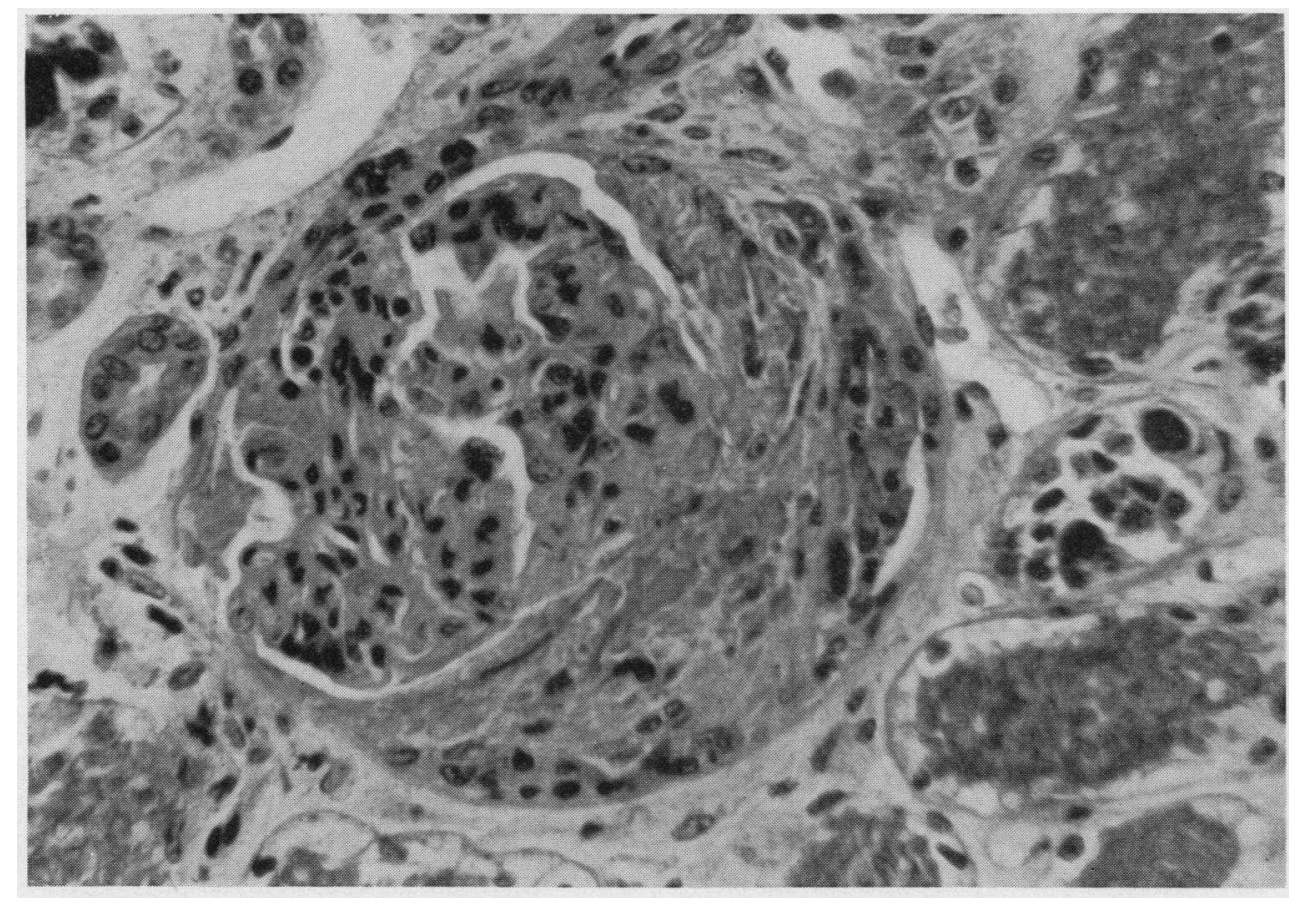

Fig. 23. O. F., Case No. 8-Microscopic Appearance of the Transplanted Kidney at POST-MORTEM

There has been a striking proliferation of the parietal layer of epithelium of Bowman's capsule, and of the epithelium of adjacent capillary loops, with resulting "crescent" formation. Elsewhere the tuft is contracted and relatively bloodless. The epithelium of nearby tubules is vacuolated, and recently extravasated blood fills the lumens. ( $\mathrm{H} \& \mathrm{E} \times 500)$ 


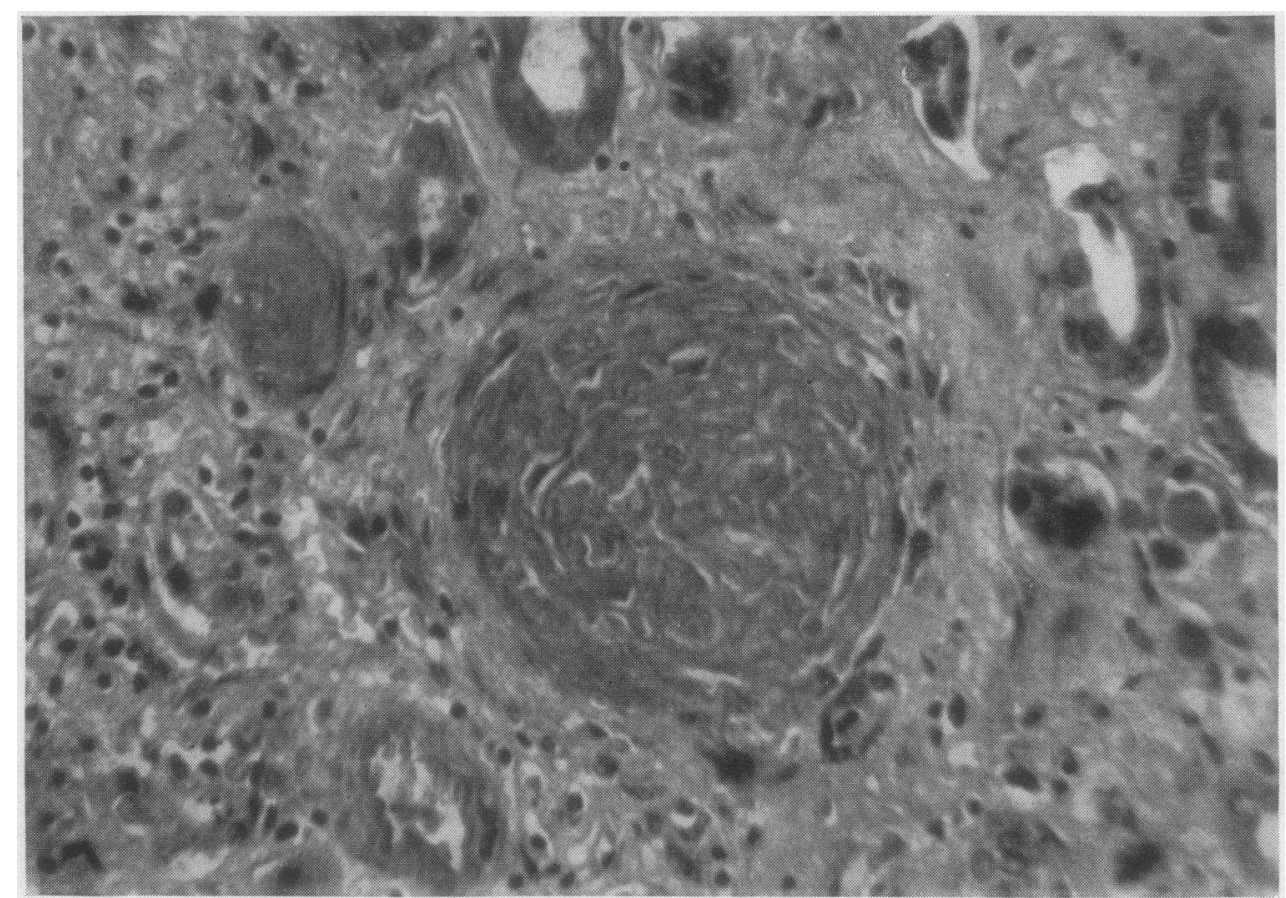

Fig. 24. O. F., Case No. 8-The Microscopic Appearance of the Patient's Own Kidney At Post-Mortem

The glomerulus in the center of the picture is obliterated and adjacent tubules are atrophic. Inflammatory cells in the periglomerular region are less conspicuous than in biopsy specimen. $(\mathrm{H} \& \mathrm{E} \times 500)$

admission he was found to have a blood pressure of $160 /$ 100 and a blood urea nitrogen of 30 . At this time he noted the onset of ankle edema at night and moderate periorbital edema. Two months prior to admission he had a severe headache and developed visual changes which were found on funduscopic examination to be due to retinal hemorrhages. $\mathrm{He}$ was hospitalized elsewhere at this time and his blood urea nitrogen was found to be $114 \mathrm{mgm}$. per cent, and his blood pressure 200/120. He had several days of gross hematuria and noted occasional nausea and vomiting. He was given three transfusions and was placed on a low protein, low salt diet. $\mathrm{He}$ entered the Peter Bent Brigham Hospital for a consideration of renal transplantation.

Physical examination: The patient was a pale young man with definite periorbital edema. Blood pressure was $188 / 118$. The optic fundi showed A-V nicking with arteriolar narrowing and irregularity. Both discs were blurred, and there were hemorrhages and exudates in both eyes. Lungs were clear. There was a Grade II apical systolic murmur. There was generalized lymphadenopathy.

Laboratory data: Blood urea nitrogen 65 to $80 \mathrm{mgm}$. per cent, carbon dioxide combining power $23.4 \mathrm{mM}$. per L., chloride $99 \mathrm{mEq}$. per L., sodium $130 \mathrm{mEq}$. per L., potassium $5.3 \mathrm{mEq}$. per L., hematocrit 32 , white blood count 9,200 with a normal differential. Urinalysis revealed a specific gravity of 1.006 , and there was $2+$ proteinuria. Microscopic examination revealed 40 to 60 red blood cells and 8 to 10 white blood cells per high power field. There was fine granular casts. PSP excretion was 7 per cent in two hours. A chest $\mathrm{x}$-ray was negative.

Hospital course: On November 6, 1952, the 21st hospital day, an operation was carried out to outline the skin flap on the right leg in preparation for doing a renal homotransplant. It was decided to create the flap in advance on this patient because his thigh was very thin and it was felt that the pedicle graft would not stand up under the increased tension that is developed when a renal transplant is placed in the thigh. The patient was discharged eight days later. Sixteen days later the patient was re-admitted and on December 3, 1952 the skin flap was elevated and then laid back down and resutured in place. The blood urea nitrogen prior to this operation was 76. Four days after this operation the patient was discharged again to await kidney transplantation.

$\mathrm{He}$ was re-admitted on February 11, 1953 and a renal transplantation to the right thigh was carried out at this time. The donor was a patient with mitral and aortic stenosis who died during a cardiac operation. The blood types of both the donor and recipient were $\mathrm{A}, \mathrm{Rh}+$, and their bloods were compatible. Although we prefer to put the right kidney in the right thigh, the blood vessels of this kidney were not suitable for use and therefore 
the left kidney was used. The kidney was placed in a polyethylene bag, which had been made especially for this purpose, and the artery, vein, and ureter were each brought out through small holes in the bottom of the bag. An end-to-end anastomosis was done between the profunda femoris and the renal artery, and an end-to-side anastomosis was made between the renal vein and the common femoral vein. The kidney was not perfused. The period of ischemia was 180 minutes. No heparin was injected. Circulation through the kidney appeared excellent. Peristaltic waves could be seen in the ureter, and the blood supply to the tip of the ureter appeared excellent. After all the bleeding points which could be seen on the kidney capsule were secured, the open end of the bag was sealed shut with the cautery. The bag was loose around the kidney and in no way constricted it (see Figure 25).

A pocket was created medially in the usual fashion and the previously outlined skin flap was again raised and was used to cover the kidney. The fascia lata was covered with two split-thickness grafts taken from the left thigh. The ureter was brought out through a stab wound

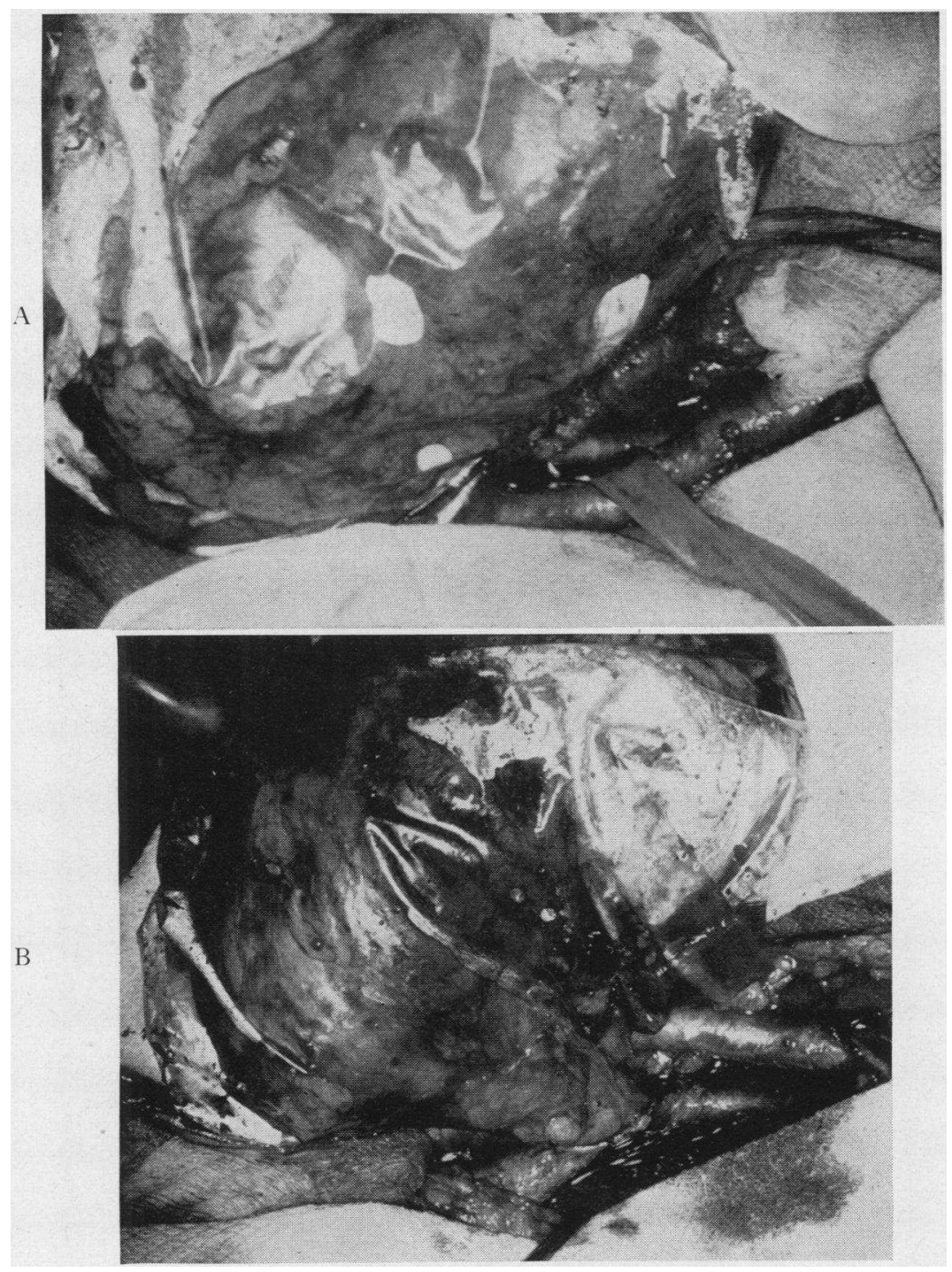

Fig. 25. G. W., Case No. 9-The Day of Operation

The homografted kidney has been sealed in a polyethylene bag. On the top (A) the anastomosis can be seen between the renal artery and the profunda femoris artery. The femoral artery is being retracted. The ureter may be seen lying on the gauze sponge at the right-hand side of the picture. On the bottom (B) is a view of the end-to-side venous anastomosis. 
in the flap and a soft rubber catheter was inserted in it. Because the left kidney was used, a U-shaped loop had to be made in the ureter. There was a large amount of oozing frcm the wound and therefore a perforated catheter was brought out through the lower end of the medial incision and connected to Wangensteen suction.

Post-operatively the patient was given $200 \mathrm{mgm}$. of testosterone in the first 24 hours and then $50 \mathrm{mgm}$. daily from then on for the next 62 days. No ACTH, cortisone, or heparin were given. Penicillin, streptomycin, Aureomycin ${ }^{\circledR}$, and Terramycin ${ }^{\circledR}$ were used at various times. The patient was placed on Terramycin ${ }^{\circledR}$ on the 29 th post-operative day and was maintained on a dose of $1.0 \mathrm{gm}$. a day to the 145 th day.

For the first two days post-operatively there was profuse bloody drainage from the operative site through the catheter that had been placed in the wound. By the third day the drainage had almost stopped, and the catheter was removed to prevent infection. The bleeding had not stopped, however, and although the patient was ordinarily hypertensive, by the 5 th day his blood pressure had fallen to shock levels. His hematocrit, which had been 32 on the 2 nd day, had fallen to 17 by the 5 th day. His thigh was moderately swollen. The patient was given protamine sulfate (although no heparin had been used), vitamin $K$, and fresh blood transfusions in an effort to decrease his tendency to bleed. For the next two days he continued to ooze, however, and by the morning of the 8th day he was in a precarious state. He had received seven blood transfusions. His hematocrit, which had been raised to 22 with the transfusions, had again dropped to 17 . His transplant had produced no urine, and the output of his own kidneys had fallen to $300 \mathrm{ml}$. (total) for the preceding two days. His thigh was tremendously swollen. The blood urea nitrogen had risen to $166 \mathrm{mgm}$. per cent, and the serum sodium had fallen to $124 \mathrm{mEq}$. per $\mathrm{L}$.

The dressings were entirely removed from the leg. The suture line between the split-thickness skin grafts and the pedicle flap had been separated and a large blood clot was lifting the pedicle flap off the anterior thigh muscles and the renal transplant. The tip of the ureter still appeared to have excellent circulation, however, and the two split skin grafts had entirely taken, having been saved by a stint which was tied in place over them. The pedicle flap, also, was of excellent color. The lateral portion of the hematoma was lifted out of the opening in the wound, and its volume was estimated at about 1000 ml. After its removal the transplanted kidney in its polyethylene covering could be seen presenting in the opening in the lateral aspect of the wound, pushed over by hematoma medial to it.

The medial wound was re-opened at operation. Blood clot amounting to an estimated $2000 \mathrm{ml}$. was removed. The kidney and ureter appeared viable. A small rip, about $2 \mathrm{~cm}$. in length, had occurred in the margin of the polyethylene bag which had been sealed with the cautery. An adhesion between subcutaneous tissue and kidney capsule had occurred through this opening. The adhesion was broken. The transplant was placed back in its medial position. The lateral margin of the pedicle flap was resutured to the split graft. The wound oozed from every surface, and it was impossible to control the bleeding completely. The medial portion of the wound was closed around three Penrose drains. The catheter was left in the ureter.

Following this operation, the patient's condition remained poor for several days. His blood urea nitrogen rose to $244 \mathrm{mgm}$. per cent on the 19th day after transplantation, the 11th day after the evacuation of the hematoma. Gradually the bleeding from the wound slowed down and stopped, and the drains were removed 15 days after the second operation. At this time the polyethylene bag could be seen through one of the drain holes.

For 11 days the transplant put out no urine. Then from the 12th to the 18 th day it put out from 5 to $26 \mathrm{ml}$. daily. On the 19th day it began to "open up," producing $75 \mathrm{ml}$., and for the next 5 days it produced gradually increasing amounts. From the 24th to the 30 th day it reached a plateau of around $400 \mathrm{ml}$. daily. This was interesting in view of the fact that the other three transplants with measurable function reached their maximal urine output from the 13 th to the 28 th day. The output continued to increase until, on the 37 th day, a 24-hour output of $1,000 \mathrm{ml}$. was reached, and from this time on the transplant elaborated 1,000 to $3,000 \mathrm{ml}$. a day until the sudden events which led to the patient's demise 6 months after the transplantation.

On the 28th day the catheter was removed from the ureter, since peristaltic waves were producing leakage of urine around the catheter. A ureterostomy cup was glued to the skin around the ureter, and the urine drained from here into a bag which was strapped to the patient's thigh (see Figures 26 and 27). The cup was changed every three weeks.

There was a considerable amount of thin purulent drainage from the drain sites in the medial wound. This cultured micrococci and $A$. acrogenes which were somewhat sensitive to Aureomycin ${ }^{\circledR}$ and Terramycin ${ }^{\circledR}$. The patient was given both drugs at various times, but proved to tolerate Terramycin ${ }^{\circledR}$ better, and so was maintained on this until the 145 th day. The three drain sites healed until only a small opening was present at the superior site, just below the inguinal ligament. A small amount of drainage persisted at this location until the 148th day, at which time all drainage stopped and the wound closed entirely.

The patient was gradually mobilized. His appetite returned, and he gained weight. His blood urea nitrogen decreased and his hematocrit rose. He learned to take care of his ureterostomy very well. On the 81 st day after the transplantation he was discharged home. From this time on, he returned every two to three weeks for brief periods of hospitalization for study. His appetite remained good, and he ultimately felt better than he had for years.

Kidney function studies were done at frequent intervals. They are summarized in the following paragraphs, together with notes of other observations which were of interest to us. 


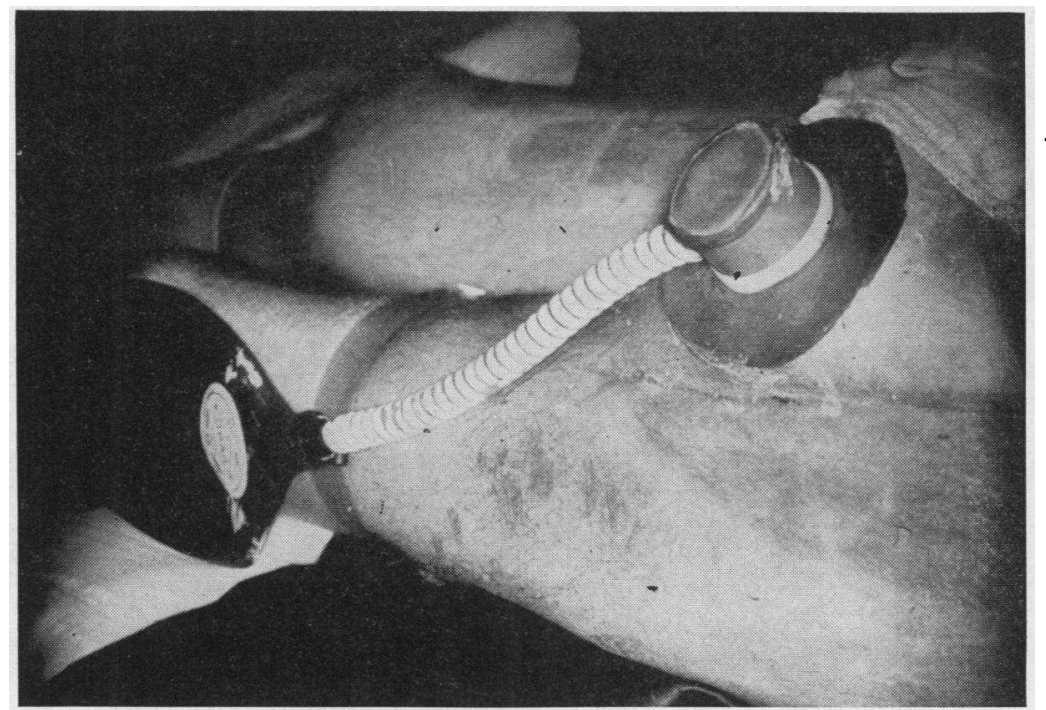

Fig. 26. G. W., Case No. 9-Lateral View of the Right Thigh

The ureterostomy cup is glued in place, and the collecting bag is strapped to the patient's leg. The graft site can be seen just beneath the cup.

\section{Excretion of metabolites and electrolytes}

In Table VII a comparison is made between transplant and bladder urine at representative periods throughout the patient's course, together with blood studies during the same period. It may be seen that the transplanted kidney, once its function reached a steady plateau, excreted more metabolites than both host kidneys. On the 65th day, for example, the patient's own kidneys together put out $2.4 \mathrm{gm}$. of urea nitrogen in 24 hours, while the transplant excreted $6.8 \mathrm{gm}$. The total urea nitrogen output was $9.2 \mathrm{gm}$., which corresponds to an output of about $18.4 \mathrm{gm}$. of urea. This would be at the lower limits of normal range ( 15 to $35 \mathrm{gm}$.) on an average protein intake. The urea clearance of the transplant (x2) on this day was $16 \mathrm{ml}$. per min. The function of the transplanted kidney with respect to the clearance of urea was thus about 25 per cent of normal.

On the 74th day the total 24-hour creatinine excretion in the bladder urine was $253 \mathrm{mgm}$., while in the urine from the transplant it was $1,000 \mathrm{mgm}$. The normal $24-$ hour output of creatinine for a man of this size is 1.2 to $1.7 \mathrm{gm}$.

The total nitrogen output of the transplanted kidney consistently ran about twice that of the total output in the bladder urine.

The potassium excretion of the transplanted kidney was greater than that in the bladder urine, and was within normal limits. The sodium and chloride excretion of both the transplant and bladder urine was quite low.

The $\mathrm{pH}$ of the bladder urine ran between 4.7 and 5.3. The $\mathrm{pH}$ of the transplant urine began at $\mathbf{5 . 6}$ on the 37 th day and rose to 7.2 by the 71 st day.

There was no sugar in the urine.

\section{Concentration and dilution tests}

The specific gravity of the bladder urine was about 1.007 , and that of the transplant varied between 1.005 and 1.012. A concentration test carried out on the 53rd day showed no significant ability of either the transplant or the host kidney to respond with increases in specific gravity. The specific gravity of host and transplant urine fell with increased fluid intake. (See also Pituitrin $\otimes_{\text {test). }}$.

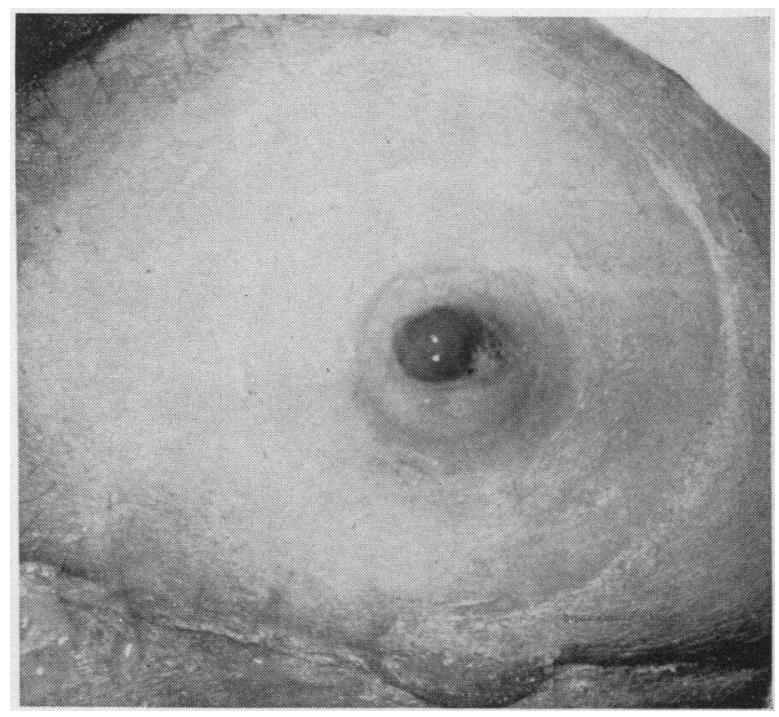

Fig. 27. G. W., Case No. 9-View of the UreterosTOMY WITH THE CUP ReMoved 


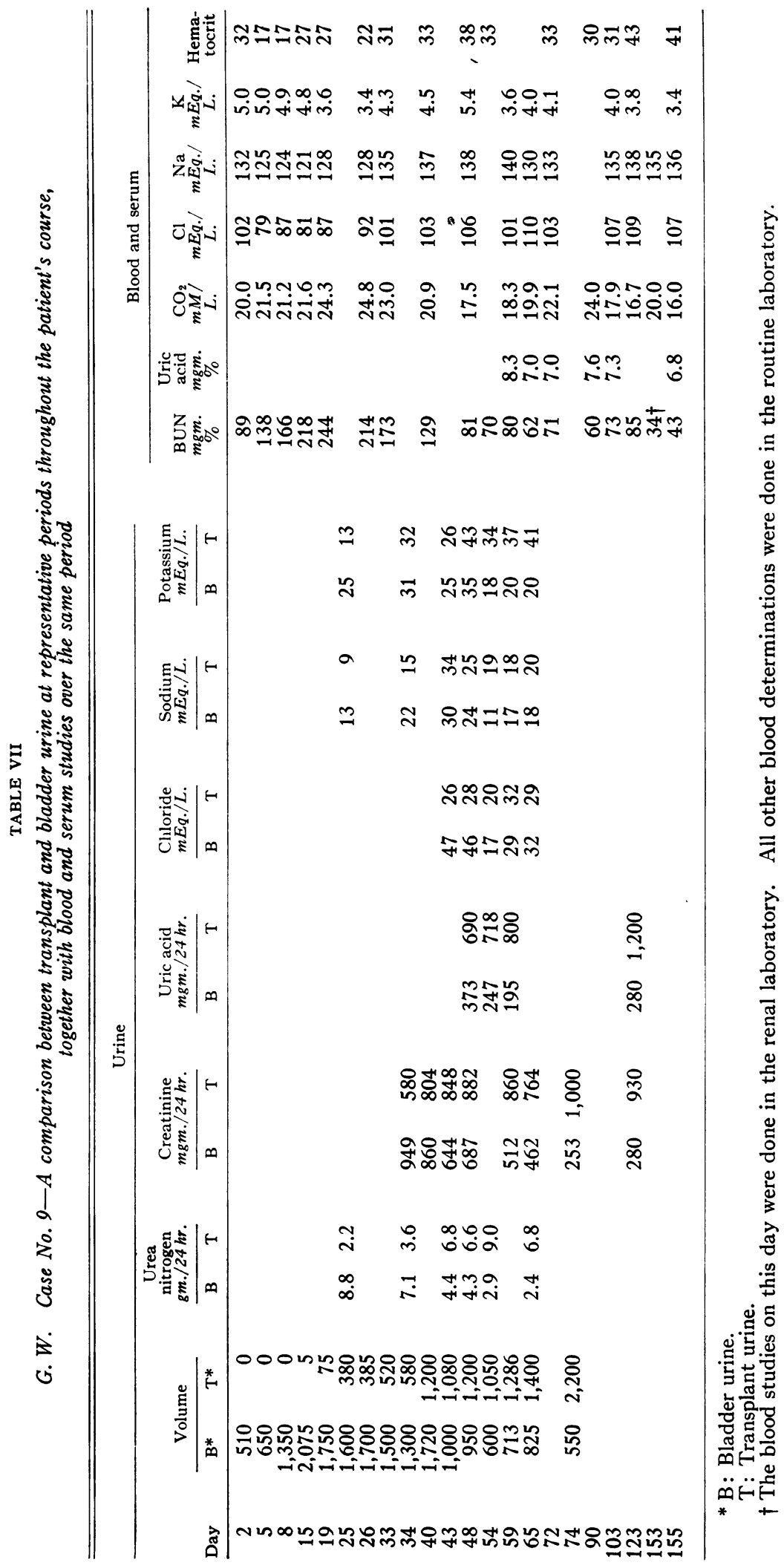


TABLE VIII

G. W. Case No. 9-4-10-53-Renal functional studies carried out on the 58th day *

\begin{tabular}{|c|c|c|c|c|c|c|}
\hline \multirow{2}{*}{\multicolumn{2}{|c|}{ Serum }} & \multicolumn{5}{|c|}{ Urine } \\
\hline & & \multicolumn{2}{|c|}{ Bladder } & & \multicolumn{2}{|c|}{ Transplant } \\
\hline $\begin{array}{l}\mathrm{pH} \\
\mathrm{Hct} . \\
\mathrm{BUN} \text { (mg. \%) } \\
\mathrm{CO}_{2} \text { (mM/L.) } \\
\mathrm{Na} \text { (mEq./L.) } \\
\mathrm{K} \text { (mEq./L.) } \\
\mathrm{PO}_{4} \text { (mM/L.) }\end{array}$ & $\begin{array}{c}7.32 \\
33 \\
60 \\
20 \\
136\end{array}$ & $\begin{array}{r}\text { Mean } \\
5.5 \\
32.5 \\
4.9 \\
17.2 \\
\end{array}$ & $\begin{array}{l}\text { S.D. } \\
( \pm .26) \\
( \pm 2.65) \\
( \pm .25) \\
( \pm .32) \\
\\
\\
.9 \\
.96\end{array}$ & $\begin{array}{l}\mathrm{C} \text { inulin (ml./min./1.73 } \mathrm{M}^{2} \text { ) } \\
\mathrm{C} \text { PAH (ml./min./1.73 } \mathrm{M}^{2} \text { ) } \\
\mathrm{C} \text { urea (ml./min.) } \\
\text { Filtration fraction } \\
\mathrm{Na} \text { conc. (mEq./L.) } \\
\mathrm{Cl} \text { conc. (mEq./L.) } \\
\mathrm{NH}_{3} \text { (mg. \%) } \\
\mathrm{K} \text { conc. (mEq./L.) } \\
\mathrm{PO}_{4} \text { (mM/L.) } \\
\text { Average volume (ml./min.) }\end{array}$ & $\begin{array}{c}\text { Mean } \\
6.9 \\
31.5 \\
6.3 \\
22\end{array}$ & $\begin{array}{l}\text { S.D. } \\
( \pm .41) \\
( \pm 3.32) \\
( \pm .3) \\
( \pm .32) \\
9 \\
2 \\
0 \\
0 \\
8.5 \\
.96\end{array}$ \\
\hline
\end{tabular}

* The clearance of inulin, PAH, and urea are the mean value for four 20-minute periods shown with the standard deviation. Serum values are those at the beginning of the clearance periods.

TABLE IX

G. W. Case No. 9-5-27-53-Renal function studies carried out on the 103rd day

\begin{tabular}{|c|c|c|c|c|}
\hline & & \multicolumn{3}{|c|}{ Urine } \\
\hline \multicolumn{2}{|l|}{ Serum } & Bladder & & Transplant \\
\hline $\begin{array}{l}\mathrm{pH} \\
\mathrm{PO}_{4}(\mathrm{mM} / \mathrm{L} .) \\
\mathrm{BUN}(\mathrm{mg} \cdot \%) \\
\mathrm{CO}_{2} \text { (mM/L.) } \\
\mathrm{Cl} \text { (mEq./L.) } \\
\mathrm{Na} \mathrm{(mEq./L.)} \\
\mathrm{K} \text { (mEq./L.) }\end{array}$ & $\begin{array}{c}7.36 \\
1.4 \\
48 \\
21.4 \\
109 \\
140 \\
4.2\end{array}$ & $\begin{array}{l}4.1 \\
23 \\
3.9 \\
18 \\
1.06 \\
41 \\
14\end{array}$ & $\begin{array}{l}\mathrm{C} \text { inulin (ml./min./1.73 } \mathrm{M}^{2} \text { ) } \\
\mathrm{C} \text { PAH (ml./min./1.73 } \mathrm{M}^{2} \text { ) } \\
\mathrm{C} \text { urea (ml./min.) } \\
\text { Filtration fraction } \\
\text { Average volume (ml./min.) } \\
\mathrm{Na} \text { conc. (mEq./L.) } \\
\mathrm{K} \text { conc. (mEq./L.) }\end{array}$ & $\begin{array}{l}7.9 \\
31 \\
7.9 \\
25 \\
1.45 \\
19 \\
22\end{array}$ \\
\hline
\end{tabular}

\section{PSP and aminophyllin tests}

Phenolsulphonephthalein tests were done on two occasions. On the 28 th day the total output of dye in two hours' time from the bladder was 2 per cent, and from the transplanted kidney 4 per cent. On the 39th day the bladder urine contained 7.5 per cent, and the transplant 5 per cent. The urinary output of the transplanted kidney increased markedly following the $I-V$ injection of aminophyllin.

\section{Clearance studies 13}

Studies of renal clearance were done on three separate occasions, (Tables VIII, IX, and X), on the 58th, the $103 \mathrm{rd}$, and the 153rd day, respectively. While the clearance of inulin and $\mathrm{PAH}$ are difficult to interpret in renal disease as far advanced as this, nevertheless under comparable circumstances, the function of the transplanted kidney in these parameters was better than both of the host kidneys combined. It is also of interest that the function of the transplant was continuing to improve at least as late as the 153rd day, when the last test was done. The lowering of the blood urea nitrogen

13 These were kindly carried out for us by Dr. John Finkenstaedt. further attests to the fact that the transplanted kidney was improving the patient's excretory ability.

\section{Pitressin ${ }^{\circledR}$ test 14}

On the 50th day a Pitressin ${ }^{\circledR}$ test was carried out in the following manner: With a water load of $20 \mathrm{ml}$. per $\mathrm{Kg}$, maximal diuresis ensued. This amounted to $2.0 \mathrm{ml}$. per min. for the patient's own kidneys (combined), and $3.0 \mathrm{ml}$. per min. for the transplant. The specific gravity of both urines fell from 1.007 to 1.001 . After the control period, 15 milliunits of Pitressin was given intravenously. The maximal decrease in minute output amounted to 65 per cent for the patient's own kidneys, and 70 per cent for the transplanted kidney. The maximal specific gravity was 1.006 for the patient's own kidneys and 1.010 for the transplant. The chloride concentration of the bladder urine increased from an average of $26.5 \mathrm{mEq}$. per $\mathrm{L}$. during maximal diuresis to a maximum of $37.0 \mathrm{mEq}$. per $\mathrm{L}$. following the administration of Pitressin $\circledast$, and that of the transplant increased from an average of $16.9 \mathrm{mEq}$. per $\mathrm{L}$. to a maximum of 33.4 mEq. per L.

${ }^{14} \mathrm{We}$ are indebted to Dr. Joseph Dingman for this study. 
TABLE $\mathrm{X}$

G. W. Case No. 9-7-14-53-Renal function studies for the transplanted kidney on the 153rd day

\begin{tabular}{|c|c|c|c|}
\hline Serum & & Transplant urine & \\
\hline $\begin{array}{l}\mathrm{BUN} \text { (mg. \%) } \\
\mathrm{pH} \\
\mathrm{CO}_{2}(\mathrm{mM} / \mathrm{L} .) \\
\mathrm{Na}(\mathrm{mEq} . / \mathrm{L} .)\end{array}$ & $\begin{array}{c}34 \\
7.4 \\
20 \\
135\end{array}$ & $\begin{array}{l}\left.\mathrm{C} \text { inulin (ml./min./1.73 } \mathrm{M}^{2}\right) \\
\mathrm{C} \mathrm{PAH}\left(\mathrm{ml} . / \mathrm{min} . / 1.73 \mathrm{M}^{2}\right) \\
\mathrm{C} \text { urea (ml./min.) } \\
\text { Filtration fraction } \\
\text { Average volume (ml./min.) } \\
\text { Na conc. (mEq./L.) } \\
\mathrm{K} \text { conc. (mEq./L.) } \\
\mathrm{PO}_{4}(\mathrm{mM} / \mathrm{L} .) \\
\mathrm{NH}_{3}(\mathrm{mg} . \%)\end{array}$ & $\begin{array}{c}8.9 \\
36 \\
8.7 \\
27 \\
2.3 \\
5 \\
12 \\
3.3 \\
19\end{array}$ \\
\hline
\end{tabular}

It would thus appear that all kidneys were able to respond somewhat to water loading and that the degree of concentration following the administration of Pitres$\sin { }^{\circledR}$, while sub-normal, was slightly greater in the case of the transplanted kidney than the host's kidneys.

\section{Urinary sediment}

Urine sediment was evaluated at intervals by the semi-quantitative method of Addis (1). Transplant and bladder urine both consistently showed many white and red blood cells, but only the urine from the bladder showed casts. A typical count is that carried out on the 71st day:

TABLE XI

G. W., Case No. 9-The results of an Addis count of bladder and transplant urine on the 71st day

\begin{tabular}{crc}
\hline \hline Excretion/24 hrs. & \multicolumn{1}{c}{ Bladder } & Transplant* \\
\hline Casts & 400,000 & 0 \\
RBC & $37,000,000$ & $3,000,000$ \\
WBC & $2,000,000$ & $2,000,000$
\end{tabular}

* Urinary cultures from the transplant grew out micrococci and $A$. aerogenes.

\section{Output of adrenal cortical hormones, and their effect on electrolyte excretion. ${ }^{15}$}

Studies were carried out on the excretion of adrenal cortical hormones in transplant and bladder urine, and their effect on the excretion of electrolytes, creatinine, and uric acid. These results may be summarized as follows :

a) After the 51st day the transplant excreted somewhat greater amounts of both 17-ketosteroids and 17hydroxysteroids than were obtained in the bladder urine.

b) The output of 17-hydroxysteroid was increased markedly in both bladder and transplant urine after the administration of $150 \mathrm{mgm}$. of hydrocortisone.

c) A similar increase in the output of 17-hydroxysteroids was seen after the administration of $100 \mathrm{mgm}$. of tetrahydrocortisone.

15 We are indebted to Drs. John C. Laidlaw and Dalton Jenkins for these studies. d) Hydrocortisone, $150 \mathrm{mgm}$., was infused intravenously over a 12-hour period. A decreased excretion of sodium, and increased secretions of potassium, chloride, creatinine, and uric acid were noted in the urine from both transplant and host kidneys. These changes were more marked in the urine from the transplanted kidney.

\section{Complement titre in peripheral blood 16}

No significant change in complement titre was noted in the post-operative period.

9. Hypertension

The patient's hypertension persisted unabated, the transplant having no noticeable effect on it.

\section{The appearance of the ureter}

The appearance of the tip of the ureter may provide a clue to the condition of the renal circulation, because its entire vascular supply comes from the renal vessels. In Case No. 4, for example, with focal infarction of the kidney the color of the ureter, which had been bright red, became an unhealthy pink. In Case No. 7, with extensive infarction of the kidney, the ureter became black.

In Case No. 9 the ureter continued to look a healthy red, month after month (see Figure 28). Peristaltic waves could be seen involving the tip, and urine was spurted out of the ureter by the force of these waves (see Figure 29).

\section{Other considerations}

The location of the kidney did not interfere with the patient's ambulation. The polyethylene covering did permit the kidney to slide about some under the flap, however. The patient noticed at an early stage that if he lay well over on his right side the kidney would sometimes slide over and kink the ureter, producing a temporary obstruction. Turning back to the other side would produce a gush of urine. He made every attempt not to sleep on the right side, but the possibility exists that some intermittent obstruction may have occurred when the patient inadvertently rolled over to this side.

On the 153rd day the patient returned to the hospital for a routine check. At that time he was feeling very well, and expressed a desire to get a job. His appetite was excellent, he had gained weight, and his blood urea nitrogen was down to $34 \mathrm{mgm}$. per cent, the lowest value we had ever obtained on this patient. His hematocrit had risen to 41 , and the blood uric acid had decreased to $6.8 \mathrm{mgm}$. per cent. The transplant was producing 1,500 to $2,000 \mathrm{ml}$. of urine daily. The ureter appeared of excellent color, as always.

The patient continued to exhibit a severe hypertension of $200-240 / 120-140$. He had been receiving Dibenzyline ${ }^{\circledR}$, $20 \mathrm{mgm}$. a day, during most of the time since the transplantation, but it had not been possible to control the hypertension with this drug. On the 100th day after the transplant, rauwolfia serpentina, two tablets daily of

\footnotetext{
16 Studies carried out by Drs. C. B. Favour and F. Adler.
} 


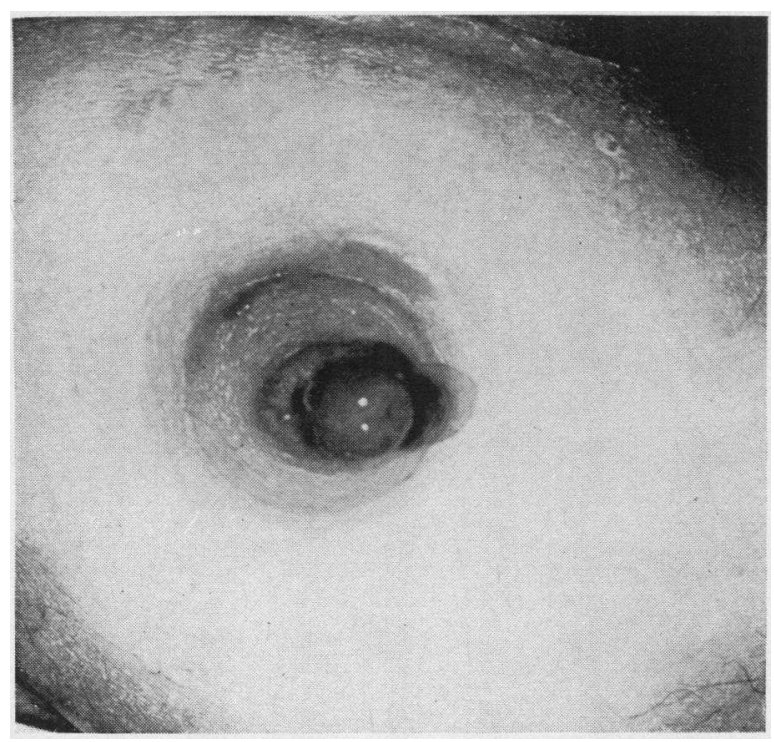

Fig. 28. G. W., Case No. 9-View of Ureter on 91st DAY

Circulation is excellent.

crude extract, was added without noticeable effect. It was decided, therefore, during this hospitalization to increase the dose of rauwolfia. The dose was increased from two to four tablets a day. No significant depression of the blood pressure was noted. On the 7th day of this hospitalization (the 160th post-transplant day) Apresoline ${ }^{\circledR}$ was added in doses up to $150 \mathrm{mgm}$. a day. On the 9th hospital day the patient noted a slight swelling of the kidney transplant area in the right thigh. By the following day this was definitely noticeable, and the patient had developed a fever of 100.5 degrees. The transplant urine, which had previously contained from 2 to 4 white blood cells per high power field, now contained from 80 to 100 . A urine culture showed $P s$. aeruginosa and $A$. aerogenes. The patient was placed on Chloromycetin ${ }^{\circledR}, 2.0$ gm. a day.

On the 13th hospital day the patient developed wheezing respiration, and physical examination revealed rales and dullness over both lung bases. On the following day the patient coughed up sputum streaked with bright red blood, and a chest $x$-ray at this time showed a bilateral hydrothorax with increased vascular markings. It was felt that the findings of swelling of the transplant, hydrothorax, and blood-streaked sputum were compatible with pulmonary emboli originating from the right femoral vein in proximity to the anastomosis of the transplant vein. The patient was started on heparin therapy.

On the 16th day a pleural friction rub was heard over the right posterior chest. The patient continued to run a spiking fever and to have tachycardia and tachypnea.

On the 18th day a pericardial friction rub was noted over the apex. There was pitting edema of the skin overlying the renal homograft, and the output of the trans- plant had dropped down to around $500 \mathrm{ml}$. a day. It was decided on this day to explore the right iliac vessels above the graft anastomosis site to see if thrombophlebitis of these vessels was present. ${ }^{17}$.At exploration the iliac veins were found to be soft and pliable and there was no evidence of thrombosis or inflammatory process.

On the day following the exploration the urinary output of the transplant, and of the host kidneys as well, dropped off still further. The patient began to vomit coffee ground material and to complain of mid-epigastric pain. Heparin therapy was therefore discontinued. The hematocrit had fallen to 24 by the 22 nd day.

The white blood count, which had reached levels of 14,000 , came down to 6,000 , and the temperature became normal from the 19th day on. The blood urea nitrogen continued to rise, however, and had reached $260 \mathrm{mgm}$. per cent by the $23 \mathrm{rd}$ day. The serum potassium gradually rose. The patient became disoriented and died on 8-6-53, the 23rd day of the last hospitalization, and 5 days short of 6 months from the time of the transplantation.

A complete post-mortem examination was carried out. There was no demonstrable myocardial infarct, but the myocardium was hypertrophied and dilated, and there was a fibrinous pericarditis. There were bilateral pleural effusions, and a fibrinous pleurisy on the right. The lungs were edematous, and there was atelectasis of the posterior portions of the lower lobes bilaterally. No evidence of pulmonary emboli could be found, however. Altered blood was found in the stomach and intestines, but no definite bleeding point was seen.

The patient's own kidneys were markedly contracted, weighing 70 grams each. Microscopically they showed chronic glomerulonephritis of a severe degree.

The renal homograft was extremely interesting. Only the central portion of the kidney was still encased in the bag, the two ends of the plastic sac having become torn

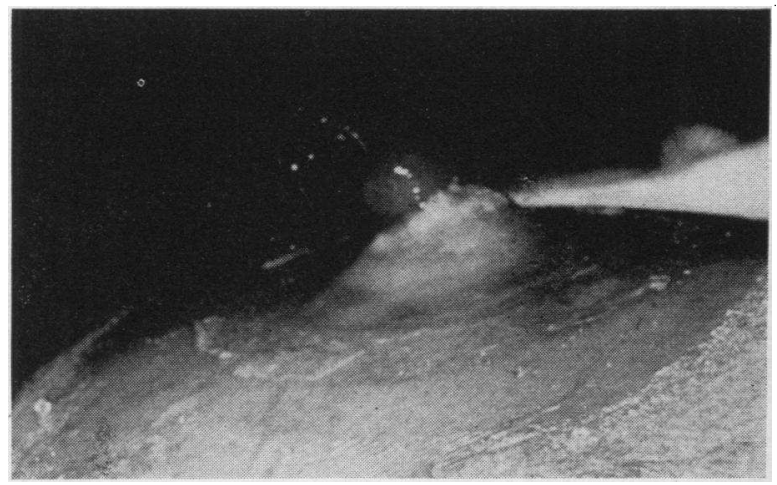

Fig.: 29. G. W., Case No. 9-Lateral View of the Ureterostomy on the 105Th Day

A peristaltic wave is spurting urine out of the end of the ureter.

${ }^{17}$ This operation was carried out by Dr. Joseph Murray. 


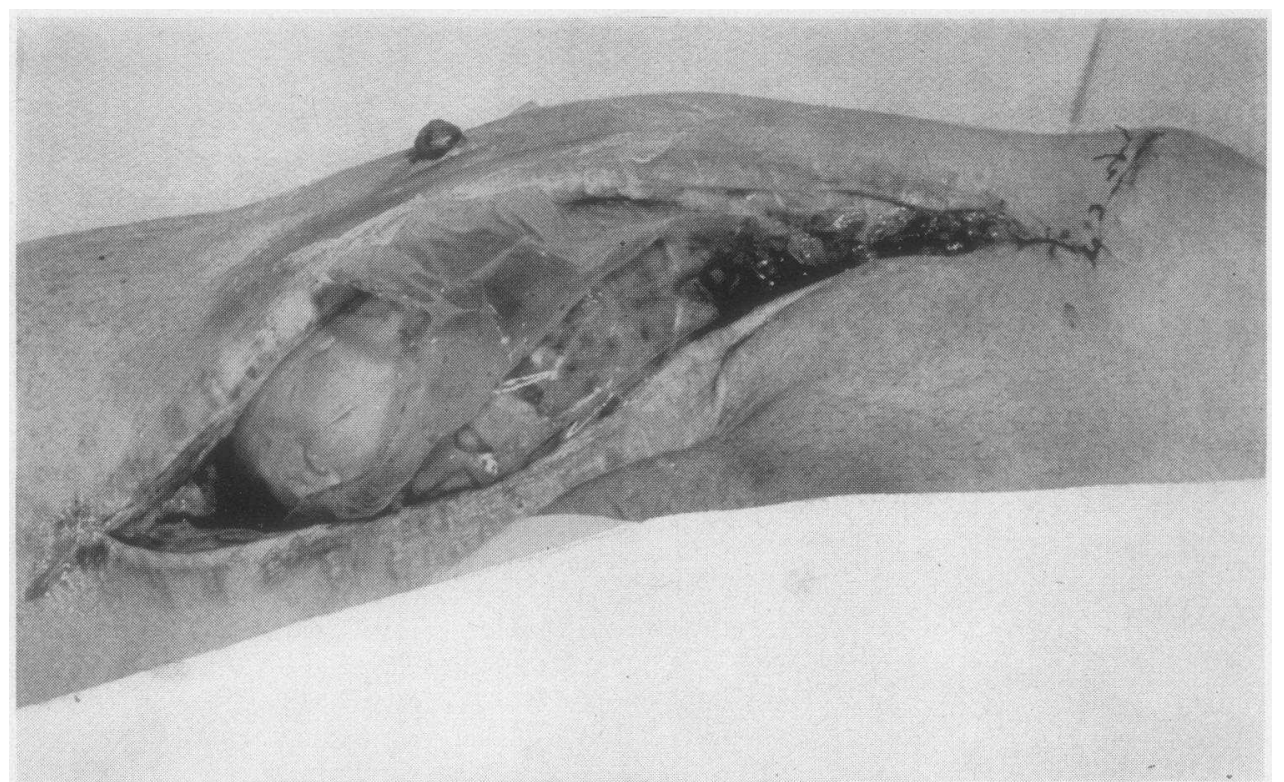

Fig. 30. G. W., Case No. 9-Medial Aspect of the Right Thigh at Post-Mortem

An incision has been made through the scar of the original wound. The ureteral stoma can be seen on the anterior surface of the thigh. The polyethylene sac encloses a broad segment of the mid-portion of the kidney. Portions of the upper and lower poles are uncovered by the sac and are in contact with host tissues.

(see figures 30-32). In spite of this, there were very few adhesions over even the uncovered portion of the kidney, perhaps because it moved back and forth under the skin. There was an acute angulation of the ureter $6 \mathrm{~cm}$. from the ureterostomy, with some dilatation above this point. This was consistent with the intermittent obstruction noted by the patient when lying on his right side, and was certainly not the cause either of the renal enlargement or the subsequent oliguria.

The transplant was swollen, pale, and mottled, and the cut surface bulged somewhat-findings felt to be consistent with ischemic nephrosis ("lower nephron

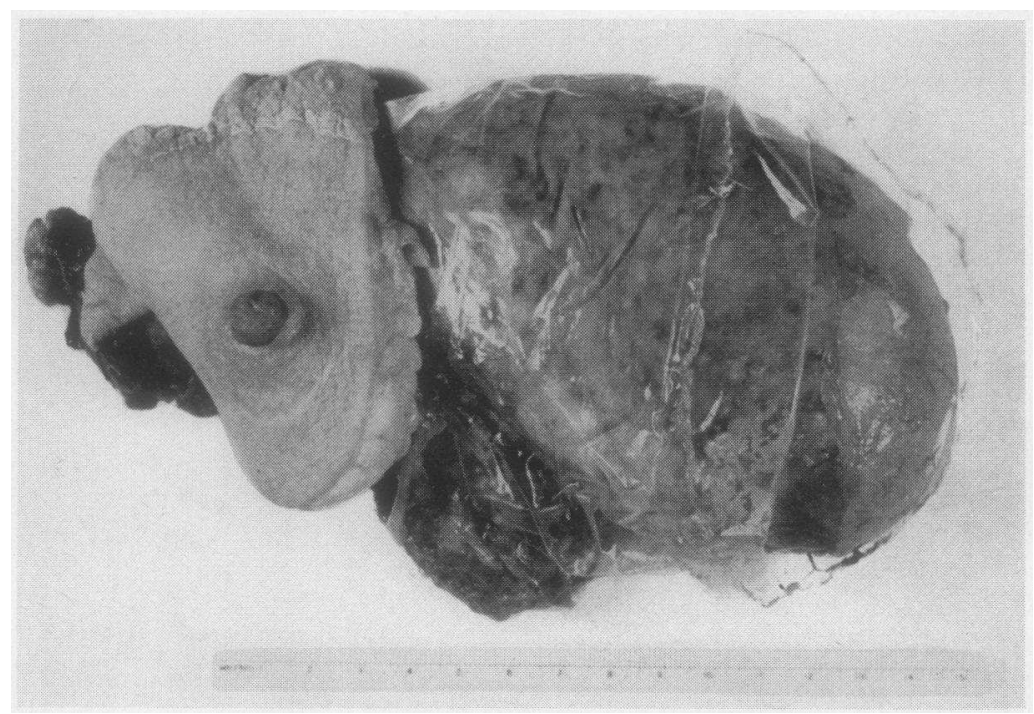

Fig. 31. G. W., Case No. 9-The Ureteral Stoma with Surrounding Skin is Seen at the Left.-At the Right the Transplant May Be Seen, with the Polyethylene Sac Covering Most of it 


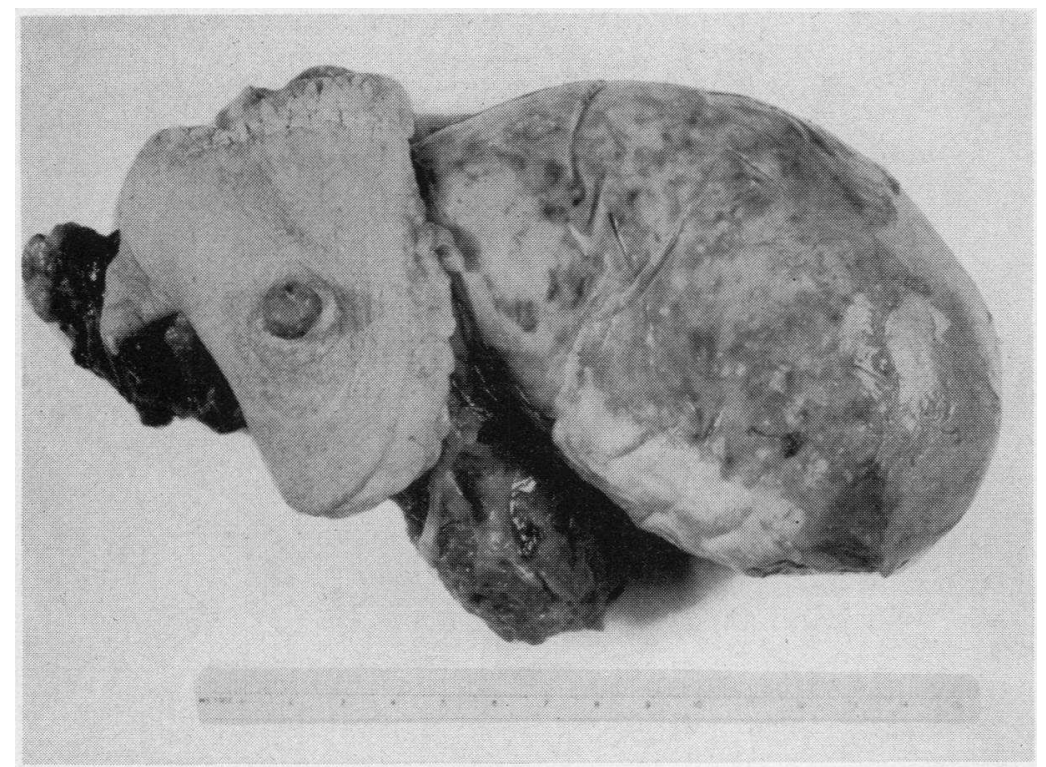

Fig. 32. G. W., Case No. 9-The Plastic Sac Has Been Removed. The Portion of the Lower Pole Which Had Been Uncovered is at the Extreme Right. The More Marked Thickening of the Capsule in the Part of the Kidney Which Had Been Covered by the Sac is APPARENT

nephrosis") (see Figure 33). There was no evidence of infection. The blood vessel anastomoses were completely patent, and there was no thrombosis or infarction to be found (see Figures 34 and 35).

The patient's own kidneys showed severe chronic glomerulonephritis.

Microscopically it was noted that the glomeruli in the outer cortex directly subjacent to the polyethylene bag

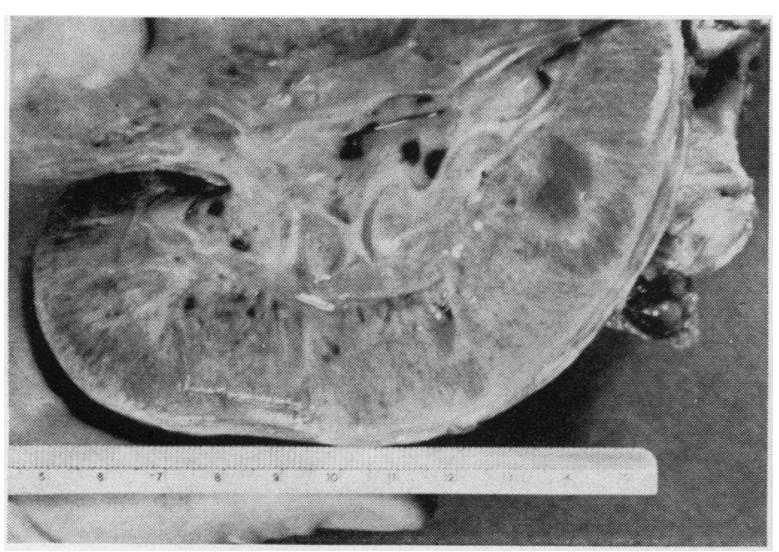

Fig. 33. G. W., CASE No. 9

The cut surface of the kidney shows pallor and interstitial edema. Accentuation of the architecture and the more marked thickening of the surface tissue where the polyethylene sac was in contact with the kidney can be seen. had become fibrosed. There was also fibrosis and marked cellular infiltration of the interstitial tissue in this zone (see Figure 36). These changes were not observed in the deeper layers of the cortex, or in the outer cortex which was uncovered by the bag, and apparently represent a direct reaction to the bag itself. The band of destruction was narrow enough not to constitute a contra-indication to the use of a bag, if such a procedure were shown to have merit. The glomeruli, with the exception of those just mentioned, appeared somewhat ischemic, but otherwise essentially normal (see Figures 37, 42, and 43).

Most of the tubules in the cortex and medulla appeared atrophic in some degree. This was noted most strikingly in the convoluted tubules. Some of the tubules showed casts, and recent degenerative alterations. There was interstitial edema, and focal areas of round cell infiltration

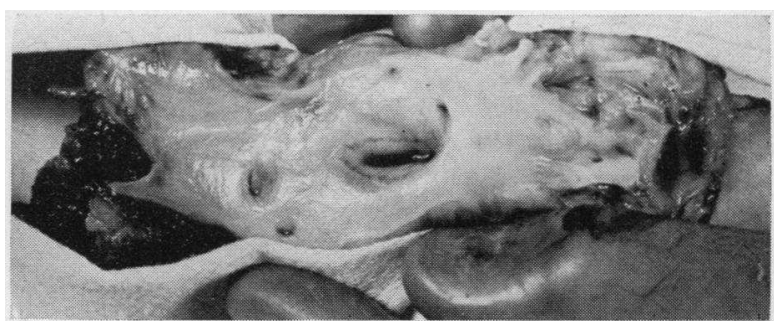

Fig. 34. G. W., Case No. 9-End-to-Side Anastomosis Between the Transplant and Host Veins

The dark wavy line represents suture. The endothelium is smooth and glistening throughout, and there is no evidence of thrombosis. 


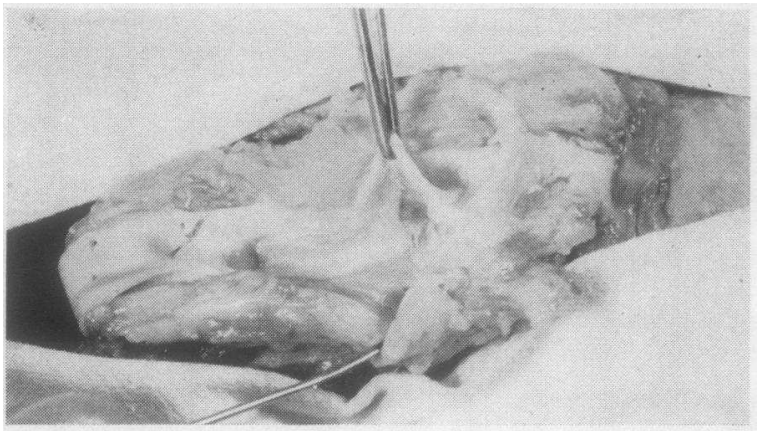

Fig. 35. G. W., CASE No. 9

The arterial anastomosis can be seen just beneath the tip of the forceps. The endothelium is smooth and glistening throughout. There is no evidence of thrombosis.

(see Figures 37, 41, and 44). The cellular infiltration was sometimes seen around arteries, sometimes around veins, and sometimes just occupying the interstitial space between tubules. There was no consistent relationship be-

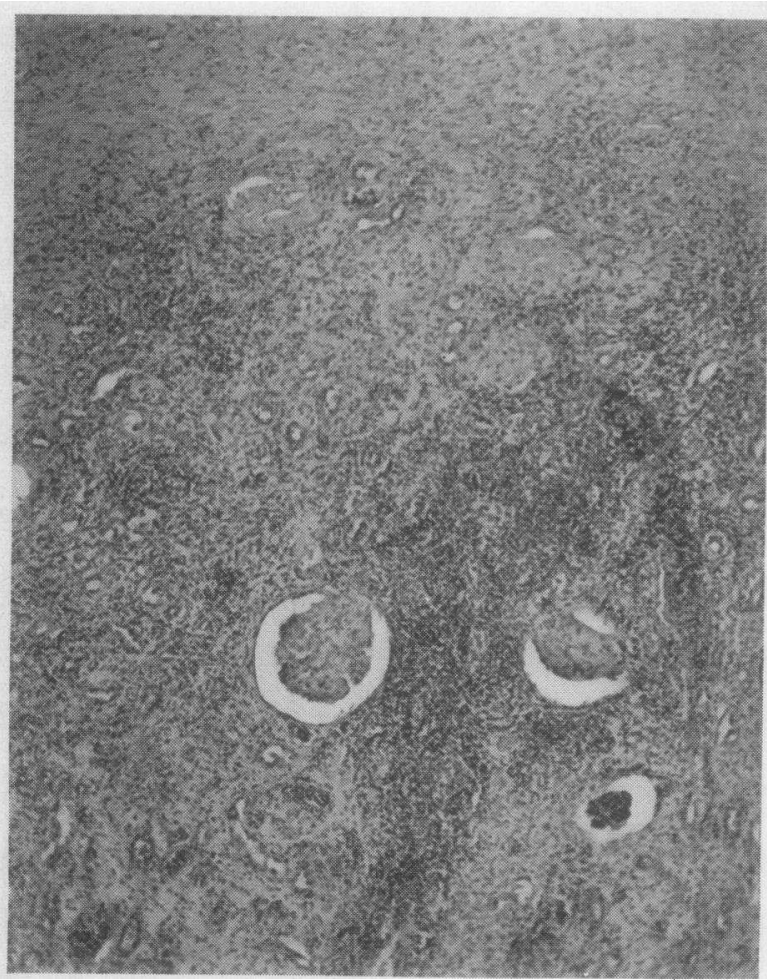

Fig. 36. G. W., Case No. 9-The Capsule and Outer Cortex of the Transplanted Kidney Directly Subjacent to the Polyethylene Sac

There is fibrosis of the glomeruli and interstitial tissue, and cellular infiltration. This picture is in contrast to the lack of glomerular damage in deeper zones of the cortex, or in the outer cortex which was not under the plastic sac. $(\mathrm{H} \& \mathrm{E} \times 75)$ tween inflammatory cells and any structural unit in the kidney. The tubular degeneration, casts, focal cellular infiltration, and interstitial edema were felt to be consistent with the picture of ischemic nephrosis.

There were striking changes in the intrinsic blood vessels. A severe degree of arteriosclerosis had developed. There was marked thickening of the intima with narrowing of the lumen, in some vessels almost to the point of occlusion. The inner portion of the intima showed dense sclerosis, and the outer portion, just within the inner

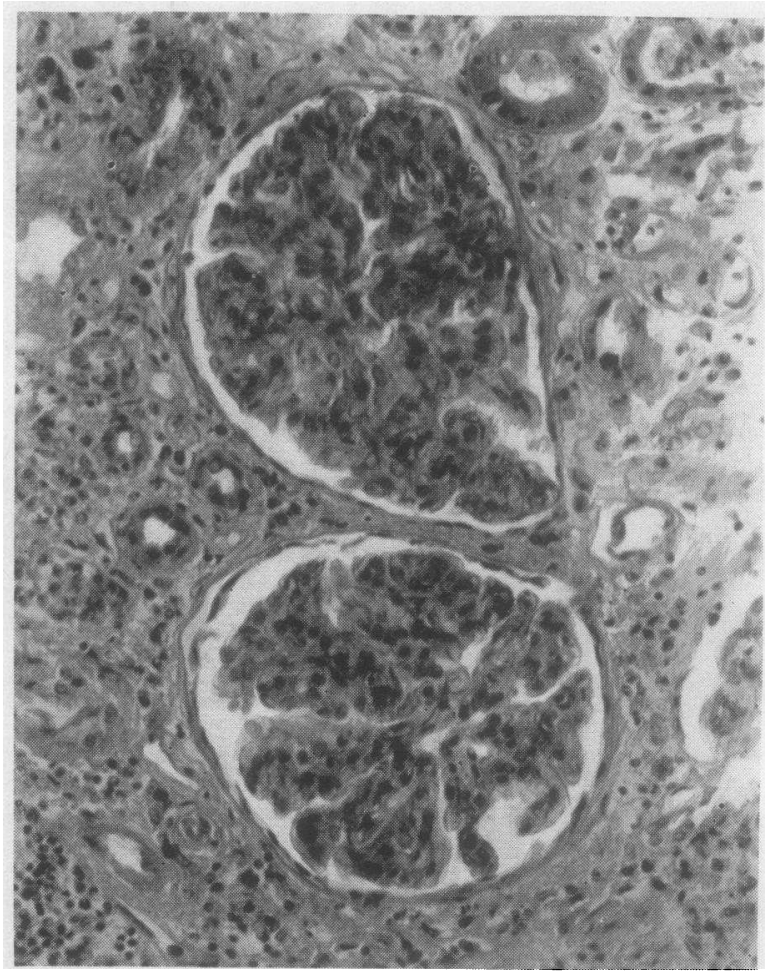

Fig. 37. G. W., Case No. 9-Microscopic View of Deeper Cortical Zone

The glomerular tufts appear ischemic, but otherwise fairly normal. There are no proliferative changes present in the glomerular capsule. The epithelium of the tubules is low and the nuclei are variable staining. There is interstitial edema and polymorphonuclear and round cell infiltration. $(\mathrm{H} \& \mathrm{E} \times 300)$

elastic lamina, contained numerous lipid-laden macrophages (see Figures 38, 39, and 40). The media was atrophic.

The inner elastic lamina was fragmented, appeared thicker than normal, and lacked the usual undulating conformation (Figure 39).

Microscopic sections of the ureter showed that the muscle coats of the ureter were still intact. While the patient was living the urine continued to be ejected from the ureter by peristaltic waves (Figure 29), which was evidence for the physiological function of the muscular layers. At the junction of the transplant ureter with the 


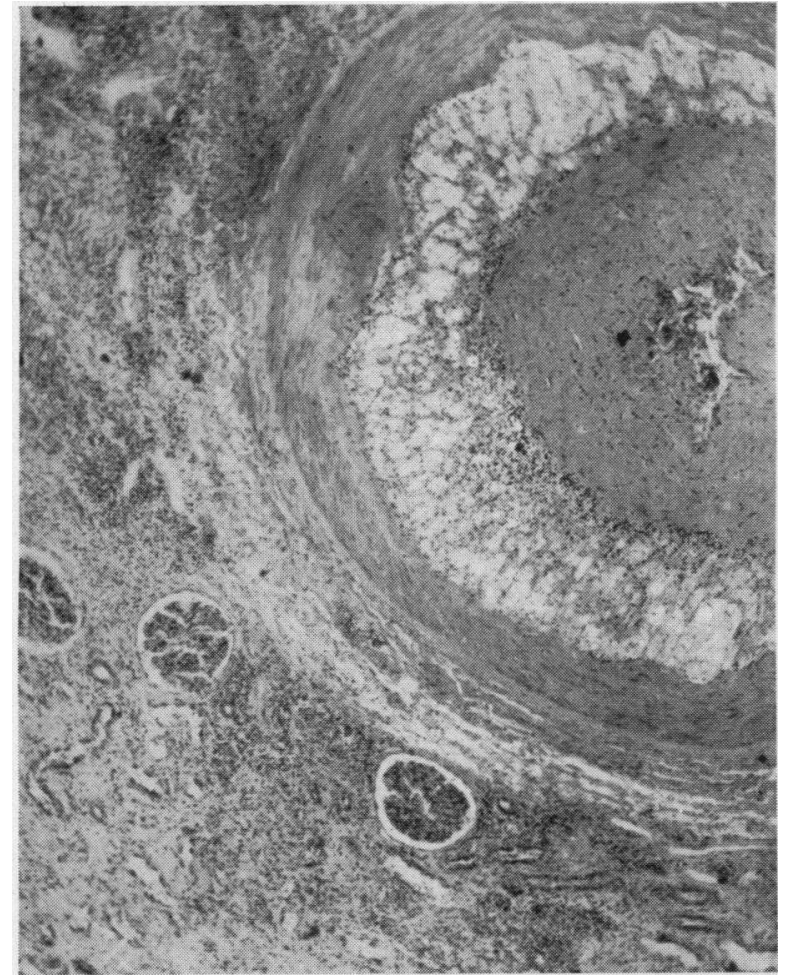

Fig. 38. G. W., Case No. 9-Low Power Microscopic View of ONe of the Intrinsic Vessels

Note the marked intimal thickening which has progressed almost to the point of complete occlusion of the vessel. The inner portion of the intima shows dense sclerosis, and the outer portion is filled with lipid-laden macrophages. The media is thinned. $(\mathrm{H} \& \mathrm{E} \times 75)$

skin, the epithelium of the host skin was directly applied to the wall of the ureter without any zone of necrosis between the two. There was some round cell infiltration in this area.

There was no evidence in the transplanted kidney of thrombosis, infarction, calcification, infection, or glomerulonephritis.

\section{DISCUsSION}

\section{The cases with measurable function}

In eight of the nine cases the homotransplantation was performed in the thigh with anastomosis of the renal vessels with the femoral vessels, and the construction of a skin ureterostomy. Four of these homografts developed measurable function. Despite the small number of cases there are certain similarities between these four which are worth noting. 1) All of the kidneys were small and had vessels whose diameters were equal to or less than those of the femoral vessels to which they were anastomosed. In three instances the small size of the kidney vessels may have been the result of severe mitral stenosis in the donor. In the fourth case the kidney was obtained from a child. 2) All of the patients received testosterone in the immediate post-operative period and for 27 to 62 days thereafter. 3) The blood types of donor and recipient were the same and the bloods crossmatched. 4) All of the kidneys went through a period of anuria from $81 / 2$ to 19 days in duration before opening up and beginning to produce urine. One of the kidneys secreted urine for 24 hours before becoming anuric. 5) During the period of maximal performance, each of the four transplanted kidneys developed function which was better than that of the recipient's own.

Beyond these five similarities, there were striking differences between the first three functioning transplants and the fourth one. The first three

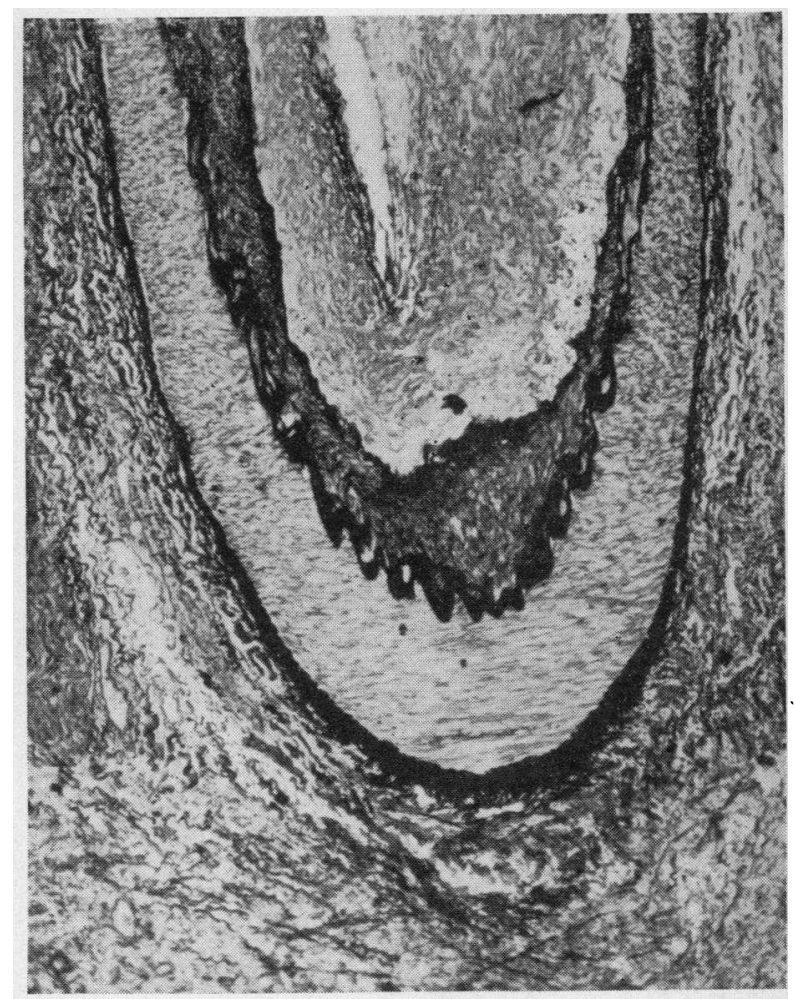

Fig. 39. G. W., Case No. 9-A Low Power Microscopic View of One of the Deeper Arteries of THE HOMOGRAFT

Marked thickening of the intima can be seen. The inner elastic lamina is split, and there is atrophy of the media. (Orcein $\times 75$ ). 


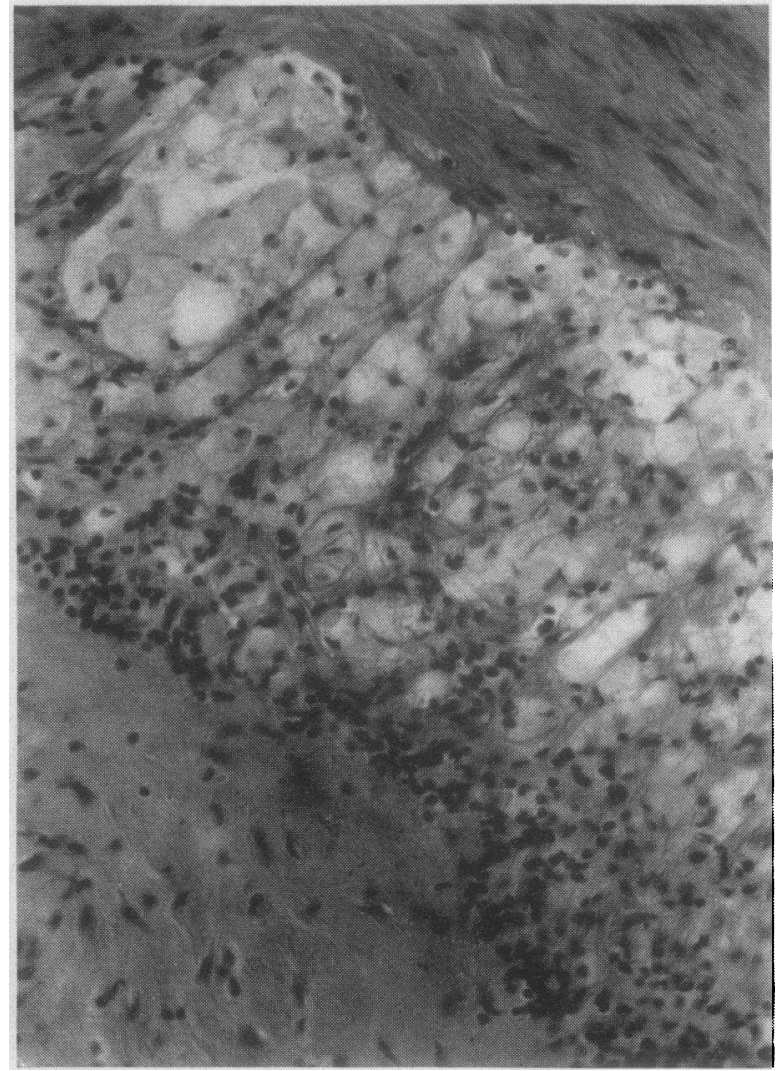

Fig. 40. G. W., Case No. 9-High Power MicroSCOPIC View of the Wall of One of the Intrinsic Homograft Vessels

In the lower left hand corner is the inner sclerotic layer of the thickened intima. In the upper right hand corner is the media. Note the marked lipoid infiltration of the inner half of the intima. $(\mathrm{H} \& \mathrm{E} \times 600)$

cases received $\mathrm{ACTH}$ and cortisone post-operatively. They all achieved maximum function between the 2nd and 4th week after transplantation. and the urine volume and excretion of metabolites fell off rapidly following this period. The final destructive processes appeared to consist of cortical ischemia, tubular degeneration, and interstitial edema and round cell infiltration. This was followed by scattered thromboses of the small intrinsic renal vessels with associated focal infarcts. All three transplants ultimately became heavily infected. The glomeruli appeared to be relatively uninvolved, except for ischemia, until the destruction of the kidney by infection was nearly complete. The main renal vessels remained patent in one case and had become thrombosed by the terminal stage of the other two cases.
The fourth functioning renal transplant (Case No. 9) was placed in a polyethylene bag at the time of transplantation. No ACTH or cortisone were given. Maximal function was not reached until the 37 th day - a time at which the function of the other transplants was already decliningand the function persisted without diminishing for over 5 months from the time of transplantation. The blood urea nitrogen came down progressively from a high of $244 \mathrm{mgm}$. per cent on the 19th day after the transplantation to a low of $34 \mathrm{mgm}$. per cent on the 153rd day. Following the failure of the transplant the blood urea nitrogen rapidly rose, over a period of two weeks, to reach a high of $260 \mathrm{mgm}$. per cent on the day the patient expired.

At necropsy the polyethylene bag was found to be intact over the central portion of the kidney,

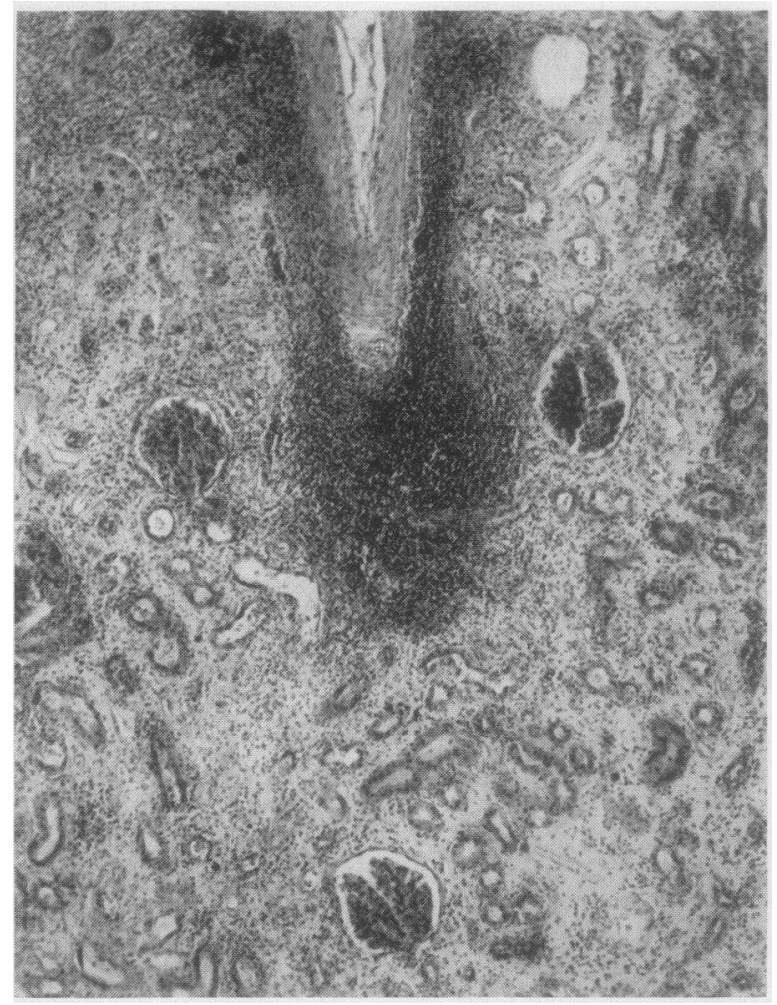

Fig. 41. G. W., Case No. 9-A Low Power Microscopic View of the Cortex of the Transplanted KIDNEY

An area of focal round cell infiltration can be seen occupying, in this instance, a perivascular position. There is atrophy of the convoluted tubules, and interstitial edema. $(\mathrm{H} \& \mathrm{E} \times 75)$ 


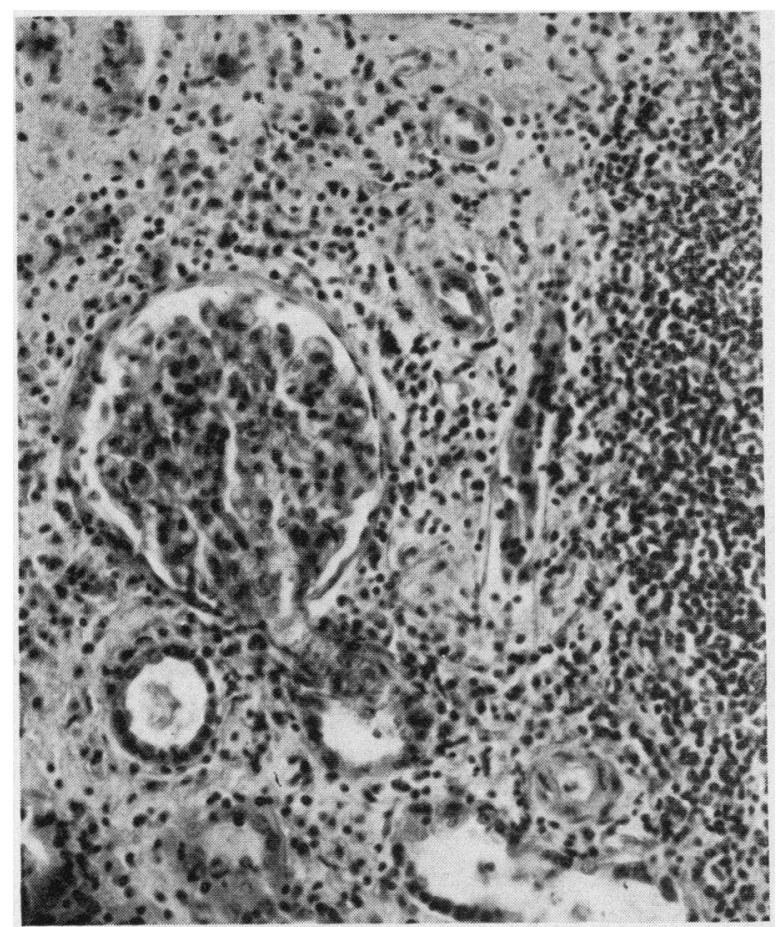

Fig. 42. G. W., Case No. 9-A Higher Magnification Detail of Figure 41

The glomerulus appears essentially normal. There is atrophy of the convoluted tubules, and lymphocytic infiltration. (H \& $\mathrm{E} \times 266)$

but to be torn over both poles. The microscopic findings in this kidney were somewhat different from the other three cases. The tubules showed signs of acute ischemic nephrosis, and there was interstitial edema and focal cell infiltration as in the other cases. There was, however, no significant infection, no thrombosis, no infarct, and no necrosis. The blood vessels had developed a severe degree of intimal thickening. There was some glomerular damage in the outer layers of the cortex in that portion of the kidney which was covered by the bag, but none in the deeper layers of the cortex, nor anywhere in the parts of the kidney which were not covered by the bag. The bag itself was presumed to have caused the glomerular changes.

\section{Cases without measurable function}

Five of the nine cases did not develop measurable function. In the first of these (Case No. 1) it was impossible to assess function adequately because the transplant was placed in the renal fossa, and the pelvis of the kidney was anastomosed to the ureter of the host. Extravasation of the urine and infection occurred. The transplant did not excrete dye or maintain the patient. Microscopically, the transplanted kidney showed an ischemic nephrosis with early reparative changes, after 37 days in the host. There was relatively little interstitial infiltration. There was no thrombosis or infarction.

In two other instances the homograft was obtained from a donor whose blood type was different from that of the host. In the first case (Case No. 2) a total infarction of the kidney occurred at sometime between the 3rd and 13th day. Marked local edema and hemorrhage in the wound undoubtedly played some part in the failure of this graft. It was decided, therefore, once again (Case No. 7) to attempt transplantation of a kidney from an incompatible donor. This kidney excreted a few milliliters of clear urine during the first 4 days of the "anuric period." The urine became bloody by the fifth day and dropped off to

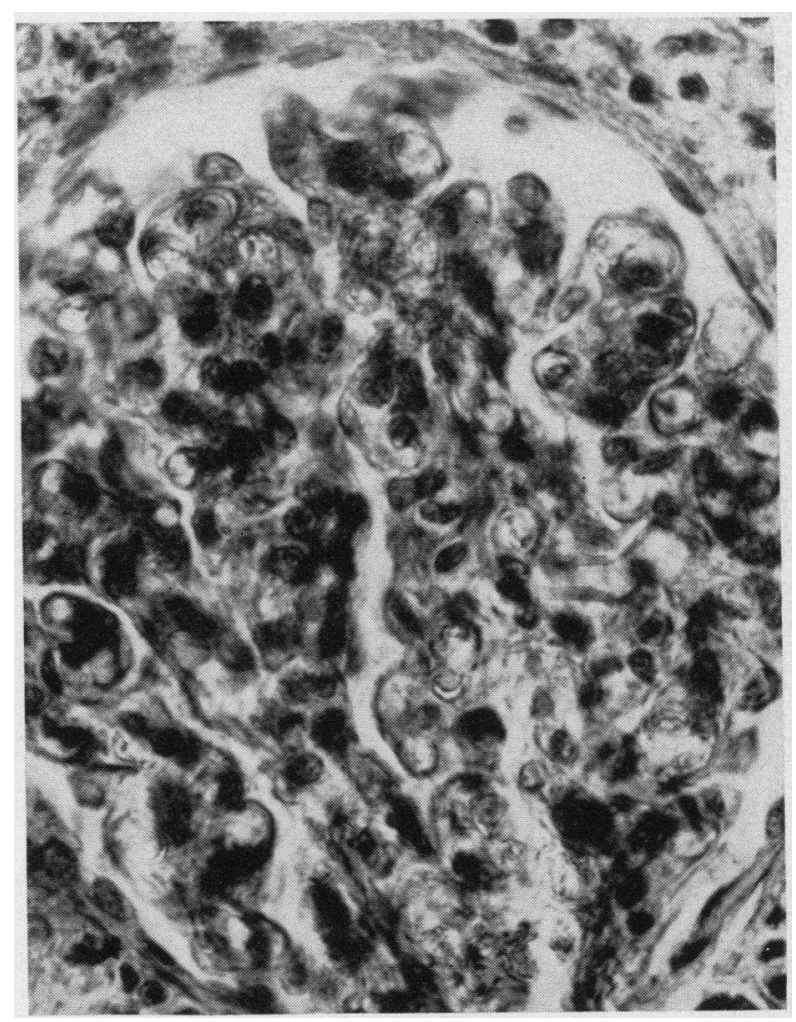

Fig. 43. G. W., Case No. 9-A High Power View of the Glomerulus in Figure 42, Showing no Essential Changes from the Normal ( $\mathrm{H} \& \mathrm{E} \times 750)$ 


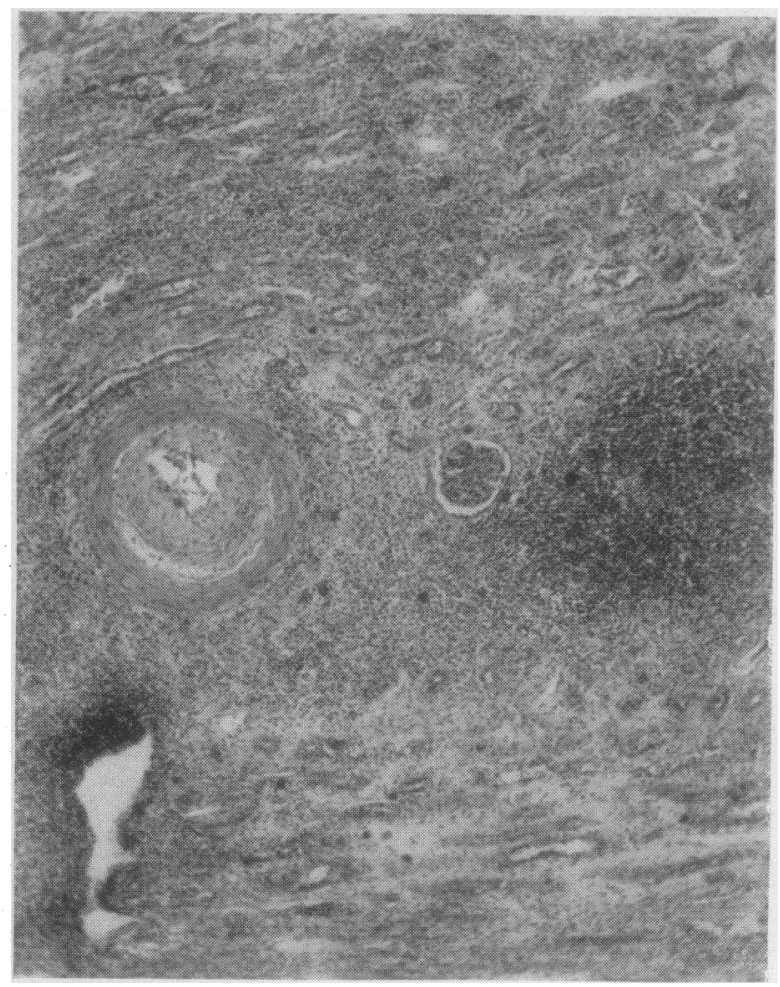

Fig. 44. G. W., Case No. 9-A Low Power MICroscopic View of the Cortex of the Transplanted KIDNEY

Here a focal area of round cell infiltration surrounds a vein. An adjacent artery shows no periarterial round cell accumulation. Tubular atrophy and interstitial edema can be seen. ( $\mathrm{H} \& \mathrm{E} \times 75)$

nothing shortly after that. Total infarction of the kidney ultimately occurred, necessitating removal on the 17th day. Unfortunately this was not a "pure" experiment and we cannot be sure that we can attribute the failure to the blood incompatibility. The following variables may also have played a part: 1) The donor was a hypertensive patient, as was the donor in Case 2. In neither of these two cases did the immediate circulation of the transplant seem to be quite as good as in the others; 2) The kidney was perfused, as was the kidney in Case 2. This was done because of the blood incompatibility. None of the other kidneys was perfused; 3 ) There was an anomalous vessel going to the lower pole of this kidney and when the circulation had been re-established, the portion of the kidney supplied by this vessel remained dark and in obvious danger of infarction; 4) No cortisone, ACTH, or testosterone was given to this patient, in contrast to most of the others.

In Case No. 6, local edema, hemorrhage, and pressure seemed to have contributed to failure of the graft, which was finally destroyed by infection and infarction.

In Case No. 8, the recipient's uremia was on the basis of periarteritis nodosa. She had been completely anuric (and maintained by dialysis of the artificial kidney) for 45 days at the time of transplantation. A biopsy of her left kidney prior to the transplantation showed severe renal damage, with inflammatory changes in the walls of the blood vessels, hypercellularity and hyalinization of the glomeruli.

Following the transplantation the patient remained anuric (maintained by dialysis) and without function from the homograft until her demise 38 days later. At post-mortem a severe glomerulonephritis was seen to have developed in the transplanted kidney, although there was no thrombosis, no infarction, and no significant infection. There was tubular damage, and hemorrhage had occurred into the lumina of many of the tubules. There was very little interstitial round cell infiltration, however, and no periarterial lesions were present. The glomerular damage seemed to dominate the picture here, the other changes appearing to be secondary to the glomerular damage and the anoxia at the time of transplantation. These changes had apparently developed in 38 days, as the other kidney of the donor was examined microscopically and found to be normal, so that the homograft is presumed to have been normal at the time of transplantation. The changes were probably well developed within two weeks or less, because, had they not been, the transplant would have been expected to "open up" after the initial post-operative anuric phase. This picture of the pathology was in marked contrast to that seen in any of the other cases.

\section{The development of glomerulonephritis in a re- nal homotransplant}

Rich and Gregory (107) produced typical periarteritis nodosa in rabbits by injecting horse serum, suggesting that periarteritis is one manifestation of the anaphylactic type of hypersensi- 
tivity. Acute, diffuse glomerulonephritis occurred in a number of these animals.

The glomerulonephritis which involved first the recipient's kidneys and later the transplanted kidney, in Case No. 8, appears, likewise, to have had its origin in a hypersensitive state induced by the injections of a foreign protein. In this case some of the clinical manifestations of the disease were ameliorated by the prolonged administration of ACTH. Progressive renal damage occurred, however, while other tissues were being sparedan observation made as well in other cases of periarteritis treated with ACTH. The terminal phases of destruction of the patient's own kidneys appear to have occurred quite rapidly, after a long period of slowly progressive changes-perhaps because the antibody titre suddenly increased. The destruction of the transplanted kidney, in any event, was very rapid.

Simonsen (119-121) describes vascular changes in $\log$ renal homotransplants which he regards as an "experimentally produced periarteritis nodosa." The glomeruli of these kidneys appear normal. No changes resembling periarteritis nodosa were seen in any of our other human transplants.

It is worth pointing out that Case No. 8 was the only one of our cases showing any evidence of primary glomerular involvement. In the experimental work on the pathogenesis of glomerulonephritis reference is made to the role of antigen-antibody reactions as possible etiologic factors in this disease. A brief mention of this work is pertinent to a discussion of the cases reported here.

Anti-kidney antibodies can be produced in one species of animal by the injection of kidney homogenates from another species. A "nephrotoxic glomerulonephritis" is produced when this heterologous kidney antiserum is injected back into an animal of the species originally donating the kidney tissue $(79.88,122)$. No such anti-kidney antibodies have been produced by the injection of homologous kidney homogenates alone, although Schwentker and Comploier (112) described their production following the injection of a mixture of homologous kidney tissue and bacterial toxin, and Hedlund (52) achieved similar results with homologous kidney tissue plus hemolytic streptococcus. Cavelti and Cavelti (24-26) have proposed a theory for the origin of human glomerulonephritis which postulates that streptococcal infection may convert kidney tissue into an antigenic form, permitting the development of anti-kidney auto-antibodies. Humphrey (60) was unable t? confirm this work Lange, Gold, Weiner, and Simon (71) found auto-antibodies to human kidney tissue in patients with glomerulonephritis. even in the chronic stage, and Lippman, Cameron. and Campbell (78) found a circulating nephrotoxic substance in patients with glomerulonephritis.

It is of note that no changes of glomerulonephritis were seen in the two renal transplants which were performed by us in patients with chronic glomerulonephritis. This was true in spite of the fact that the homotransplant persisted in one of the cases for a period far longer than that which was necessary for the development of the glomerulonephritis in Case No. 8. It is possible that in chronic glomerulonephritis the anti-kidney autoantibody titre falls to ineffective levels after a time, and that glomerular changes would have been observed had the transplantations been carried out in the acute phase of the disease.

\section{The post-transplant anuric period}

All four of the transplanted kidneys which ultimately showed measurable function developed anuria. or marked oliguria, following transplantation. and then "opened up" after 9 to 19 days. This course resembles that seen with acute ischemic nephrosis following anoxic or toxic injury in the normal human. Two of the kidneys began to function immediately after transplantation (Cases No. 5 and No. 6), but stopped secreting after a few hours. One re-opened 13 days later. The other never functioned, probably due to local factors. These two kidneys were both from living donors with normal renal function-one a child and one an adult. Both went through relatively short periods of anoxia (55 and $14 \mathrm{~min}$ utes).

It is likely, therefore, that the post-operative anuric phase is due to the prolonged period of ischemia which the transplants suffer. Most of the donors were in profound shock for some period of time prior to their demise, and this may well have contributed to the ischemic nephrosis 
which was felt to be the basis of the anuria. This exposure to anoxia was often continued after the completion of the transplantation, because the recipients were severely anemic and suffered from various degrees of shock in the immediate postoperative period. The thought occurred to us that the initial anoxia might in some way delay the destruction of the transplant by immune mechanisms.

The anuric period is not an invariable part of the course of the human renal transplant, however. One of us (JPM) has had the opportunity of observing the result of a renal homograft performed at the Necker Hospital in Paris. The surgical management was undertaken by Drs. Oeconomos, Vaysse, Michon, and Delinotte, and medical care was under the supervision of Drs. Hamburger, Richet, and Antoine. In this instance a sixteenyear-old boy had a right nephrectomy for traumatic hematoma of the kidney, following which absence of the left kidney was discovered. On the eighth day of anuria a normal kidney was removed from the patient's mother and transplanted into the pelvis of the patient by anastomosis with the iliac vessels. The period of anoxia was 53 minutes. A uretero-ureteral anastomosis allowed the patient to void in normal fashion. The mother's blood type was identical with that of the patient. Urine was elaborated from the homograft within two hours after the completion of surgery, and a good urinary volume and function was maintained for three weeks, thereafter, with marked improvement in the clinical condition and azotemia. However, quite suddenly, on the 23rd post-operative day, function of the homograft ceased. There had been no preceding hematuria, infection, or mechanical obstruction. A biopsy at this time showed numerous bloodless vessels and glomeruli, with marked infiltration of the parenchyma by leucocytes, predominantly lymphocytes and plasma cells. There was widespread degeneration of tubular epithelium ${ }^{18}$ (101).

\section{Antibody production in nephritis}

Patients with Bright's disease show hypoproteinemia and exhaustion of reserve protein (62). This is partly due to decreased protein intake, and partly to urinary protein loss, but apparently also

\footnotetext{
$18 \mathrm{We}$ are indebted to Dr. Hamburger for furnishing us with details of this case.
}

to depressed formation of serum protein in nephritis (13). In the nephrotic syndrome the hypoproteinemia is characterized by very low levels of gamma globulin, in spite of the reversed $A / G$ ratio $(85,86,125)$. There is some evidence that under these circumstances antibody formation and resistance to infection is decreased $(16,17,42$, $67,87,91)$, although this has been disputed by others $(6,8,100)$. The lack of agreement is dependent partly on the variable degree of hypoproteinemia present in the animals or patients under study, on the type of antigen used to elicit the immune response, and on the means by which the plasma proteins were lowered.

It is possible that a subnormal antibody production may have contributed to the prolonged survival of the renal homografts seen in some of our patients with chronic renal failure, although there is no direct evidence to indicate that this is so. The more rapid destruction of the homograft noted by Michon and his associates (101) in their case may have been related to the fact that the patient was a healthy young boy in acute uremia, with presumably normal immune mechanisms.

\section{The effect of various hormones}

$\mathrm{ACTH}$ and cortisone were given in four cases, and ACTH alone in two. We can come to no conclusion about the merit of corticoids or ACTH on the basis of these few cases. No ACTH or cortisone were used in Case No. 9, in which the transplant functioned longer than in any of the others. Persky and Jacobs (106) found that ACTH and cortisone in experimental studies did not prolong the survival of renal homotransplants in the dog. Baker, Gordon, Huffer, and Miller (5) found that treatment with nitrogen mustard plus cortisone, with or without splenectomy, significantly prolonged renal homograft survival in the dog. They point out that because all the animals lost weight the results may be due to the poor nutritional status of the treated animals. The effect of ACTH on skin homografts has been debated, but most investigators now feel that it does not significantly prolong the graft take $(7,41)$. Cortisone has been found by some workers to prolong skin graft survival $(9,10,15)$ and by others to have no effect in this regard $(41,133,134)$. Because these substances may contribute to the spread of 
infection, and because their contribution to the life of the graft has not been spectacular, it is felt that they do not offer any hope for the prolongation of human renal homografts.

Testosterone was used in all cases, because of the reported finding that this substance helps to maintain renal weight $(64,65)$, produces renal hypertrophy (113), and protects against tubular damage under some circumstances $(53,55,113$, 114), and for its anticatabolic effect.

Growth hormone was not tried, but studies with this substance might be of interest.

\section{Blood groups}

It is generally accepted that blood groups are of no importance in the destruction of skin homografts in the human $(48,96,138)$ or tumor or skin grafts in the fowl $(49,66)$. No studies have been done on the effect of blood groups in renal homotransplantation. Our own results in transplants done in the presence of $\mathrm{ABO}$ incompatibility are not conclusive, as previously stated, because other variables were present in the two cases reported here. We have been influenced by these results, however, to the extent that we do not feel that renal transplantation in the presence of blood incompatibility is wise, if only on the basis of possible local damage to the kidney.

Simonsen (121) has been able to demonstrate incomplete immune agglutinins against the donor's erythrocytes in cases of homotransplantation in the dog. He points out, however, that there is no evidence that these antibodies are identical to those destroying the transplants.

It is of interest that all of the patients with functioning renal homotransplants received blood transfusions at various intervals during their postoperative course. No deleterious effect either to the graft or the patient was noted as a consequence of this.

\section{Biological immunity}

The acquired immunity theory of homograft rejection was hinted at in the work of Schöne (110), and clarified and strengthened by Medawar (9298). This concept holds that the homograft is destroyed as a consequence of the development by the host of specific antibodies against it. Evidence for this is to be found in the following observa- tions: 1) Second set homografts from the same donor are destroyed more rapidly than the first set $(48,77,93) ; 2)$ Second set homografts from another donor are also destroyed more rapidly than the first set, but not so rapidly as secondary transplants from the original donor, (95) suggesting that there is some sharing of antigens between individuals; 3) Direct contact between isolated homologous cells in vivo does not lead to their destruction (50), suggesting that homograft rejection is a general rather than local phenomenon; 4) Homografts can persist for long periods in areas devoid of lymphatic drainage; in these areas they can still be destroyed by the placing in another site of a second graft from the same donor $(97,102,118,124,137)$. Under these circumstances, therefore, the initial graft apparently does not elicit an antibody response, but is still vulnerable to antibodies developed by the host against the second graft.

The chief objection to the theory of acquired immunity at the present time is that it has never been possible to detect circulating antibodies either following the initial transplant, or on repeated "immunization" of the animal.

Loeb has devised a theory, on the basis of his work with implants, which states that lymphocytic infiltration, brought about by "differentials," is the direct cause of homograft disintegration. Immune responses are held to be unessential (8082). We agree with Medawar, Dempster, and Simonsen that Loeb's theory of differentials is very confusing, and at times "impenetrably metaphysical" (121).

Extensive reviews of these and other concepts of the cause of biological incompatibility are available in the literature $(31,39,80,81,94,121)$. The acquired immunity theory is outlined here so that our results can be considered in the light of their possible significance to immune mechanisms of homograft destruction.

The enclosure of a renal transplant in a plastic bag.

In Case No. 9 the donor kidney was encased in a plastic envelope at the time of transplantation. This was done in an attempt to isolate it from the local lymphatic drainage, in the hope that this might decrease antibody formation against it. There is a good deal of evidence to show that 
lymphatic tissue plays an important role in antibody production $(12,40,96,97,102,117,118$, $124,137)$, and that regional lymphatics are concerned with the development of antibodies against locally injected antigens $(37,38,90)$. Since the plastic bag became torn at some time in the postoperative period, we didn't succeed in isolating the kidney permanently. It is possible, however, that the bag may have played some role in delaying the development of the immune reaction. Experiments are under way in the experimental animal to study the effect on the survival of renal homotransplants of their isolation, by various means, from regional lymphatic drainage (59).

\section{$A$ comparison between renal homografts in the dog and in the human.}

Recently Dempster (33, 34) and Simonsen $(120,121)$ have reported on functional, pathological, and immunological features of renal homotransplants in dogs. The results which they obtained that permit a comparison with our cases are summarized in Table XII.

A fever, associated with loss of appetite and apathy has been described by Dempster in dogs (34). Similar findings were usually noted with homograft destruction in the human. When present the fever was always associated with infection. It was apparently of a milder nature than that observed in dogs.

Homograft survival and function in the human was much better than that seen in the dog. The ability of the human kidney to recover from the ischemic nephrosis seen in the immediate postoperative period is evidence both for its adequate viability and for its freedom from overwhelming antibody attack during this period.

The human renal homografts were sometimes densely adherent to the surrounding tissue. In Case No. 4 a thick pseudocapsule had formed. In general the degree of reaction surrounding the transplant correlated with the amount of destruction, infarction, and infection present. In Case No. 9 there were very few adhesions between the transplant and the surrounding tissue, presumably due to the presence of the bag, and the fact that the kidney could move about in the wound. In Case No. 8, too, very few adhesions were present.

The microscopic picture seen in the human renal transplants corresponds in most cases closely to that described in the dog by Dempster (33). It should be noted, however, that the reaction in the human was much less intense and rapid. Thus Dempster (30) described the microscopic pathology of a dog's kidney 5 days after transplantation as follows: "The kidney is enlarged and its architecture grossly altered by edema, hemorrhagic and non-hemorrhagic necrosis. Most of the glomeruli and many tubules appear necrotic. In addition to hemorrhage, the interstitial tissue of the cortex and outer medulla is heavily infiltrated with polymorphonuclear leukocytes, lymphocytes, histiocytes, and plasma cells. Most of the cortical arteries and veins are dilated and are involved in the necrotising process, and a number are thrombosed. No organisms can be seen in a Leishmann stain. The sinus renalis is massively infiltrated with fibrin, red cells, polymorphonuclear leucocytes, and lymphocytes and histiocytes." This can be compared with the picture seen in the human after 37 days (Case No. 1). The glomeruli appeared relatively bloodless, but there was no appreciable inflammation or increased cellularity. The tubules showed a moderate amount of degeneration, which was prominent in the proximal tubules and in the loops of Henle. Calcium oxalate crystals were present in the lumen of the tubules. There was also some regeneration of tubular epithelium which was most noticeable in the distal tubules (see Figure 5). There was very little interstitial infiltration, and no appreciable edema. There was no necrosis or hemorrhage (see Figures 4 and 5). The histologic picture resembled that seen in severe acute ischemic nephrosis (103).

In Case No. 8, also, very little interstitial infiltration was present, and no appreciable edema.

The blood vessel changes were of interest. No changes resembling periarteritis nodosa were seen. This is in contrast to the findings reported by Simonsen (121) in dog homotransplants. These changes were not observed by Dempster in dogs.

What was the cause of the tremendous atherosclerosis seen in the large and medium sized intrarenal vessels in Case No. 9? Both Dempster and Simonsen describe endothelial swelling in the intrarenal vessels in dog homotransplants. Could this have been an extension of a process 
TABLE XII

A comparison between experimental renal homografts reported by Dempster and Simonsen and the human renal homografts reported in this paper

\begin{tabular}{|c|c|c|}
\hline \multicolumn{3}{|c|}{ Function and gross observations } \\
\hline Dempster $(33,34)$ & Simonsen and his associates $(120,121)$ & Human renal homotransplants reported here \\
\hline $\begin{array}{l}\text { 1. Toxic syndrome: High fever, loss appetite } \\
\text { coincides with disintegration. Infection plays } \\
\text { role. Not present if both kidneys out-due } \\
\text { hypothermia of uremia. }\end{array}$ & $\begin{array}{l}\text { 1. Toxic syndrome: High fever associated with } \\
\text { degeneration of kidney, confirming Dempster's } \\
\text { findings. }\end{array}$ & $\begin{array}{l}\text { 1. Toxic syndrome: A fever was usually associ- } \\
\text { ated with the degeneration of the transplant. } \\
\text { Infection was of ten present, however. The } \\
\text { symptoms abated with the removal of the trans- } \\
\text { plant, as reported in dogs by Dempster (46). } \\
\text { In one instance marked hypothermia was pres- } \\
\text { ent (Case No. 8), probably due to uremia. }\end{array}$ \\
\hline $\begin{array}{l}\text { 2. Survival of kidney (number of days kidney } \\
\text { secreted urine): } \\
\text { a) As 3rd kidney: 1-5 days (av. 2.2 D) } \\
\text { b) One host kidney out: } 1-8 \text { D (av. 3.7 D). } \\
\text { c) Both host kidneys out: } 1-10 \mathrm{D} \text { (av.4.4 D). }\end{array}$ & $\begin{array}{l}\text { 2. Survival of kidney: In most cases urine secre- } \\
\text { tion was not measured accurately. The bi- } \\
\text { laterally nephrectomized dogs lived 5-12 days, } \\
\text { av. } 7.8 \text { D. In } 7 \text { cases where urine secretion } \\
\text { could be estimated lasted } 5-12 \text { days, av. } 7.8 \mathrm{D} \text {. }\end{array}$ & $\begin{array}{l}\text { 2. Survival of kidney: In the } 4 \text { functioning } \\
\text { transplants urinary secretion lasted for from } \\
37 \text { to } 180 \text { days, with an average of } 97 \text { days. }\end{array}$ \\
\hline $\begin{array}{l}\text { 3. Reactions with surrounding tissues: Capsule } \\
\text { did not adhere to host tissues, except in one } \\
\text { case. (Transplants done in neck.) }\end{array}$ & $\begin{array}{l}\text { 3. Reactions with surrounding tissues: Trans- } \\
\text { plant partly covered by adhesions of omentum. } \\
\text { (Transplants done in abdomen.) }\end{array}$ & $\begin{array}{l}\text { 3. Reactions with surrounding tissues: In cases } \\
\text { with the greatest degree of destruction, ad- } \\
\text { hesions to the surrounding tissue were most } \\
\text { marked. In Case No. } 4 \text { a thick pseudocap- } \\
\text { sule had formed. Case No. } 8 \text { was an exception } \\
\text { (see Text). }\end{array}$ \\
\hline $\begin{array}{l}\text { 4. Period of anuria: Began secreting almost } \\
\text { immediately. Did not again secrete once it } \\
\text { became anuric. }\end{array}$ & $\begin{array}{l}\text { 4. Period of anuria: Began secreting few min- } \\
\text { utes to one hour. Did not again secrete once } \\
\text { it became anuric. }\end{array}$ & $\begin{array}{l}\text { 4. Period of anuria: } 8 \frac{1}{2} \text { to } 19 \text { days, except for } \\
\text { one case (Case No. } 5 \text { ) which secreted for } 24 \\
\text { hours and then became anuric. The trans- } \\
\text { plants were able to recover from this period of } \\
\text { anuria. }\end{array}$ \\
\hline $\begin{array}{l}\text { 5. Function of homolransplant: Blood urea rises } \\
\text { steadily despite adequate volume frcm trans- } \\
\text { plant (up to } 10 \mathrm{cc} / \text { min.) when host is bilater- } \\
\text { ally nephrectomized. }\end{array}$ & $\begin{array}{l}\text { 5. Function of homotransplant: Blood urea rose } \\
\text { steadily in all } 10 \text { cases with bilateral nephrec- } \\
\text { tomy. In one of these there was a slight one } \\
\text { day decrease on the } 3 \text { rd day. }\end{array}$ & $\begin{array}{l}\text { 5. Function of homotransplant: The blood urea } \\
\text { nitrogen came down in two cases with renal } \\
\text { homotransplants (Case No. } 4 \text { and No. 9). } \\
\text { The transplants could be demonstrated to be } \\
\text { functioning at about } 25 \% \text { of normal during } \\
\text { these periods. }\end{array}$ \\
\hline
\end{tabular}

Microscopic pathology

\section{Primary transplants:}

a) Interstitial: Cellular infiltration almost entirely confined to cortex. Starts as immature plasma cell infiltration around small blood vessels. Later, cells are mature plasma cells and are found everywhere, except medulla. Polys found in terminal stages. Edema not prominent.

b) Glomeruli: Relatively bloodless. No cellular change either in endothelium or epithelium of tufts. Basement membrane may be somewhat thickened.

c) Tubules: In late stages tubular casts are present, and droplet degeneration present in tubular cells.

d) Blood vessels: Renal artery normal, intrarenal branches, large and small, show endothelial swelling and pyronin-positive cells.

\section{Primary transplants:}

a) Interstitial: Focal interstitial round cell infiltration, more pronounced cortex than medulla. Localized chiefly around glomeruli and blood vessels. Cells are half lymphocytes and half pyronine-staining mononuclear cells. Terminally, marked edema and infilcells. Terminally, marked

b) Glomeruli: Normal.

c) Tubules: In early stages (3-4 days) may have casts, but of ten normal. Later many casts, sometimes calcified. Tubules may be dilated, or compressed and fragmented by violent interstitial processes. Coagulation necrosis of entire tubule may occur.

d) Blood vessels: 3-4 days: Intima and media of larger vessels normal. Intertubular capillaries show endothelial swelling. Terminal: Intima of all sized vessels from capillaries to large arteries shows swelling and pyroninophilia of the endothelium. There is perinascular infiltration and necrosis of the adventitia, resembling periarteritis nodosa. Arterioles and capillaries of glomeruli show

e) Ischemia occurs as terminal event. a) Interstitial: Focal interstitial round cell infiltration, more pronounced in the cortex than medulla. No specific localization. No pyronine stains done. Marked interstitial edema occurred in some cases. Remarkably little occurred in some cases. Remarkably little interstitial infiltration was
the end of almost $\mathbf{4 0}$ days.

b) Glomeruli: Relatively bloodless. No cellular changes, except in Case No. 8 where severe glomerulonephritis developed.

c) Tubules: Tubular changes in the later stages appear to be the result of ischemic nephrosis. Casts, and some degree of tubular degeneration was always present.

d) Blood vessels: No changes resembling periarteritis nodosa were seen. In Case No. 9 marked intimal thickening had occurred in the larger intra-renal vessels, but not in the renal larger intra-renal vessels, but not in the renal
artery. It was less marked or absent in the artery. It was less marked or absent in the
smaller vessels. This was not seen in the other smaller vessels. This was not seen in the other
cases. In the late stages of destruction of most cases. In the late stages of destruction of most
of the other cases thrombosis began in the of the other cases thrombosis began in the
smaller intra-renal vessels, extending progressmaller intra-renal vesse
sively to the larger ones.

e) Ischemia may cause renal changes. because they didn't survive as long. Against this, however, is the observation that early stages of this lesion were not seen in any of the other cases, and the kidney which survived for the next longest period of time (101 days) did not show any

such changes. Were these changes related in beginning, as Dempster suggests, because the small renal blood vessels are antigenic, antibody fixing, and antibody producing? Progressive changes may have occurred in the blood vessel walls in this case over several months, whereas they might not have been seen in the other cases 
some way to the fact that the patient had chronic glomerulonephritis? This is unlikely, because no glomerular changes of any significance occurred. Could the atherosclerosis have been caused by persistent severe hypertension applied to a kidney from a host with chronic cardiac failure and hypotension? This we must regard as the most likely cause.

If the development of acquired immunity is the underlying cause of homograft failure, what is the immediate cause of the renal transplant destruction? Simonsen (121) believes that the host's antibodies act in the interstitial tissue to produce allergic vascular lesions resembling periarteritis nodosa. This produces interstitial edema and hemorrhage, interfering with the nutrition and function of the tubules. Direct tubular damage by the antibody cannot be ruled out. Dempster (33) considers that the antibody acts on the small blood vessels of the cortex to produce a generalized vascular spasm, most marked in the tuft capillaries. The swelling and differentiation of the endothelial cells contributes to the slowing down of the renal circulation. The decreased blood flow through the tuft leads to decreased urinary excretion and generalized tubular damage.

The histological picture seen in the human homotransplant seems most in line with Dempster's theory. The changes seen in the uninfected transplant are those of severe ischemic nephrosis, and are compatible with a markedly decreased glomerular blood flow. Certainly in Case No. 9 the severe atherosclerosis must have contributed to the decreased blood flow.

\section{Summary of the observations made herein which relate to immune mechanisms of homograft destruction.}

1) The rapid development of glomerulonephritis in a kidney transplanted to a patient with periarteritis, and the absence of this finding in transplants done in patients with chronic glomerulonephritis suggest that the titre of anti-glomerular antibodies in this latter disease must be at ineffective levels.

2) The absence of changes of periarteritis in transplants done in patients not suffering from this disease is in contrast with the reported presence of these changes in dog homotransplants (121).
3) The question is raised whether the period of anoxia suffered by the transplants prior to the re-establishment of a blood supply, or the posttransplantation ischemic nephrosis are able, in any degree, temporarily to depress the antigenicity of the kidney, or the ability of the host to form antibodies against it? No answer is available to this question at the moment.

4) The question is also raised whether there is a decreased ability of the patient with chronic nephritis to form antibodies against homotransplants, which permits a prolonged survival of transplants in these patients?

5) There is evidence that skin shares antigens with leukocytes, but not with erythrocytes (96). No deleterious effect upon the transplant was noted in those patients receiving multiple blood transfusions, nor were there any transfusion reactions. If antigens are shared between different individuals, those which are present in the blood do not seem to have any significance in homograft rejection.

6) Cortisone and ACTH appeared to have no effect on the survival of human renal homotransplants. All of the long term survivals received testosterone, but no conclusion can be reached as to its possible effect.

7) In general, the histologic changes seen in the transplanted human kidney are similar to those reported by Dempster in the dog. The ability of the human kidney to recover from a prolonged period of post-transplantation anuria is unique, however, as were the appearance of glomerulonephritis in one case and arteriosclerosis in another.

8) The immune response to a transplanted kidney in the human is less intense than that in experimental animals reported in the literature, and those in our own experience (59). We cannot agree, on the basis of the foregoing study, with Loeb, who states that the higher in the phylogenetic scale an animal is, the more highly developed is its ability to form antibodies; nor with Dempster, who on accepting this dictum (33) states that "sufficient experiments have been carried out to make it quite clear that any attempt at homotransplanting kidneys in humans, at this stage, is doomed to failure and would be a dangerous procedure" (30). 
What is the status of human renal homotransplants at the present time?

Simonsen (119-121) believes that the only real hope of making homotransplantation of the kidney a feasible procedure in cases of chronic uremia in the human has to be based on the following conditions: "First, that the most important individual-specific antigens are shared by the kidney and $\mathrm{RBC}$, so that a gross biological incompatibility can be eliminated by detailed blood group determination; secondly, that the kidney's defense reaction against the recipient's antibodies and/or antigens can check a less significant biological incompatibility without thereby destroying the kidney, and thus provide a more or less complete adaptation to the recipient."

From a practical point of view this offers little hope. In the first place enough human homotransplantations of skin have been done to indicate that there must be a large number of individual specific antigens in the general population not to have encountered compatible pairs by random selection. In the second place we found it extremely difficult to obtain kidneys from donors with the same $\mathrm{ABO}$ and $\mathrm{Rh}$ groups as the intended recipient. Several of our proposed recipients died in the hospital while awaiting a donor of the right blood type. Therefore, even if one were able to identify a donor whose blood (and renal) antigens were almost identical to those of the recipient, it would be unlikely that the donor kidney would become available at the right time, or that it would be suitable from other points of view (age, infection, cancer, etc.).

Renal homotransplantation has no place in the therapy of human patients at this time. Our own further studies in this field await the outcome of problems now under investigation in the experimental animal. We feel that it will prove valuable, as new data is accumulated in the laboratory, however, to continue to investigate the problem of human renal homotransplantation in the light of these advances. Biological rejection in the human does not seem to be as violent, at least as regards renal transplantation, as that found in the experimental animal.

\section{SUMMARY AND CONCLUSIONS ${ }^{19}$}

1. Nine cases of homotransplantation of the kidney in man are reported.

2. Five of the nine transplants did not develop measurable function for various reasons.

3 . Four of the nine transplants developed measureable function. The kidneys secreted urine for from 37 to 180 days.

4. It is possible for transplants which have been anoxic for 3 to $3 \frac{1}{2}$ hours to develop function in the host which is about 25 per cent of normal.

5. All of the transplanted kidneys went through a period of anuria beginning either immediately after transplantation or 24 hours later. The anuria lasted from $81 / 2$ to 19 days in the four cases which ultimately showed measurable function. This was felt to be due to the ischemic interval incident to and following transplantation. The ability of the kidney to recover from this anuria has no parallel in animal experiments.

6. The general pathologic picture which accompanies homograft failure in the human is qualitatively similar to that seen in experimental animals, but appears much more slowly. Pathological changes were observed in two human renal homotransplants, however, that have not been seen in animal experiments:

a) Severe acute glomerulonephritis developed within 38 days in a homograft performed in a patient with polyarteritis nodosa.

b) Marked atherosclerosis of intra-renal vessels occurred within 183 days in a homotransplant taken from a patient with mitral and aortic stenosis and placed in a patient with severe hypertension.

7. Renal homograft rejection in the human is much less violent and slower to develop than it is in experimental animals.

8. The disease of the recipient appeared to be able to modify adversely-in the case of poly-

19 Since this paper was written another article has appeared (Murray, G., and Holden, R., Am. J. Surg., $1954,87,508$.) dealing with renal homotransplantation in the human. Transplants were performed in four cases, with death of the patient in three. In the fourth case the transplanted kidney is thought to be viable and effective after fifteen months. No function studies or biopsies are available, however, to indicate conclusively that the kidney is alive and functioning. 
arteritis nodosa-the course of the transplanted kidney. The question is raised as to whether there is a depressed antibody formation in chronic renal disease which can favorably influence transplant survival by diminishing the host reaction against the transplant.

9. Although auto-antibodies against renal tissue are said to be present in the blood of patients with chronic glomerulonephritis, they did not lead to the development of glomerulonephritis in kidneys homografted to patients with this disease.

10. An attempt to reduce the immune response against a renal homograft is described.

11. ACTH and cortisone did not appear to exert any pronounced beneficial effect on the survival of human renal transplants.

12. At the present state of our knowledge, renal homotransplants do not appear to be justified in the treatment of human disease.

13. It is our conviction that this experience serves to indicate certain important species differences in renal homograft response, and that as cellular and animal experimentation progresses, constant cross-check with clinical experience is vitally essential to progress in this field of work.

\section{ACKNOWLEDGMENTS}

The authors gratefully acknowledge the help of the following members of the staff of the Peter Bent Brigham Hospital: Dr. Francis D. Moore, Dr. J. Hartwell Harrison, and Dr. Dwight W. Harken. Without their active cooperation and assistance this study could not have been carried out. Many other members of the staff assisted in the care and study of the patients whose cases are reported here. We want particularly to thank the following: Doctors Frank Adler, John Brooks, Hathorne Brown, Arnold Colodny, Frank Collins, Gustave Dammin, Robert Desautels, Joseph Dingman, Cutting Favour, John Finkenstaedt, Clinton Hawn, Dalton Jenkins, John Laidlaw, Charles Macgregor, Donald Matson, Joseph Murray, Stephen Smith, Philip Walker, John Weller, and Norbert Wilhelm. We are also indebted to Doctors William Brickley and Richard Ford.

\section{REFERENCES}

1. Addis, T., Glomerular Nephritis. New York, Macmillan Co., 1948, p. 67.

2. Archibald, R. M.. Colorimetric determination of urea. J. Biol. Chem., 1945, 157, 507.

3. Asper, S. P., Jr., Schales, O., and Schales, S. S., Importance of controlling $\mathrm{pH}$ in the Schales and Schales method of chloride determination. J. Biol. Chem., 1947, 168, 779.
4. Avramovici, A., Les transplantations du rein. Lyon chir., 1924, 21, 734.

5. Baker, R., Gordon R., Huffer, J., and Miller, G. H., Jr., Experimental renal transplantation. I. Effect of nitrogen mustard, cortisone, and splenectomy. Arch. Surg., 1952, 65, 702.

6. Balch, H. H., Relation of nutritional deficiency in man to antibody production. J. Immunol., 1950, 64, 397.

7. Baxter, H., Schiller, C., Whiteside, J. H., Lipshutz, H., and Straith, R. E., The effect of ACTH on the survival of homografts in man. Plast. \& Reconstruct. Surg., 1951, 7, 492.

8. Bieler, M. M., Ecker, E. E., and Spies, T. D., Serum proteins in hypoproteinemia due to nutritional deficiency. J. Lab. \& Clin. Med., 1947, 32, 130.

9. Billingham, R. E., Krohn, P. L., and Medawar, P. B., Effect of cortisone on survival of skin homografts in rabbits. Brit. Med. J., 1951, 1, 1157.

10. Billingham, R. E., Krohn, P. L., and Medawar, P. B., Effect of locally applied cortisone acetate on survival of skin homografts in rabbits. Brit. Med. J., 1951, 2, 1049.

11. Billingham, R. E., Homografts. Brit. J. Plastic Surg., 1952, 5, 1.

12. Bjørneboe, M., and Gormsen, H., Experimental studies on the rôle of plasma cells as antibody producers. Acta path. et microhiol. Scandinav., 1943, 20, 649.

13. Bloomfield, A. L., The effect of restriction of protein intake on the serum protein concentration of the rat. J. Exper. Med., 193?, 57, 705.

14. Bonsnes, R. W., and Taussky, H. H., On the colorimetric determination of creatinine by the Jaffe reaction. J. Biol. Chem., 1945, 158, 581.

15. Cannon, J. A., and Longmire, W. P., Jr., Studies of successful skin homografts i: the chicken. Ann. Surg., 1952, 135, 60.

16. Cannon, P. R., Chase, IV. E., and Wissler, R. W., The relationship of the protin-reserves to antibody-production. I. The effects of a low-protein diet and of plasmapheresis upon the formation of agglutinins. J. Immunol., 1943, 47. 133.

17. Cannon, P. R., The importance of proteins in resistance to infection. J. A. M. A., 1945, 128, 360.

18. Carrel, A., La technique opératoire des anastomoses vasculaires et la transplantation des viscères. Lyon méd., 1902, 98, 859.

19. Carrel, A., and Guthrie, C. C., Functions of a transplanted kidney. Science, 1905, 22, 473.

20. Carrel, A., and Guthrie, C. C., Anastomosis of blood vessels by the patching method and transplantation of the kidney. J. A. M. A., 1906, 47, 1648.

21. Carrel, A., and Guthrie, C. C., Successful transplantation of both kidneys from a dog into a bitch with removal of both normal kidneys from the latter. Science, 1906, 23, 394. 
22. Carrel, A., Transplantation in mass of the kidneys. J. Exper. Med., 1908, 10, 98.

23. Carrel, A., The transplantation of organs. New York Med. J., 1914, 99, 839.

24. Cavelti, P. A., and Cavelti, E. S., Studies on the pathogenesis of glomerulonephritis. II. Production of glomerulonephritis in rats by means of auto-antibodies to kidney. Arch. Path., 1945, 40, 158.

25. Cavelti, P. A., and Cavelti, E. S., Studies on the pathogenesis of glomerulonephritis. III. Clinical and pathological aspects of the experimental glomerulonephritis produced in rats by means of autoantibodies to kidney. Arch. Path., 1945, 40, 163.

26. Cavelti, P. A., Pathogenesis of glomerulonephritis and rheumatic fever. Arch. Path., 1947, 44, 119.

27. Chinard, F. P., Interactions of quaternary ammonium compounds and proteins. A simple method for the rapid estimation of urinary protein concentrations with alkyldimethylbenzyl-ammonium compounds. J. Biol. Chem., 1948, 176, 1439.

28. Dederer, C., Studies in the transplantation of whole organs. I. Autotransplant of the left kidney to the neck with right nephrectomy in the dog. J. A. M. A., 1918, 70, 6.

29. Dederer, C., Successful experimental homotransplantation of the kidney and the ovary. Surg., Gynec., \& Obst., 1920, 31, 45.

30. Dempster, W. J., Observations on the behaviour of the transplanted kidney in dogs. Ann. Roy. Coll. Surgeons., 1950, 7, 275.

31. Dempster, W. J., Problems involved in the homotransplantation of tissues, with particular reference to skin. Brit. Med. J., 1951, 2, 1041.

32. Dempster, W. J., The relationship between the antigens of skin and kidney of the dog. Brit. J. Plastic Surg., 1953, 5, 228.

33. Dempster, W. J., Kidney homotransplantation. Brit. J. Surg., 1953, 40, 447.

34. Dempster, W. J., A toxic syndrome observed in dogs with transplanted kidneys. Acta med. Scandinav., 1953, 144, 361.

35. Dubost, C., Oeconomos, N., Vaysse, J., Hamburger, J., Milliez, P., and Lebrigand, J., Note préliminaire sur l'étude des fonctions rénales de reins greffés chez l'homme. Bull. et mém. Soc. méd. d. hôp. de Paris, 1951, 67, 105.

36. Dubost, C., Oeconomos, N., Nenna, A., and Milliez, $P .$, Résultats d'une tentative de greffe rénale. Bull. et mém. Soc. méd. d. hôp. de Paris, 1951, 67, 1372.

37. Ehrich, W. E., and Harris, T. N., The formation of antibodies in the poplitial lymph node in rabbits. J. Exper. Med., 1942, 76, 335.

38. Ehrich, W. E., and Harris, T. N., The site of antibody formation. Science, 1945, 101, 28.

39. Eichwald, E. J., Acquired immunity to the graft. J. Nat. Cancer Inst., 1953, 14, 705.
40. Ellis, J. T., and Kidd, J. G., Inhibition of BrownPearce carcinoma cells by suspensions of lymph nodes and spleen from immune hosts. Cancer Research, 1952, 12, 259.

41. Ellison, E. H., Martin, B. C., Williams, R. D., Clatworthy, H. W., Hamwi, G., and Zollinger, R. M., The effect of ACTH and cortisone on the survival of homologous skin grafts. Ann. Surg., 1951, 134, 495.

42. Farr, L. E., The significance of protein metabolism in the nephrotic child. J. Pediat., 1940, 17, 734.

43. Finerty, J. C., Parabiosis in physiological studies. Physiol. Rev., 1952, 32, 277.

44. Finkelstein, N., Aliminosa, L. M., and Smith, H. W., The renal clearances of hippuric acid and pyridone derivatives. Am. J. Physiol., 1941, 133, 276.

45. Fiske, C. H., and Subbarow, Y., The colorimetric determination of phosphorous. J. Biol. Chem., 1925, 66, 375.

46. Floresco, N., Recherches sur la transplantation du rein. J. de physiol. et de path. gén., 1905, 7, 47.

47. Folin, O., and Bell, R. D., Applications of a new reagent for the separation of ammonia. I. The colorimetric determination of ammonia in urine. J. Biol. Chem., 1917, 29, 329.

48. Gibson, T., and Medawar, P. B., The fate of skin homografts in man. J. Anat., 1943, 77, 299.

49. Haddow, A., Erythrocyte individuality in relation to the transplantation of an induced fowl sarcoma. J. Path. \& Bact., 1934, 39, 345.

50. Harris, M., The compatibility of rat and mouse cells in mixed tissue cultures. Anat. Rec., 1943, 87, 107.

51. Hawn, C. V. Z., Hume, D. M., Merrill, J. P., and Miller, B. F., Pathologic changes in eight human renal homotransplants. Federation Proc., 1953, 12, 391. (abst).

52. Hedlund, P., The pathogenesis of glomerulonephritis. Scandinav. J. Clin. \& Lab. Invest., 1949, 1, 351.

53. Henderson, E., Seneca, H., Abd. el Messih, G., and Weinberg, M., Androgens and renal function. Effect of testosterone proprionate in uremia due to cholera. J. Clin. Endocrinol., 1948, 8, 851.

54. Holloway, J. K., The effect of diuretics on transplanted kidneys. J. Urol., 1926, 15, 111.

55. Homburger, F., Forbes, I., and Desjardins, R., Renotropic effects of some androgens upon experimental hydronephrosis and upon the clitoris in the mouse. Endocrinology, 1950, 47, 19.

56. Hufnagel, C. A., Resection and grafting of the thoracic aorta with minimal interruption of the circulation. Amer. Coll. Surg. Bull., 1949, 34, 38 (Abst.).

57. Hufnagel, C. A., and Gillespie, J. F., The treatment of aneurysms of the aorta. Bull., Georgetown Univ. M. Center, 1951, 4, 124.

58. Hume, D. M., Merrill, J. P., and Miller, B. F., Homologous transplantation of the human kidneys. J. Clin. Invest., 1952, 31, 640 (Abst.). 
59. Hume, D. M., and Egdahl, R., Studies in progress.

60. Humphrey, J. H., The pathogenesis of glomerulonephritis : a re-investigation of the auto-immunisation hypothesis. J. Path. \& Bact., 1948, 60, 211.

61. Ibuka, K., (a) Function of the autogenous kidney transplant. Am. J. Med. Sc., 1926, 171, 407. (b) Function of the homogenous kidney transplant. Am. J. Med. Sc., 1926, 171, 420.

62. Keutmann, E. H., and Bassett, S. H., Dietary protein in hemorrhagic Bright's disease. II. The effect of diet on serum proteins, proteinuria, and tissue proteins. J. Clin. Invest., 1935, 14, 871.

63. Kolff, W. J., New Ways of Treating Uraemia; The Artificial Kidney, Peritoneal Lavage, Intestinal Lavage. London, J. and A. Churchill, Ltd., 1947.

64. Korenchevsky, V., and Dennison, M., The manifold effects of castration in male rats. J. Path. \& Bact., 1934, 38, 231.

65. Korenchevsky, V., and Dennison, M., The effect on male rats of the simultaneous administration of male and female sexual hormones and relation to the assay of the hormones. Biochem. J., 1934, 28, 1486.

66. Kozelka, A. W., Serological studies of tissue antagonism in the domestic fowl. Physiol. Zoöl., 1933, 6, 159.

67. Krebs, E. G., Depression of gamma globulin in hypoproteinemia due to malnutrition. J. Lab. \& Clin. Med., 1946, 31, 85.

68. Küss, R., Teinturier, J., and Milliez, P., Quelques essais de greffe de rein chez l'homme. Mém. Acad. de chir., 1951, 77, 755.

69. Küss, R., Personal Communication, Feb. 5, 1952.

70. Landsteiner, E., and Hufnagel, C. A., Personal Communication.

71. Lange, K., Gold, M. M. A., Weiner, D., and Simon, V., Autoantibodies in human glomerulonephritis. J. Clin. Invest., 1949, 28, 50.

72. Lawler, R. H., West, J. W., McNulty, P. H., Clancy, E. J., and Murphy, R. P., Homotransplantation of the kidney in the human. J. A. M. A., 1950, 144, 844.

73. Lawler, R. H., West, J. W., McNulty, P. H., Clancy, E. J., and Murphy, R. P., Homotransplantation of the kidney in the human. Supplemental report of a case. J. A. M. A., 1951, 147, 45.

74. Lefebvre, L., Transplantation prolongée de reins au cou. Arch. internat. de physiol., 1949, 57, 110.

75. Lefebvre, L., Reins au cou préalablement perfusés et conservés à basse température. Compt. rend. Soc. de biol., 1951, 145, 1895.

76. Legrain, M., and Merrill, J. P., Short-term continuous transperitoneal dialysis. New England J. Med., 1953, 248, 125.

77. Lehrfeld, J. W., and Taylor, A. C., The dosage phenomenon in rat skin homografts. Plast. \& Reconstruct. Surg., 1953, 12, 432.
78. Lippman, R. W., Cameron, G., and Campbell, D. H., The specificity of anti-kidney antibody determined by its effect upon tissue culture explants. Proc. Nat. Acad. Sc., 1950, 36, 576.

79. Lippman, R. W., Marti, H. U., and Campbell, D. H., Nephrotoxic globulin nephritis. I. Course after a single intravenous injection. Arch. Path., 1952, 53, 1.

80. Loeb, L., Transplantation and individuality. Physiol. Rev., 1930, 10, 547.

81. Loeb, L., The Biological Basis of Individuality. Springfield, Charles C Thomas, 1945.

82. Loeb, L., Organismal differentials and organ differentials. Proc. Nat. Acad. Sc., 1953, 39, 127.

83. Longmire, W. P., Jr., and Smith, S. W., Homologous transplantation of tissues: A review of the literature. Arch. Surg., 1951, 62, 443.

84. Longmire, W. P., Jr., The homologous transplantation of tissues: clinical aspects. J. Nat. Cancer Inst., 1953, 14, 669.

85. Luetscher, J. A., Jr., Electrophoretic analysis of plasma and urinary proteins. J. Clin. Invest., 1940, $19,313$.

86. Luetscher, J. A., Jr., Electrophoretic analysis of proteins of plasma and serous effusions. J. Clin. Invest., 1941, 20, 99.

87. Madden, S. C., Winslow, P. M., Howland, J. W., and Whipple, G. H., Blood plasma protein regeneration as influenced by infection, digestive disturbances, thyroid, and food proteins. J. Exper. Med., 1937, 65, 431.

88. Masugi, M., Utber die experimentelle Glomerulonephritis durch das spezifische Antinierenserum. Beitr. z. path. Anat. z. allg. Path., 1934, 92, 429.

89. Matson, D. D., A new operation for the treatment of communicating hydrocephalus. Report of a case secondary to generalized meningitis. J. Neurosurg., 1949, 6, 238.

90. McMaster, P. D., and Hudack, S. S., The formation of agglutinins within lymph nodes. J. Exper. Med., 1935, 61, 783.

91. McNaught, J. B., Scott, V. C., Woods, F. M., and Whipple, G. H., Blood plasma protein regeneration controlled by diet. J. Exper. Med., 1936, 63, 277.

92. Medawar, P. B., Notes on the problems of skin homografts. Bull. War Med., 1943, 4, 1.

93. Medawar, P. B., The behaviour and fate of skin autografts and skin homografts in rabbits. J. Anat., 1944, 78, 176.

94. Medawar, P. B., A second study of the behaviour and fate of skin homografts in rabbits. J. Anat., 1945, 79, 157.

95. Medawar, P. B., Immunity to homologous grafted skin. I. The suppression of cell division in grafts transplanted to immunized animals. Brit. J. Exper. Path., 1946, $27,9$. 
96. Medawar, P. B., Immunity to homologous grafted skin. II. The relationship between the antigens of blood and skin. Brit. J. Exper. Path., 1946, 27, 15.

97. Medawar, P. B., Immunity to homologous grafted skin. III. The fate of skin homografts transplanted to the brain, to subcutaneous tissue, and to the anterior chamber of the eye. Brit. J. Exper. Path., 1948, 29, 58.

98. Medawar, P. B., Tests by tissue culture methods on the nature of immunity to transplanted skin. Quart. J. Micr. Sci., 1948, 89, 239.

99. Merrill, J. P., Thorn, G. W., Walter, C. W., Callahan, E. J., III, and Smith, L. H., Jr., Use of artificial kidney. I. Technique. J. Clin. Invest., 1950, 29, 412.

100. Metcoff, J., Darling, D. B., Scanlon, M. H., and Stare, F. J., Nutritional status and infection response. I. Electrophoretic, circulating plasma protein, hematologic, hematopoietic, and immunologic responses to Salmonella Typhimurium (Bacillus Aertrycki) infection in the protein-deficient rat. J. Lab. \& Clin. Med., 1948, 33, 47.

101. Michon, L., Hamburger, J., Oeconomos, N., Delinotte, P., Richet, G., Vaysse, J., and Antoine, B., Une tentative de transplantation rénale chez l'homme: aspects médicaux et biologique. Presse méd., 1953, 61, 1419.

102. Murphy, J. B., The lymphocyte in resistance to tissue grafting, malignant disease, and tuberculous infection. Monographs Rockefeller Inst. Med. Res., No. 21, 1926.

103. Oliver, J., Macdowell, M., and Tracy, A., The pathogenesis of acute renal failure associated with traumatic and toxic injury. Renal ischemia, nephrotoxic damage and the ischemuric episode. J. Clin. Invest., 1951, 30, 1305.

104. Oudot, J., Transplantation rénale. Presse méd., 1948, 56, 319.

105. Parkinson, D., and Woodworth, H. C., Observations on vessel and organ transplants. Exper. Med. \& Surg., 1947, 5, 49.

106. Persky, L., and Jacobs, S., Effect of ACTH and cortisone on homogenous kidney transplants. Proc. Soc. Exper. Biol. \& Med., 1951, 77, 66.

107. Rich, A. R., and Gregory, J. E., The experimental demonstration that periarteritis nodosa is a manifestation of hypersensitivity. Bull. Johns Hopkins Hosp., 1943, 72, 65.

108. Rogers, B. O., Guide and bibliography for research into the skin homograft problem. Plast. \& Reconst. Surg., 1951, 7, 169.

109. Schales, O., and Schales, S. S., A simple and accurate method for the determination of chloride in biological fluids. J. Biol. Chem., 1941, 140, 879.

110. Schöne, G., Ǔber transplantationsimmunität. München med. Wchnschr., 1912, 59, 457.

111. Schreiner, G. E., Determination of inulin by means of resorcinol. Proc. Soc. Exper. Biol. \& Med., 1950, 74, 117.
112. Schwentker, F. F., and Comploier, F. C., The production of kidney antibodies by injection of homologous kidney plus bacterial toxins. J. Exper. Med., 1939, 70, 223.

113. Selye, H., a. The effect of testosterone on the kidney. J. Urol., 1939, 42, 637.

b. On the protective action of testosterone against the kidney damaging effect of sublimate. J. Pharmacol. \& Exper. Therap., 1940, 68, 454.

114. Selye, H., and Friedman, S. M., The beneficial action of testosterone in experimental renal atrophy caused by ligature of the ureter. Endocrinology, 1941, 29, 80.

115. Servelle, M., Soulié, P., Rougeulle, J., Delahaye, G., and Touche, M., Greffe d'un rein de supplicié à une malade avec rein unique congénital, atteinte de néphrite chronique hypertensive azotémique. Bull. et mém. Soc. méd. d. hôp. de Paris, 1951, 67, 99.

116. Servelle, M., Soulié, P., Rougeulle, J., Delahaye, G., and Touche, M., La greffe du rein. Rev. de chir., Paris, 1951, 70, 186.

117. Siebert, W. J., Auto and homoiotransplantation of thyroid gland into brain of guinea pigs. Proc. Soc. Exper. Biol. \& Med., 1928, 26, 236.

118. Shirai, Y., On the transplantation of the rat sarcoma in adult heterogenous animals. Japan Med. World, 1921, 1: (2), 14.

119. Simonsen, M., and Sørensen, F., Homoplastic kidney transplantation in dogs. Acta chir. Scandinav., 1949, 99, 61.

120. Simonsen, M., Buemann, J., Gammeltoft, A., Jensen, $\mathrm{F}$., and Jørgensen, $\mathrm{K}$., Biological incompatibility in kidney transplantation in dogs. I. Experimental and morphological investigations. Acta path. et microbiol. Scandinav., 1953, 32, 1.

121. Simonsen, M., Biological incompatibility in kidney transplantation in dogs. II. Serological investigations. Acta path. et microbiol. Scandinav., 1953, 32, 36.

122. Smadel, J. E., Experimental nephritis in rats induced by injection of anti-kidney serum. (1) Preparation and immunological studies of nephrotoxin. J. Exper. Med., 1936, 64, 921.

123. Stephenson, K. L., The present status of parabiosis as related to skin transplantation. Plast. \& Reconstruct. Surg., 1953, 12, 335.

124. Tansley, K., The development of the rat eye in graft. J. Exper. Biol., 1946, 22, 221.

125. Thorn, G. W., Armstrong, S. H., Jr., Davenport, V. D., Woodruff, L. M., and Tyler, F. H., Chemical, clinical, and immunological studies on the products of human plasma fractionation. XXX. The use of salt-poor concentrated human serum albumin solution in the treatment of chronic Bright's disease. J. Clin. Invest., 1945, 24, 802.

126. Tissue transplantation conference, proceedings. J. Nat. Cancer Inst., 1953, 14, 665.

127. Transplantation bulletin. Vol. 1, number 2, Jan. 1954, p. 45. 
128. Ullmann, E., Experimentelle Nierentransplantation. Wien. klin. Wchnschr., 1902, 15, 281, 707.

129. Van Slyke, D. D., and Neill, J. M., The determination of gases in blood and other solutions by vacuum extraction and manometric measurement. I. J. Biol. Chem., 1924, 61, 523.

130. Villard, E., and Tavernier, L., La transplantation du rein. Presse méd., 1910, 18, 489.

131. Villard, E., and Perrin, E., Transplantations rénales. Lyon chir., 1913, 10, 109.

132. Voronoy, Sobre el bloqueo del aparato retículoendotelial del hombre en algunas formas de intoxicación por el sublimado $\mathrm{y}$ sobre la transplantación del riñón cadavérico como método de tratamiento de la anuria consecutiva a aquella intoxicación. Siglo méd., 1936, 97, 296.

133. Weisman, P. A., Quinby, W. C., Wight, A., and Cannon, B., The adrenal cortical hormones and homografting: exploration of a concept. Ann. Surg., 1951, 134, 506.
134. Weisman, P. A., Wight, A., Quinby, W. C., and Cannon, B., The failure of adrenal cortical hormones to prolong the survival of homologous skin grafts. Plast. \& Reconstruct. Surg., 1951, 8, 417.

135. Williamson, C. S., Some observations on the length of survival and function of homogenous kidney transplants. Preliminary report. J. Urol., 1923, $10,275$.

136. Williamson, C. S., Further studies on the transplantation of the kidney. J. Urol., 1926, 16, 231.

137. Woodruff, M. F. A., The transplantation of homologous tissue and its surgical applications. Ann. Roy. Coll. Surgeons, 1952, 11, 173.

138. Woodruff, M. F. A., and Allan, T. M., Blood groups and the homograft problem. Brit. J. Plastic Surg., 1953, 5, 238.

139. $\mathrm{Wu}, \mathrm{P}$. P. T., and Mann, F. C., Histologic studies of autogenous and homogenous transplants of the kidney. Arch. Surg., 1934, 28, 889. 